Universidade de São Paulo

Escola Superior de Agricultura "Luiz de Queiroz"

Avaliação do risco de resistência de lepidópteros-praga (Lepidoptera:

Noctuidae) à proteína Cry1Ac expressa em soja MON 87701 × MON 89788 no Brasil

\title{
Oderlei Bernardi
}

Tese apresentada para obtenção do título de Doutor em Ciências. Área de concentração: Entomologia 
Oderlei Bernardi

Engenheiro Agrônomo

Avaliação do risco de resistência de lepidópteros-praga (Lepidoptera: Noctuidae) à proteína Cry1Ac expressa em soja MON 87701 × MON 89788 no Brasil

Orientador:

Prof. Dr. CELSO OMOTO

Tese apresentada para obtenção do título de Doutor em Ciências. Área de concentração: Entomologia

\section{Piracicaba}

2012 
Dados Internacionais de Catalogação na Publicação DIVISÃO DE BIBLIOTECA - ESALQ/USP

\section{Bernardi, Oderlei}

Avaliação do risco de resistência de lepidópteros-praga (Lepidoptera: Noctuidae) à proteína Cry1Ac expressa em soja MON 87701 × MON 89788 no Brasil / Oderlei Bernardi. - - Piracicaba, 2012.

116 p. : il.

Tese (Doutorado) - - Escola Superior de Agricultura "Luiz de Queiroz", 2012.

1. Dosagem 2. Lagartas - Resistência 3. Manejo integrado 4. Plantas transgênicas 5. Proteínas de plantas I. Título

CDD 633.34

B523a

"Permitida a cópia total ou parcial deste documento, desde que citada a fonte - 0 autor" 
A Deus, pelo dom da vida e por estar sempre ao meu lado em todos os momentos.

AGRADEÇO

Aos meus pais Delvino Bernardi e Zeli Maschio Bernardi, irmão Daniel Bernardi pelo afeto, incentivo e apoio em minha formação pessoal e profissional.

\section{DEDICO E AGRADEÇO}




\section{AGRADECIMENTOS}

Ao Prof. Dr. Celso Omoto pela orientação, ensinamentos, confiança, amizade e oportunidade para realização deste trabalho.

A todos os professores do Programa de Pós-Graduação em Entomologia da Escola Superior de Agricultura "Luiz de Queiroz" (ESALQ/USP), pelos conhecimentos transmitidos.

Ao Conselho Nacional de Desenvolvimento Científico e Tecnológico (CNPq) pela concessão da bolsa de estudo.

À Monsanto do Brasil Ltda pelo apoio técnico-financeiro para realização deste estudo, em especial a Samuel Martinelli, Gláucia S. Malvestiti, Patrick M. Dourado, Wladecir S. Oliveira, Fábio S. Tagliaferro, Geraldo U. Berger e Graham P. Head (Monsanto LLC, St. Louis, EUA).

A todos os amigos e colegas do Programa de Pós-Graduação em Entomologia (ESALQ/USP) pelo agradável convívio e companheirismo.

Aos amigos do Laboratório de Resistência de Artrópodes a Pesticidas (ESALQ/USP), Eloisa Salmeron, Daniel Bernardi, Rodrigo José Sorgatto, Nádia Fernanda Bertan Casarin, Karina Cordeiro Albernaz e Felipe Antônio Domingues, pelo convívio, companheirismo, amizade, conhecimentos transmitidos e auxílios prestados na condução deste trabalho.

Aos amigos e colegas que são ou foram do Laboratório de Resistência de Artrópodes a Pesticidas (ESALQ/USP), Oscar Arnaldo Batista Neto e Silva, Alex Sandro Poltronieri, Edgar Francisco Gaona Mena, Juliano Ricardo Farias, José Bruno Malaquias, Dariane Sagaseta de Oliveira Souza, Vitor Antônio Correa Pavinato, Pablo Fresia Coronel, Danielle Thomazoni, Patrick Marques Dourado e Everaldo Batista Alves, pelo convívio, companheirismo e auxílios prestados.

Aos técnicos do laboratório de Resistência de Artrópodes a Pesticidas (ESALQ/USP), Gislaine Aparecida Amâncio de Oliveira Campos e Luis Ricardo Sesso, pelo convívio agradável e auxílios prestados. 
Aos estagiários do Laboratório de Resistência de Artrópodes a Pesticidas (ESALQ/USP), Alexandre Donizeti Barbosa, Luis Gustavo Bergamasco de Aguiar, Rebeca da Silva Ribeiro, Dalton Campacci Pavan, Isabela Maganeti Dal Pozzo, Vitória Grisotto Valério, Guilherme Libardi Miraldo, Ricardo Ferraz Silveira, Vinícius Durrer, Renato Augusto do Carmo de Lacerda e Renato Jun Horikoshi, pelo convívio, companheirismo e auxílio prestado na condução desse trabalho.

Aos amigos com quem morei em Piracicaba, Fernando Rodrigues, Marcelo Pedreira Miranda, Samuel Roggia, Rejane Cristina Roppa Kuss Roggia, Geraldo Vasconcelos, Emídio Cantídio Almeida de Oliveira, Daniel Bernardi, Fabio Mielezrski, Fabrício Becker Peske, Mário Borges Trzeciak, Juliano Ricardo Farias e Márcio Blanco das Neves, obrigado pelo convívio agradável, apoio em todos os momentos, companherismo e incentivo.

À minha querida amiga Luiza Cristiane Fialho Zazycki, pelo apoio, companheirismo, incentivo e auxílios prestados.

A todos os funcionários do Departamento de Entomologia e Acarologia da ESALQ/USP, pela dedicação e aos serviços prestados.

À bibliotecária Silvia Maria Zinsly da Biblioteca Central (ESALQ/USP), pelo auxílio na formatação deste trabalho.

A todos aqueles que direta ou indiretamente contribuíram para o êxito deste trabalho, o meu sincero agradecimento. 


\section{SUMÁRIO}

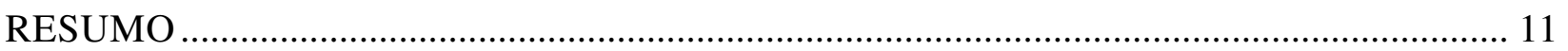

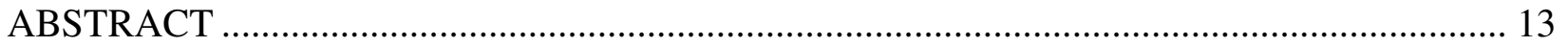

1 INTRODUÇÃO

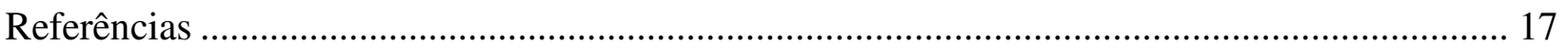

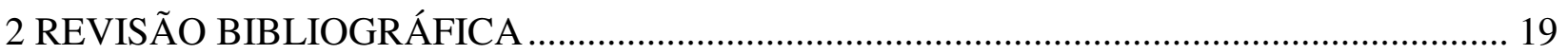

2.1 Aspectos bioecológicos de lepidópteros-praga (Lepidoptera: Noctuidae) da soja................... 19

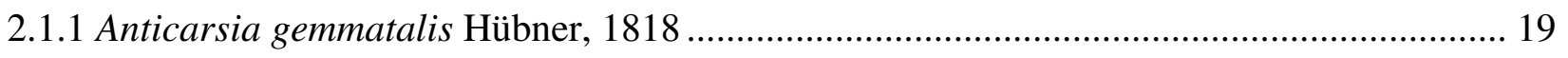

2.1.2 Pseudoplusia includens (Walker, 1857) ...................................................................... 20

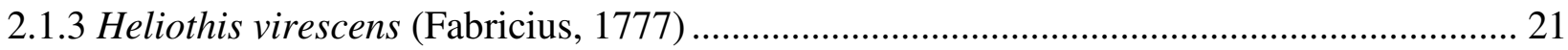

2.1.4 Spodoptera cosmioides (Walker, 1898)........................................................................ 23

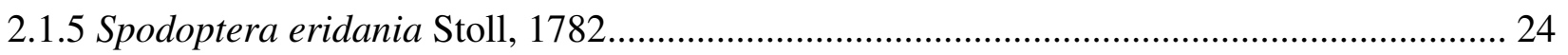

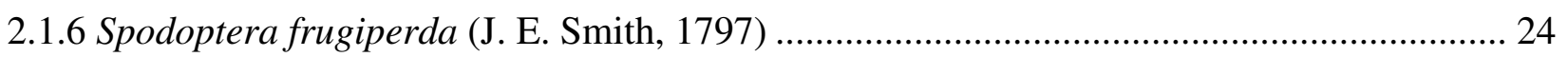

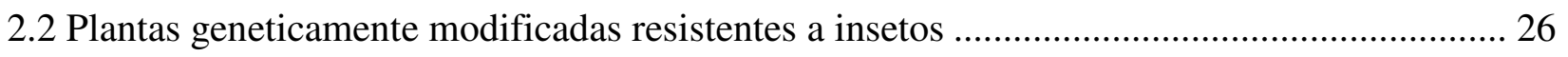

2.3 Potencial de insetos-praga para evolução da resistência a proteínas inseticidas de $B t$............ 29

2.4 Estratégia de alta dose e refúgio para o MRI a plantas $B t$.................................................... 34

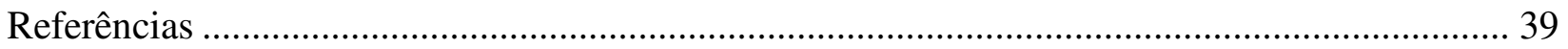

3 AVALIAÇÃO DO CONCEITO DE ALTA DOSE E EFICÁCIA DA SOJA MON $87701 \times$ MON 89788 CONTRA A. gemmatalis E P. includens (LEPIDOPTERA: NOCTUIDAE) NO

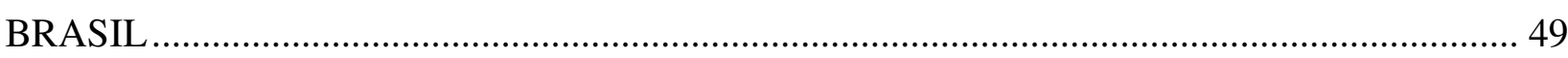

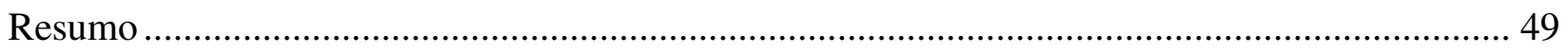

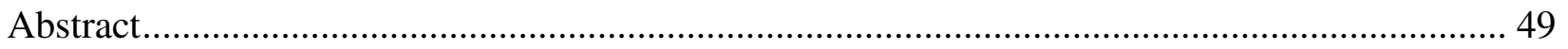

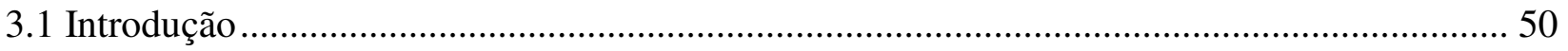

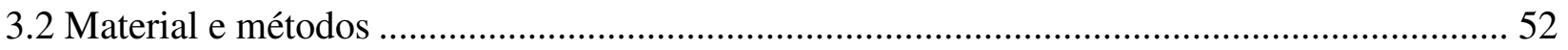

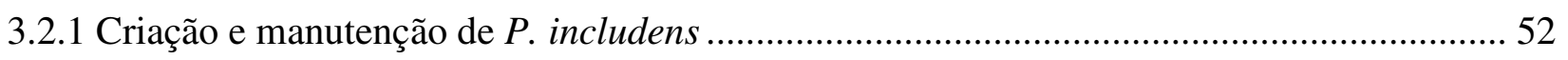

3.2.2 Linha básica de suscetibilidade de A. gemmatalis e P. includens à proteína Cry1 Ac.......... 53

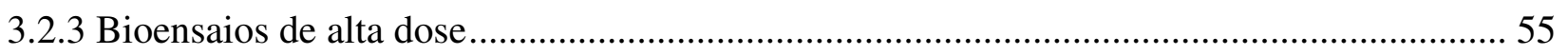

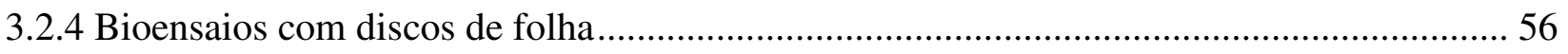

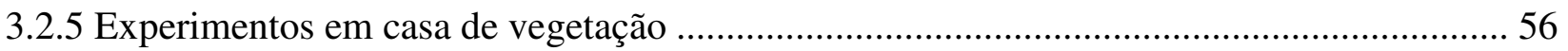

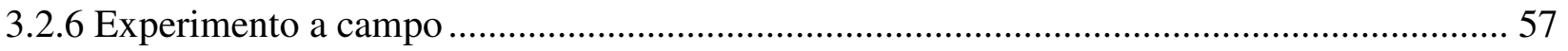




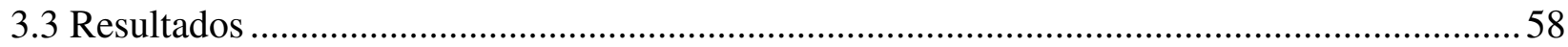

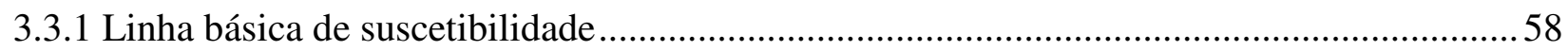

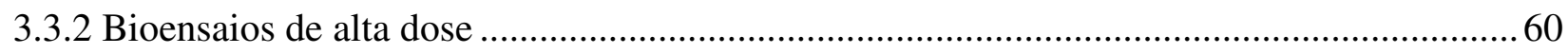

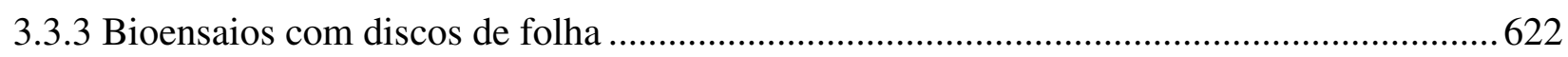

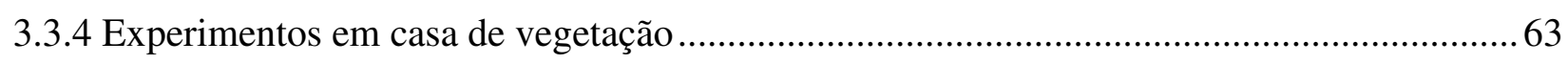

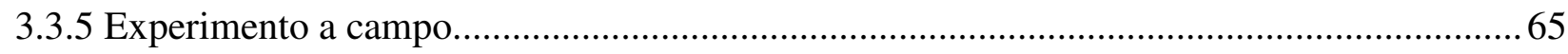

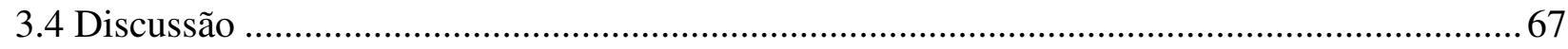

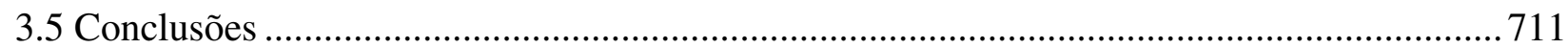

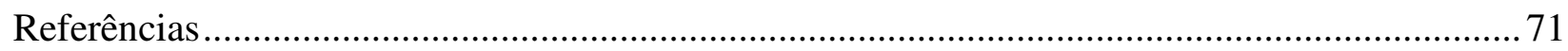

4 ATIVIDADE BIOLÓGICA DA PROTEÍNA Cry1Ac EXPRESSA EM SOJA MON 87701

$\times$ MON 89788 CONTRA Heliothis virescens NO BRASIL ...................................................... 75

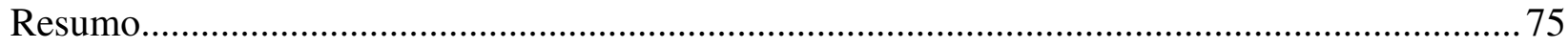

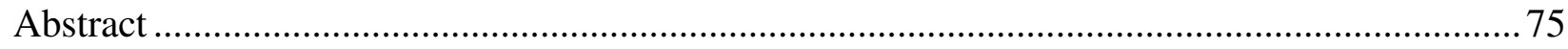

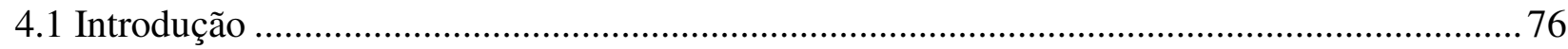

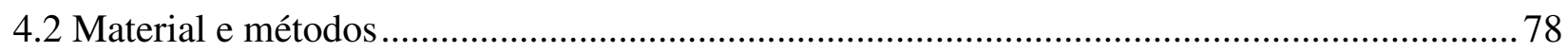

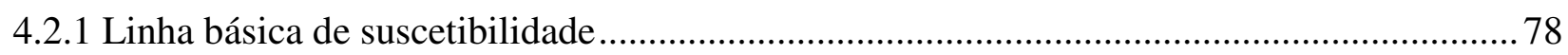

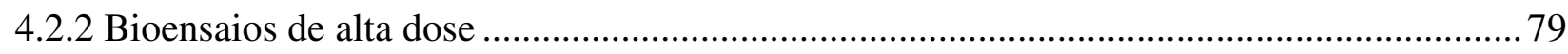

4.2.3 Bioensaios com discos de folha, trifólios e vagens......................................................... 80

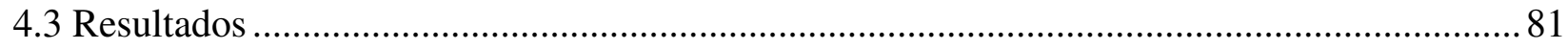

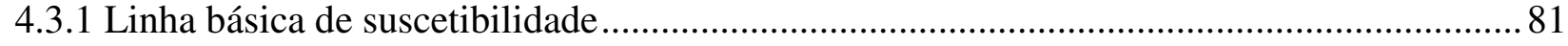

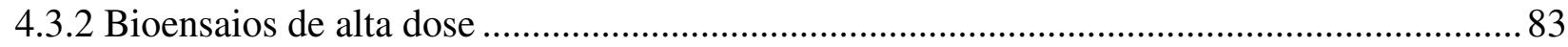

4.3.3 Bioensaios com discos de folha, trifólios e vagens.......................................................... 84

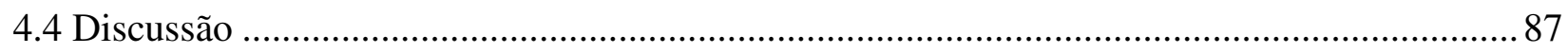

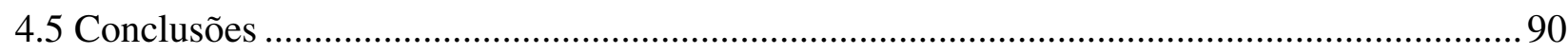

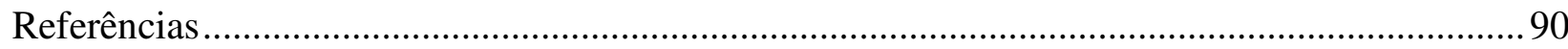

5 CARACTERIZAÇÃO DA ATIVIDADE DA SOJA MON $87701 \times$ MON 89788 CONTRA ESPÉCIES DE Spodoptera (LEPIDOPTERA: NOCTUIDAE) ................................................. 95

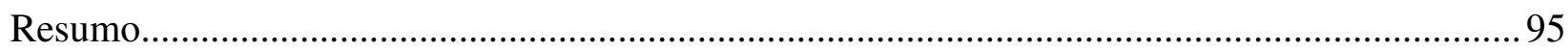

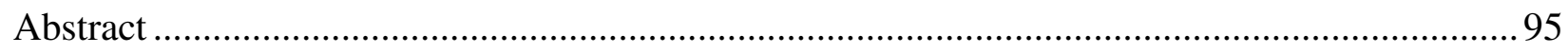

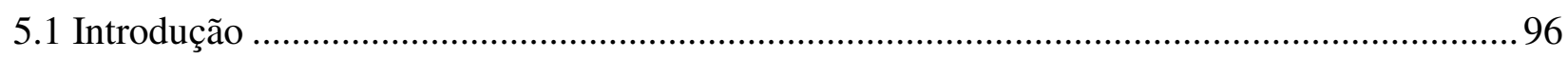

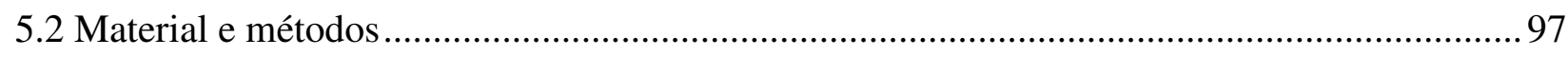

5.2.1 Suscetibilidade de espécies de Spodoptera a Cry1 Ac ................................................... 97 
5.2.2 Bioensaios com discos de folha.

98

5.2.3 Parâmetros biológicos de espécies de Spodoptera em soja MON $87701 \times$ MON 89788 .... 99

5.3 Resultados 100

5.3.1 Suscetibilidade de espécies de Spodoptera a Cry1Ac 100

5.3.2 Bioensaios com discos de folha. 1022

5.3.3 Parâmetros biológicos de espécies de Spodoptera em soja MON 87701 × MON 89788 .. 106 5.4 Discussão 111

5.5. Conclusões 113

Referências 113 


\section{RESUMO}

\section{Avaliação do risco de resistência de lepidópteros-praga (Lepidoptera: Noctuidae) à proteína Cry1Ac expressa em soja MON 87701 × MON 89788 no Brasil}

A soja geneticamente modificada MON $87701 \times$ MON 89788, Glycine max (L.) Merrill, que expressa genes que codificam a proteína Cry1Ac de Bacillus thuringiensis var. kurstaki Berliner e a proteína 5-enolpiruvilchiquimato-3-fosfato sintase de Agrobacterium sp., foi liberada para uso comercial no Brasil em 2010. Para subsidiar um programa de Manejo da Resistência de Insetos (MRI) foi realizada a avaliação de risco de evolução de resistência a Cry1Ac para as pragas-alvo primárias, Anticarsia gemmatalis Hübner e Pseudoplusia includens (Walker), a praga-alvo secundária Heliothis virescens (Fabricius) e as pragas nãoalvo Spodoptera cosmioides (Walker), Spodoptera eridania (Stoll) e Spodoptera frugiperda (J. E. Smith). Em bioensaios com a proteína Cry1Ac purificada incorporada em dieta artificial, verificou-se que Cry1Ac foi extremamente ativa para A. gemmatalis [CL ${ }_{50}$ (IC 95\%) $=0,23(0,15-0,34) \mu \mathrm{g}$ Cry $1 \mathrm{Ac} / \mathrm{mL}$ de dieta], $P$. includens $\left[\mathrm{CL}_{50}(\mathrm{IC} 95 \%)=3,72(2,65-4,86)\right.$ $\mu \mathrm{g}$ Cry1 Ac/mL de dieta] e $H$. virescens [CL50 (IC 95\%) $=0,026(0,021-0,033) \mu \mathrm{g}$ de Cry $1 \mathrm{Ac} / \mathrm{mL}$ de dieta]. Em contraste, na máxima concentração testada de $100 \mu \mathrm{g}$ Cry1 Ac/mL de dieta, $S$. cosmioides e $S$. eridania apresentaram mortalidade $<13 \%$, e $S$. frugiperda de $\approx$ $50 \%$. Em bioensaios com tecido liofilizado de soja MON $87701 \times$ MON 89788, diluído 25 vezes em dieta artificial, houve $100 \%$ de mortalidade para A. gemmatalis e $H$. virescens e até $96 \%$ para $P$. includens. Entretanto, as lagartas sobreviventes de $P$. includens apresentaram enfezamento larval $>95 \%$. Em bioensaios com discos de folha em laboratório (para $A$. gemmatalis, $P$. includens e $H$. virescens), vagens (para $H$. virescens) e elevada infestação em condições de casa de vegetação e de infestação natural em campo (para A. gemmatalis e $P$. includens) foram obtidas alta eficácia da soja MON $87701 \times$ MON 89788 no controle das pragas-alvo primárias e secundária. Por outro lado, a soja MON $87701 \times$ MON 89788 apresentou baixa eficácia para $S$. cosmioides e $S$. eridania (mortalidade $<7 \%$ ) e atividade intermediária para $S$. frugiperda (32 a 47\% mortalidade). A soja MON $87701 \times$ MON 89788 não afetou os parâmetros biológicos de $S$. cosmoides e $S$. eridania. Para $S$. frugiperda houve prolongamento da fase larval $(\approx 5$ dias $)$, menor viabilidade larval e total, aumento no intervalo entre gerações $(\approx 8$ dias) e redução na taxa intrínseca de crescimento $(\approx 41 \%)$. No contexto do MRI, a soja MON $87701 \times$ MON 89788 expressa a proteína Cry1Ac em níveis que constituem alta dose para $A$. gemmatalis e $H$. virescens, e muito próximo a alta dose para $P$. includens. Por outro lado, para as espécies de Spodoptera, a soja MON $87701 \times$ MON 89788 é um evento de baixa dose, pois permite que indivíduos suscetíveis completem o ciclo biológico. Em termos de MIP, a soja MON $87701 \times$ MON 89788 apresenta um elevado nível de controle de A. gemmatalis, $P$. includens e $H$. virescens. No entanto, a soja MON $87701 \times$ MON 89788 não ocasiona controle efetivo de espécies de Spodoptera. As informações obtidas no presente trabalho contribuirão para subsidiar programas de MRI e preservar a durabilidade dessa tecnologia para o MIP-Soja no Brasil.

Palavras-chave: Soja transgênica; Anticarsia gemmatalis; Pseudoplusia includens; Spodoptera spp.; Alta dose; Manejo da Resistência de Insetos 


\section{ABSTRACT \\ Resistance risk assessment of lepidopterous pests (Lepidoptera: Noctuidae) to Cry1Ac protein of MON $87701 \times$ MON 89788 soybean in Brazil}

Genetically modified MON $87701 \times$ MON 89788 soybean, Glycine max (L.) Merrill, expressing genes that code for the Cry1Ac protein of Bacillus thuringiensis var. kurstaki Berliner and the 5-enolpyruvylshikimate-3-phosphate synthase protein of Agrobacterium sp., has been registered for commercial use in Brazil in 2010. To develop a program of Insect Resistance Management (IRM) for this event, we conducted resistance risk assessment to the primary target pests, Anticarsia gemmatalis Hübner and Pseudoplusia includens (Walker), the secondary target pest Heliothis virescens (Fabricius) and the non-target pests Spodoptera cosmioides (Walker), Spodoptera eridania (Stoll) and Spodoptera frugiperda (J. E. Smith) to the Cry1Ac protein. In bioassays with purified Cry1Ac protein incorporated into artificial diet, Cry1Ac was highly active for A. gemmatalis $\left[\mathrm{LC}_{50}(95 \% \mathrm{FL})=0.23(0.15-0.34) \mu \mathrm{g}\right.$ Cry $1 \mathrm{Ac} / \mathrm{mL}$ of diet], $P$. includens $\left[\mathrm{LC}_{50}(95 \% \mathrm{FL})=3.72(2.65-4.86) \mu \mathrm{g}\right.$ Cry $1 \mathrm{Ac} / \mathrm{mL}$ of diet] and $H$. virescens $\left[\mathrm{LC}_{50}(95 \% \mathrm{FL})=0.026(0.021-0.033) \mu \mathrm{g}\right.$ Cry1 Ac/mL of diet]. In contrast, even at the highest concentration tested of $100 \mu \mathrm{g}$ Cry $1 \mathrm{Ac} / \mathrm{mL}$ of diet, the mortality observed to $S$. cosmioides and $S$. eridania was $<13 \%$ and to $S$. frugiperda was $\approx 50 \%$. In bioassays with freeze-dried MON $87701 \times$ MON 89788 soybean tissue, diluted 25 times in artificial diet, there was $100 \%$ mortality to A. gemmatalis and H.virescens and up to $96 \%$ for $P$. includens. However, the surviving $P$. includens larvae showed $>95 \%$ larval stunting. In bioassays with leaf discs in the laboratory to (A. gemmatalis, $P$. includens and $H$. virescens), pods $(H$. virescens), high pest infestation studies under greenhouse conditions and in natural infestation in the field (to A. gemmatalis and to $P$. includens) showed a very high level of efficacy against these primary and secondary target pests. On the other hand, soybean MON $87701 \times$ MON 89788 showed low efficacy to S. cosmioides and S.eridania (mortality < 7\%), and intermediate activity to $S$. frugiperda (32 to $47 \%$ of mortality). MON $87701 \times$ MON 89788 soybean did not affect the biological parameters of $S$. cosmoides and $S$. eridania. For $S$. frugiperda, the larval stage was prolonged $(\approx 5$ days), with reduction on larval and total viability, increase in generation time $(\approx 8$ days $)$ and reduction in the intrinsic rate of increase $(\approx 41 \%)$. In the context of IRM, MON $87701 \times$ MON 89788 soybean expresses the Cry1Ac protein at levels that are high-dose for $A$. gemmatalis and $H$. virescens, and near to the highdose for P. includens. On the other hand, for the Spodoptera species, MON $87701 \times$ MON 89788 soybean is a low-dose event, because it allows susceptible individuals to complete larval developement. In terms of IPM, MON $87701 \times$ MON 89788 soybean provided a high level of control of $A$. gemmatalis, $P$. includens and $H$. virescens. However, MON $87701 \times$ MON 89788 soybean was not effective to control Spodoptera species. The information obtained in this research will contribute to develop IRM programs and to preserve the durability of this technology for soybean IPM in Brazil.

Keywords: Transgenic soybean; Anticarsia gemmatalis; Pseudoplusia includens; Spodoptera spp.; High-dose; Insect Resistance Management 


\section{INTRODUÇÃO}

Plantas geneticamente modificadas (GM) resistentes a insetos representam um novo método de controle de insetos-praga para programas de Manejo Integrado de Pragas (MIP) em diversos agroecossistemas. Essas plantas se caracterizam por expressar genes da bactéria entomopatogênica Bacillus thuringiensis Berliner $(B t)$ que codificam a expressão de proteínas com ação inseticida. Muitos são os benefícios do uso de plantas $B t$ na agricultura, que incluem um controle mais eficiente de insetos-praga, diminuição no uso de inseticidas, e o favorecimento e manutenção de populações de inimigos naturais nas áreas de cultivo, possibilitando a integração com o controle biológico em programas de MIP e permitindo a prática de uma agricultura mais sustentável (ROUSH; MCKENZIE, 1987).

A utilização de plantas $B t$ tem sido crescente na agricultura mundial desde 1996 (JAMES, 2010). Entretanto, no Brasil, somente em 2005, a Comissão Técnica Nacional de Biossegurança (CTNBio) aprovou a liberação comercial da primeira planta $B t$ para o controle de insetos, o algodão Gossypium hirsutum L. que expressa a proteína Cry1Ac de Bt $\left(\right.$ Bollgard $\left.^{\circledR}\right)$. Em 2007, houve a liberação do primeiro evento de milho Zea mays L. resistente a insetos que expressa a proteína Cry1Ab de Bt (Yieldgard $^{\circledR}$ ). Por sua vez, em 2010 foi liberado o primeiro evento de soja resistente a insetos, a soja MON $87701 \times$ MON 89788 (Bt/RR2), Glycine $\max ($ L.) Merrill que possui genes que codificam a expressão da proteína proteína Cry1Ac de $B t$ e a proteína 5-enolpiruvilchiquimato-3-fosfato sintase (EPSPS) de Agrobacterium sp. que confere tolerância ao herbicida glifosato.

A soja MON $87701 \times$ MON 89788 tem como pragas-alvo primárias de controle Anticarsia gemmatalis Hübner e Pseudoplusia includens (Walker) e pragas-alvo secundárias Heliothis virescens (Fabricius), Crosidosema aporema (Walsingham) e Rachiplusia nu (Guenée). Além das pragas-alvo primárias e secundárias, outras pragas não-alvo que atacam soja como Spodoptera eridania Stoll, Spodoptera cosmioides (Walker) e Spodoptera frugiperda (J. E. Smith) também serão expostas à proteína Cry1Ac. Nessa situação, a avaliação do risco de resistência das pragas-alvo e não-alvo da soja MON $87701 \times$ MON 89788 é de fundamental importância para o estabelecimento de estratégias pró-ativas de Manejo da Resistência de Insetos (MRI).

Nesse contexto, o estabelecimento de estratégias de MRI para evitar ou retardar a evolução da resistência de insetos a soja MON $87701 \times$ MON 89788 se configura num dos principais desafios para a sustentabilidade dessa nova tecnologia para o MIP da soja no Brasil. A evolução da resistência é o resultado da pressão de seleção que, consequentemente pode 
ocasionar mudanças na composição genética das populações aumentando a frequência relativa de alguns indivíduos "pré-adaptados" (CROW, 1957). Nesse contexto, resistência é definida como o desenvolvimento de uma habilidade herdada de um organismo de tolerar doses de tóxicos que seriam letais para a maioria dos indivíduos da espécie (CROFT; VAN DE BANN, 1988). No caso de plantas $B t$, significa dizer que um indivíduo pode crescer e se desenvolver se alimentando apenas da planta $B t$, e em seguida, acasalar e produzir descendentes viáveis (ANDOW, 2008).

Para a sustentabilidade da soja MON $87701 \times$ MON 89788 para o MIP é fundamental o estabelecimento pró-ativo de estratégias de MRI. O primeiro passo no estabelecimento de um programa de MRI inclui o desenvolvimento de técnicas adequadas de bioensaio para avaliar a resposta de populações das pragas-alvo à proteína de $B t$ mediante obtenção das linhas básicas de suscetibilidade, a partir das quais, é possível identificar as doses diagnósticas a serem utilizadas no monitoramento da resistência, permitindo discriminar os fenótipos resistentes e suscetíveis, bem como identificar potenciais mudanças na suscetibilidade das populações em resposta à pressão de seleção exercida pela cultura Bt (FISCHHOFF, 1996). Adicionalmente, o conhecimento da expressão da proteína inseticida (baixa ou alta dose) permite identificar as pragas-alvo que poderiam mais rapidamente evoluir para resistência, bem como refinar as estratégias de MRI.

Embora as estratégias de MRI das pragas-alvo de proteínas inseticidas de $B t$ expressas pelas plantas geneticamente modificadas não seja uma condicionante para a aprovação de plantas $B t$ no Brasil, esse é um dos aspectos que tem recebido muita atenção de acadêmicos e especialistas da indústria na formulação de estratégias para impedir ou retardar a evolução da resistência de insetos a proteínas inseticidas de $B t$ expressas em plantas transgênicas (TABASHNIK et al., 1994). Dentre as várias estratégias de MRI que tem sido propostas para evitar ou retardar a evolução da resistência, uma estratégia bastante utilizada é a expressão de altas doses da proteína inseticida nos tecidos da planta e o plantio e manutenção de áreas de refúgio (plantas não-Bt) (ALSTAD; ANDOW, 1995; GOULD, 1994; GOULD, 1998; HUANG; ANDOW; BUSCHMAN, 2011). Entende-se por alta dose a expressão da proteína inseticida em concentração de pelo menos 25 vezes a que seria necessária para matar $99 \%$ de uma população suscetível de referência. Uma baixa dose é qualquer quantidade que não atenda a definição de alta dose (TABASHNIK, 1994; CAPRIO; SUMMEFORD; SIMS, 2000).

O MRI difere para plantas de alta e baixa dose, isso é facilmente observado em estudos de simulação com uso de modelos matemáticos, os quais mostram claramente que a 
alta dose retarda a evolução da resistência mais eficientemente que uma baixa dose (ROUSH, 1994; ALASTAD; ANDOW, 1995). Além disso, a alta dose permite maiores opções de MRI como a utilização de áreas de refúgio de menor tamanho, as quais são mais facilmente implementadas, em comparação a áreas de refúgio para baixa dose (STORER et al., 2003). Por sua vez, o refúgio compreende a área onde a praga não é exposta à pressão de seleção pela mesma proteína inseticida presente no campo Bt, na qual pode sobreviver, reproduzir e acasalar-se com os indivíduos sobreviventes no campo Bt. Desse modo, a evolução da resistência pode ser retardada se: (i) os raros insetos homozigotos resistentes (RR) da cultura $B t$ acasalarem com os insetos homozigotos suscetíveis (SS) da área de refúgio e (ii) se o heterozigoto (RS) resultante do acasalamento for morto pela alta dose da proteína inseticida expressa na planta Bt (BRAVO; SOBERÓN, 2008). Em outras palavras, a alta dose torna a resistência funcionalmente recessiva, o resultado final é uma baixa sobrevivência de insetos heterozigotos (RS), os quais, no início do processo de evolução da resistência são os principais carreadores dos alelos da resistência (GOULD, 1998).

Nesse contexto, para entender o valor da soja MON $87701 \times$ MON 89788 para o MIP e subsidiar programas de MRI à proteína Cry1Ac objetivou-se:

- Avaliar a adequabilidade ao conceito de alta dose e o nível de controle fornecido pela soja MON $87701 \times$ MON 89788 contra A. gemmatalis e P. includens no Brasil;

- Avaliar a atividade biológica da proteína Cry1Ac expressa em soja MON $87701 \times$ MON 89788 contra $H$. virescens no Brasil;

- Caracterizar a eficácia da soja MON 87701 × MON 89788 para algumas espécies do gênero Spodoptera.

\section{Referências}

ALSTAD, D.N.; ANDOW, D.A. Managing the evolution of insect resistance to transgenic plants. Science, Washington, v. 268, p. 1394-1396, 1995.

ANDOW, D.A. The risk of resistance evolution in insects to transgenic insecticidal crops. Collection of Biosafety Reviews, Trieste, v. 4, p. 142-199, 2008.

BRAVO, A.; SOBERÓN, M. How to cope with insect resistance to $B t$ toxins? Trends in Biotechnology, St. Louis, v. 26, n. 10, p. 573-579, 2008. 
CAPRIO, M.A.; SUMMERFORD, D.V.; SIMS, S.R. Evaluating transgenic plants for suitability in pest and resistance management programs. In: LACEY, L.A.; KAYA, H.K. (Ed.). Field manual of techniques in invertebrate pathology. Dordrecht: Kluwer Academic, 2000. cap. 8, p. 805-828.

CROFT, B.A.; VAN DE BANN, H.E. Ecological and genetic factors influencing evolution of pesticide resistance in tetranychid and phytoseiid mites. Experimental and Applied Acaralogy, Amsterdam, v. 4, p. 277-300, 1988.

CROW, J.F. Genetics of insecticide resistance to chemicals. Annual Review of Entomology, Standfort, v. 2, p. 227-246, 1957.

FISCHHOFF, D.A. Insect-resistant crop plants. In: PERSLEY, G.J. (Ed.). Biotechnology and Integrated Pest Management. Wallingford: CAB International. 1996. p. 214-227.

GOULD F. Potential and problems with high-dose strategies for pesticidal engineered crops. Biocontrol Science and Technology, Oxford, v. 4, n. 4, p. 451-461, 1994.

GOULD F. Sustainability of transgenic insecticidal cultivars: integrating pest genetics and ecology. Annual Review of Entomology, Standfort, v. 43, p. 701-26, 1998.

HUANG, F.; ANDOW, D.A.; BUSCHMAN, L.L. Success of the high-dose/refuge resistance management strategy after 15 years of $B t$ crop use in North America. Entomologia Experimentalis et Applicata, Dordrecht, v. 140, n. 1, p. 1-16, 2011.

JAMES, C. Global status of commercialized biotech/GM crops. Ithaca: ISAAA Briefs, 2010. $275 \mathrm{p}$.

ROUSH, R.T.; MCKENZIE, J.A. Ecological genetics of insecticide and acaricide resistance. Annual Review of Entomology, Stanford, v. 32, p. 361-380, 1987.

ROUSH R.T. Managing pests and their resistance to Bacillus thuringiensis: Can transgenics be better than sprays? Biocontrol Science and Technology, London, v.4, p.501-516, 1994.

STORER, N.P.; PECK, S.L.; GOULD, F.; VAN DUYN, J.W.; KENNEDY, G.G. Spatial processes in the evolution of resistance in Helicoverpa zea (Lepidoptera: Noctuidae) to $B t$ transgenic corn and cotton in a mixed agro-ecosystem: a biology-rich stochastic simulation model. Journal of Economic Entomology, Lanham, v. 96, p. 156-172, 2003.

TABASHINIK, B. Evolution to resistence to Bacillus thurigiensis. Annual Review of Entomology, Stanford, v. 39, p. 47-79, 1994. 


\section{REVISÃO BIBLIOGRÁFICA}

\subsection{Aspectos bioecológicos de lepidópteros-praga (Lepidoptera: Noctuidae) da soja}

\subsubsection{Anticarsia gemmatalis Hübner, 1818}

Dentre os insetos-praga da cultura da soja, Anticarsia gemmatalis Hübner, conhecida como lagarta-da-soja apresenta-se como um dos mais importantes insetos desfolhadores (HOFFMANN-CAMPO et al., 1985). É considerado um dos principais insetos-praga da soja no Hemisfério Ocidental ocorrendo desde os EUA até a Argentina (TURNIPSEED; KOGAN, 1976). No Brasil, este lepidóptero, pode causar desfolhamentos severos à soja, desde o Rio Grande do Sul até os estados da região Centro-Oeste (GAZZONI et al., 1981).

A lagarta-da-soja é um inseto polífago, com preferência de alimentação em soja, mas com registro de surtos em algodão (HINDS; OSTERBERGER, 1931), alfafa (ELLISOR; GRAHAM, 1937), arroz (TARRAGÓ et al., 1977) e trigo (SILVA et al., 1968). Nos EUA estudos ecológicos indicaram 38 espécies vegetais e mais cinco espécies de Begoniaceae, Gramineae e Malvaceae como hospedeiros adequados ao desenvolvimento de A. gemmatalis (HERZOG; TODD, 1980). No que diz respeito ao Manejo da Resistência de Insetos (MRI), a característica de polifagia pode colaborar para o retardamento da evolução da resistência a plantas $B t$, devido à imigração de indivíduos suscetíveis provenientes de áreas ocupadas com o cultivo de hospedeiros alternativos da praga (GEORGHIOU; TAYLOR, 1986). Por outro lado, a polifagia pode afetar a dinâmica populacional e condição de praga, podendo oferecer a espécie um grande potencial para a constância de suas populações e do seu aumento no ambiente (FITT, 1989).

O sucesso de A. gemmatalis como praga se deve em parte ao alto potencial reprodutivo da espécie. Cada fêmea tem a capacidade de ovipositar até 1000 ovos (LEPPLA, 1976), sendo esses depositados isoladamente na parte inferior das folhas, no caule, nos ramos e pecíolos, mas com maior concentração nos terços médio e inferior das plantas de soja (FERREIRA; PANIZZI, 1978). O período larval de A. gemmatalis compreende 5-6 ínstares, com duração de $\approx 14$ dias (GAMUNDI, 1988).

A. gemmatalis apresenta várias gerações sobrepostas por ano (multivoltino) sendo que parte da população sobrevive em plantas hospedeiras alternativas, principalmente nas regiões mais quentes. Em soja foi mencionado que o inseto pode ter três gerações anuais (SILVEIRA NETO; BERTI FILHO; CARVALHO, 1973). Entretanto, é provável que o número de gerações seja superior a quatro gerações, considerando-se aspectos como o uso de genótipos 
de soja mais precoces, semeaduras antecipadas e sobreposição de ciclos de cultivares de soja semeada cedo e tardiamente (BRAGA et al., 2011). Portanto, o maior número de gerações pode intensificar a exposição ao longo do tempo de uso da soja MON $87701 \times$ MON 89788 aumentando o risco de evolução da resistência, caso não sejam implementadas estratégias de MRI.

Estudo realizado com marcadores moleculares em populações de A. gemmatalis coletadas em Marianna e Quincy (EUA), La Virgínia (Argentina), Londrina, Passo Fundo e Planaltina (Brasil) indicaram maior similaridade entre as populações do Brasil e EUA do que entre as populações da Argentina e do Brasil, sugerindo que o fluxo gênico pode estar ocorrendo entre populações de A. gemmatalis do Brasil e EUA (SOSA-GÓMEZ, 2004). As similaridades genéticas encontradas entre indivíduos de populações geograficamente distantes indicam que existe migração entre populações de A. gemmatalis. O conhecimento da existência de eventos migratórios é de extrema importância ao MRI à soja MON $87701 \times$ MON 89788 porque populações sedentárias ou que tenham uma taxa reduzida de imigrantes suscetíveis têm maior potencial de evoluir para resistência.

\subsubsection{Pseudoplusia includens (Walker, 1857)}

Das lagartas desfolhadoras da soja, Pseudoplusia includens (Walker), conhecida como lagarta-falsa-medideira, é o Plusiinae mais abundante da cultura da soja. Sua distribuição é restrita ao Hemisfério Ocidental, ocorrendo desde o Norte dos EUA até o Sul da América do Sul (ALFORD; HAMMOND JUNIOR, 1982). No Brasil, nos últimos anos, a lagarta-falsamedideira tem se tornado um sério problema fitossanitário na cultura da soja, com vários surtos, ocorrendo isolada ou associada à lagarta-da-soja. Isso possivelmente esteja relacionado ao aumento das aplicações de fungicidas para o controle da ferrugem asiática da soja, Phakopsora pachyrhizi Sydow, que tem como consequência a diminuição do controle biológico natural. Soma-se a isso, sua maior tolerância aos inseticidas químicos e biológicos à base de $B t$ quando comparada com a lagarta-da-soja, sendo considerada pelos agricultores uma espécie de difícil controle.

A lagarta-falsa-medideira é um inseto polífago com capacidade de se desenvolver em 73 plantas hospedeiras, pertencentes a 29 famílias. Além da soja e algodão foi constatada em feijão, fumo, girassol, alface, tomate, couve-flor entre outras (HERZOG; TODD, 1980). No entanto, $P$. includens possui preferência e melhor adaptação à soja, em relação a outras 17 culturas estudadas (KHALSA; KOGAN; LUCKMANN, 1979). A polifagia é uma 
característica que pode colaborar com a dinâmica populacional e condição de praga, uma vez que, as populações podem desenvolver-se simultaneamente em diferentes plantas hospedeiras dentro de uma região, ou podem persistir no ambiente em baixa densidade até a fêmea encontrar um hospedeiro capaz de sustentar o desenvolvimento das lagartas.

A capacidade reprodutiva é um fator importante para o sucesso de $P$. includens como praga. Fêmeas de $P$. includens ovipositam em média de 700 ovos, os quais são depositados na face inferior das folhas e, nos dois terços superiores do dossel das plantas (JOST; PITRE, 2002). Entretanto, variações no potencial reprodutivo de $P$. includens, têm sido observadas entre 500 a 1300 ovos por fêmea (JENSEN; NEWSON; GIBBENS, 1974). Em soja e algodoeiro, $P$. includens apresenta duração do período lagarta-adulto de $\approx 26$ dias, com 5-6 ínstares larvais (MITCHEL, 1967). As lagartas em ínstares iniciais apresentam o hábito de se alimentarem das folhas mais tenras do terço inferior das plantas de soja, tornando-se menos exigentes à medida que se desenvolvem, quando passam a se alimentar de folhas mais fibrosas.

Os surtos de $P$. includens parecem ser maiores em agroecossistemas onde a soja e o algodão são cultivados nas proximidades. Estudos realizados em Louisiana (EUA) constataram um aumento na longevidade, oviposição e frequência de cópulas quando foi fornecido o néctar das flores de algodoeiro para adultos de $P$. includens. Isso em parte pode explicar o maior índice populacional de $P$. includens em soja quando existem áreas de algodão nas proximidades (JENSEN; NEWSON; GIBBENS, 1974). Situação semelhante pode ocorrer no Brasil Central, com a sobreposição de áreas de cultivo de soja MON $87701 \times$ MON 89788 com áreas de algodão Bt $\left(\right.$ Bollgard $^{\circledR}$, Bollgard II $^{\circledR}$ e Widestrike $\left.^{\circledR}\right)$, resultando em um período adicional de exposição à proteína Cry1Ac, o que pode favorecer a seleção de genótipos resistentes. Nesse cenário, é de fundamental importância considerar o sistema de cultivo de algodão e soja para o estabelecimento das estratégias de MRI de $P$. includens em ambas as culturas.

Nos EUA foi relatado que $P$. includens possui comportamento migratório, no entanto, suas populações são residentes na Flórida e Sul do Texas (HERZOG; TODD, 1980). No Brasil, até o momento, não existem estudos para avaliar a estruturação genética dessa espécie.

\subsubsection{Heliothis virescens (Fabricius, 1777)}

Heliothis virescens (Fabricius) é uma espécie nativa de regiões tropicais e subtropicais, e encontra-se amplamente distribuída na América do Sul e América do Norte 
(FITT, 1989). De acordo com Capinera (2001), H. virescens é uma espécie nativa dos EUA, porém Poole; Mitter e Huettel (1993) sugerem que o centro de diversidade da espécie seja o Brasil.

H. virescens é uma praga com alto potencial reprodutivo, sendo que cada fêmea pode ovipositar de 500 a 800 ovos durante sua vida reprodutiva (MORETI, 1980). O tempo total de uma geração é relativamente curto $(\approx 45$ dias $)$ e combinado com uma alta fecundidade, permite que $H$. virescens tenha uma alta capacidade de aumento populacional e sobreposição de gerações (MORETI, 1980). Em soja não se tem informações do número de gerações a cada ciclo de cultivo, mas em algodão esse inseto pode completar até três gerações em um único ciclo da cultura (DEGRANDE, 1998). O conjunto de características descritas anteriormente permite que $H$. virescens explore diversos hospedeiros cultivados e não cultivados, levando a rápidas taxas de crescimento e grande potencial de danos a culturas como algodão e soja.

No Brasil, H. virescens é uma das pragas-chave da cultura do algodão. Entretanto, nos últimos anos, este inseto também tem se destacado como importante problema fitossanitário na cultura da soja, principalmente nas regiões produtoras do Cerrado (TOMQUELSKI; MARUYAMA, 2009). H. virescens é uma espécie polífaga capaz de se alimentar em algodão, soja, tabaco, tomate, milho, girassol e feijoeiro (FITT, 1989).

A capacidade de dispersão é o segundo fator importante para o sucesso de $H$. virescens como praga. Os movimentos locais dentro das culturas e entre hospedeiros alternativos nas proximidades são de suma importância na dinâmica sazonal dessa praga, especialmente, nos mais diversos sistemas de cultivo onde os locais de alimentação e de oviposição podem estar permanentemente disponíveis (FITT, 1989). Os adultos são migrantes facultativos, podendo migrar em resposta às más condições locais para a reprodução (por exemplo, escassez de fontes de néctar ou hospedeiros para alimentação das lagartas) (FITT, 1989). De acordo com Schneider (1999), H. virescens apresenta movimento de longo alcance, sendo que a distância média percorrida por esta espécie, avaliada por meio da técnica de marcação, liberação e recaptura foi de $10 \mathrm{~km}$ em ambientes heterogêneos no Oeste do Mississipi (EUA). No Brasil, estudos com marcadores moleculares demonstraram que há uma ausência ou incipiente estruturação genética entre as populações de $H$. virescens que infestam algodão e soja, desse modo, para serem eficientes as estratégias de MRI deve considerar os agroecossistemas de produção dessas duas culturas (ALBERNAZ, 2011; DOMINGUES, 2011).

O conjunto de características descritas anteriormente permite que as populações de $H$. virescens sejam expostas à grande pressão de seleção por proteínas inseticidas de $B t$ expressas 
nas culturas do algodão e soja, tornando de fundamental importância o estabelecimento de estratégias de MRI.

\subsubsection{Spodoptera cosmioides (Walker, 1898)}

Das lagartas que atacam soja, Spodoptera cosmioides (Walker) tem distribuição restrita a América do Sul. Trata-se de uma espécie polífaga que se alimenta de um grande número de plantas cultivadas e espontâneas. No Brasil, seus hospedeiros são as culturas do amendoim, alfafa, algodão, arroz, aveia, batata-inglesa, berinjela, ervilha, feijão, girassol, fumo, milho, soja, sorgo, tomate e trigo (BAVARESCO et al., 2004). Entretanto, apesar da ampla gama de hospedeiros, sua ocorrência como praga é relatada em apenas algumas culturas, e geralmente relacionada a desequilíbrios provocados pelo uso de inseticidas de amplo espectro (HABIB; PALEARI; AMARAL, 1983). Nos estados de São Paulo, Paraná e Santa Catarina surtos da praga causaram severos danos em culturas de interesse econômico entre as quais o algodão e a soja. Em soja, além de ocasionar desfolha, a partir do início da fase reprodutiva, juntamente com Spodoptera eridania Stoll torna-se uma das principais pragas que atacam as vagens.

De acordo com Bavaresco et al. (2004), as fêmeas de S. cosmioides podem ovipositar mais de 1000 ovos. Habib; Paleari e Amaral (1983) observaram diferenças no período de oviposição e na fecundidade de $S$. cosmioides quando alimentada com soja e algodão na fase larval, sendo o algodão mais adequado para desenvolvimento do inseto, com 5 e 6 ínstares quando alimentada com folhas de algodoeiro e soja, respectivamente. Bavaresco et al. (2004), em laboratório verificaram que $S$. cosmioides apresentara duração da fase larval de $\approx 19$ dias e do período lagarta-adulto de $\approx 36$ dias.

A fase pupal de $S$. cosmioides é significativamente maior para os machos do que para as fêmeas (BAVARESCO et al., 2004). Esse fenômeno é denominado de protoginia, que é um mecanismo que reduz a probabilidade de acasalamento entre indivíduos descendentes da mesma postura, permitindo que as fêmeas ao emergir antes dos machos voem para outros locais ou, se permanecerem na área, acasale com machos provenientes de outras posturas (CROCOMO; PARRA, 1985). Diante disso, existe a possibilidade que $S$. cosmioides acasale fora da área de cultivo onde tenha completado seu desenvolvimento larval e pupal, tal fato pode configurar um comportamento migratório do inseto para áreas adjacentes a de cultivo de soja MON $87701 \times$ MON 89788 e assim aumentar a probabilidade de acasalamento com insetos de genótipo suscetível, retardando a evolução de resistência. 


\subsubsection{Spodoptera eridania Stoll, 1782}

Spodoptera eridania Stoll é uma espécie polífaga, a qual se alimenta de um grande número de plantas cultivadas e de hospedeiros alternativos. No Brasil, S. eridania é citada atacando algodão, soja, amendoim, alface, tomate, couve, mamona, pimentão e aboboreira (SILVA et al., 1968). É uma praga em expansão pela frequência crescente e intensidade de danos em diversas regiões produtoras de algodão e soja no Cerrado, onde tradicionalmente não era considerada importante para essas culturas (SANTOS; MENEGUIM; NEVES, 2005).

S. eridania possui alto potencial reprodutivo com capacidade de ovipositar de 600 a 900 ovos. Em laboratório, S. eridania apresenta de 6 a 7 ínstares larvais quando alimentadas com folhas de soja e algodão, respectivamente (SANTOS; MENEGUIM; NEVES, 2005). A duração da fase larval varia de 12 a 18 dias, sendo que, as lagartas criadas em folhas de algodoeiro apresentam desenvolvimento mais rápido e maior peso de pupas, comparativamente àquelas criadas em folhas de soja. Desse modo, a redução no peso das pupas de lagartas alimentadas com folhas de soja pode afetar a oviposição, diminuindo a quantidade de ovos (LYNCH; PAIR; JOHNSON, 1983).

No Cerrado brasileiro, S. eridania demonstra comportamento migratório ao passarem das plantas de soja em final de ciclo para plantas invasoras conhecidas como corda-de-viola, onde causam desfolhamento e completam seu desenvolvimento. Nessa região, a planta invasora corda-de-viola ocorre na maioria das áreas cultivadas com algodoeiro, soja e adjacências e permanece vegetando por um período maior que as plantas cultivadas. Por essa razão, acredita-se que a disponibilidade sequencial de hospedeiros alternativos possa viabilizar o desenvolvimento e a permanência de S. eridania em áreas de cultivo de algodão e soja. A diminuição ou se possível a eliminação de plantas de corda-de-viola e o distanciamento espacial entre talhões cultivados com soja e algodão podem ser, entre outras, estratégias para o MIP da praga (SANTOS; MENEGUIM; NEVES, 2005). Essas medidas podem reduzir a densidade populacional de $S$. eridania e também contribuir para o MRI em soja MON $87701 \times$ MON 89788 .

\subsubsection{Spodoptera frugiperda (J. E. Smith, 1797)}

Spodoptera frugiperda (J. E. Smith) é migratória e endêmica no Hemisfério Ocidental, sendo a cultura do milho o seu principal hospedeiro. O sucesso de $S$. frugiperda como praga é consequência da elevada capacidade de dispersão dos adultos ao longo da faixa de 
distribuição de suas plantas hospedeiras (SPARKS, 1979). As lagartas alimentam-se de uma série de plantas cultivadas ocorrendo praticamente em todos os estados brasileiros. No Brasil, além das culturas do algodão e do milho foram relatados ataques em arroz (BOTTON et al., 1998), amendoim (ISIDRO; ALMEIRA; PEREIRA, 1997), soja (MOSCARDI; KASTELIC, 1985), sorgo (CORTEZ; WAQUIL, 1997), trigo (TAKAHASHI; NAKANO; OSI, 1980), entre outras. Em soja os ataques de $S$. frugiperda são mais frequentes a plântulas devido à presença de lagartas da palhada ou resteva. Os ataques mais intensos a cultura da soja têm ocorrido em áreas de cultivo no Cerrado, estando geralmente associados a períodos ou anos mais secos e/ou cultivos em épocas de menor precipitação. Ademais, em soja a presença de gramíneas invasoras (ex. papuã (Brachiaria spp.) e milhã (Digitaria spp.)) pode ocasionar o surgimento de elevadas populações de S. frugiperda.

S. frugiperda tem alta capacidade reprodutiva, sendo que cada fêmea pode ovipositar mais de 1000 ovos (VALICENTE; COSTA, 1991). S. frugiperda apresenta de 4 a 7 ínstares larvais, variando conforme a fonte de alimento, temperatura, sexo e genética (PITRE; HOGG, 1983). Quando alimentada com algodão, soja e milho, S. frugiperda apresentou maior tempo de desenvolvimento em algodão e soja e pupas menos pesadas em comparação àquelas geradas de lagartas alimentadas com folhas de milho (PITRE; HOGG, 1983).

A ampla gama de hospedeiros de $S$. frugiperda ocasionou mudanças comportamentais e fisiológicas devido à utilização de um ou outro hospedeiro, permitindo a diferenciação de raças de $S$. frugiperda. Raças de $S$. frugiperda foram identificadas em plantas de milho e algodão (Raça C) e a plantas de arroz (Raça R) (PASHLEY; JOHNSON; SPARKS, 1985). Estas duas raças já foram identificadas e caracterizadas nos EUA (PASHLEY; MARTIN, 1987) e no Brasil (BUSATO et al., 2004). Entretanto, para as plantas hospedeiras algodão e milho não foram identificados nenhum agrupamento capaz de separar e associar as populações de $S$. frugiperda, sugerindo a existência de um nível significativo de fluxo gênico entre as populações provenientes dessas plantas hospedeiras (MARTINELLI et al., 2006). O entendimento da estrutura genética e do nível intra-específico em populações de uma praga é essencial para o estabelecimento e refinamento das estratégias de MRI a plantas Bt (CAPRIO; TABASHNIK, 1992).

O controle de $S$. frugiperda não tem se mostrado uma tarefa fácil e bem definida, pois esse inseto possui resistência a maioria dos grupos químicos de inseticidas. A liberação comercial de plantas $B t$ tem fornecido uma nova ferramenta de controle de $S$. frugiperda, a qual tem se mostrado bastante eficiente. No entanto, a grande capacidade reprodutiva, o intervalo entre gerações relativamente curto, a polifagia e o sistema de cultivo de milho, 
algodão e soja $B t$ expõe as populações de $S$. frugiperda a repetidas pressões de seleção a proteínas de $B t$ com mesmo sítio de ação e conformação estrutural, propiciando um cenário favorável para evolução da resistência, caso as estratégias de MRI não sejam efetivamente implementadas.

\subsection{Plantas geneticamente modificadas resistentes a insetos}

A clonagem e a caracterização de genes da bactéria Bacillus thuringiensis Berliner (Bt) codificadores de proteínas com atividade tóxica a insetos revelaram novas perspectivas de uso dessa bactéria para o controle de insetos-praga. Mediante uso de técnicas de engenharia genética foi possível introduzir esses genes codificadores de proteínas inseticidas nos genomas dos vegetais, permitindo a expressão contínua dessas proteínas em todos os tecidos da planta e atingindo, assim, apenas os insetos-praga que se alimentam dos tecidos (SCHNEP; WHITELEY, 1981).

O processo de obtenção de uma planta $B t$ é bastante complexo. Primeiramente, uma cepa de $B t$ que é ativa contra os insetos-praga é identificada e os genes que produziram a proteína são isolados. Esses genes geralmente não expressam a proteína $B t$ em níveis suficientemente elevados, então versões truncadas do gene são sintetizadas mediante alterações no códon e eliminação de certas sequências. Plantas na fase de cultura de tecido são então transformadas via Agrobacterium tumefaciens ou biobalística, com o gene $B t$, juntamente com um marcador selecionado, o qual é utilizado para identificar as plantas em que o gene $B t$ foi inserido de forma estável no genoma. Comumente são utilizados marcadores que conferem resistência a antibióticos (ex. kanamicina), a herbicida ou que expressam determinadas substâncias químicas para identificação das células transformadas (ex. bglucoronidase) (FISCHHOFF, 1987).

Devido à complexidade do processo de transformação, somente em 1987 foram obtidas as primeiras plantas $B t$, mediante a inserção de genes cry que codificam a síntese de proteínas inseticidas em plantas de tomate (proteína Cry1Ab) e tabaco (proteína Cry1Ac) (FISCHHOFF, 1987). Desde então, vários genes cry foram introduzidos em diversas plantas como algodão, arroz, milho, batata, canola e soja (JOUANIN et al., 1998; PARROTT et al., 1994; STEWART et al, 1996; MACRAE et al., 2005; HOMRICH et al., 2008). Além dos genes cry, algumas plantas $B t$, como milho e algodão expressam Proteínas Inseticidas Vegetativas (VIP) de $B t$, as quais se mostraram eficientes no controle de alguns insetos-praga economicamente importantes. 
As primeiras plantas $B t$ apresentavam baixos níveis de expressão dos genes cry (menos que $0,001 \%$ do total de proteínas solúveis na folha), entretanto, com uso de técnicas de biologia molecular, que permitiram a construção e expressão de genes parcial ou totalmente sintéticos, foram obtidos níveis mais altos de expressão $(0,02$ - 1\%) (JOUANIN et al., 1998). Koziel et al. (1993), através da inserção de um gene truncado crylAb, conseguiram a expressão da proteína Cry1Ab em altos níveis em plantas de milho, a qual proporcionou proteção contra danos de Ostrinia nubilalis (Hübner). Essa constatação demonstrou que a partir de alterações específicas na sequência de DNA dos genes de B. thuringiensis era possível obter aumentos significativos na produção e acúmulo de proteínas inseticidas nos tecidos das plantas $B t$.

Proteínas inseticidas de $B t$ matam os insetos por um processo bastante complexo. O modo de ação das proteínas Cry tem sido caracterizado principalmente em lepidópteros, nos quais a ação primária é a lise das células epiteliais do intestino médio de insetos-alvo pela formação de poros nas microvilosidades apicais das membranas das células. As proteínas Cry passam de protoxinas (inclusão cristalina) para oligômeros que se inserem em membranas que causam o vazamento de íons e a lise celular. As inclusões cristalinas são ingeridas por larvas e são dissolvidas em meio alcalino do intestino, e as protoxinas inativas são solubilizadas por proteases do intestino médio, produzindo proteínas resistentes a proteases de 60 a $70 \mathrm{kDa}$ (BRAVO; GILL; SOBERÓN, 2005). A ativação da toxina envolve a remoção proteolítica de um peptídeo N-terminal (25-30 aminoácidos para proteínas Cry1, 58 para Cry3A e 49 para Cry2Aa) e, aproximadamente metade da proteína restante do C-terminal em longas protoxinas Cry. A toxina ativada se liga a receptores glicoprotéicos específicos nas microvilosidades das células epiteliais do intestino médio, antes de se inserirem dentro da membrana. A inserção das toxinas gera a formação de poros líticos nas microvilosidades da membrana apical. Posteriormente, ocorre lise celular e o rompimento do epitélio do intestino médio liberando o conteúdo celular, fornecendo aos esporos um meio esporulante, que leva a uma septicemia e a morte do inseto. Um processo similar ocorre quando as proteínas Cry são expressas em plantas. As proteínas ativadas ligam-se, então, aos receptores de membrana do intestino médio nos insetos suscetíveis, inserem-se na membrana apical e formam poros. Essa formação de poros causa a perda da regulação osmótica e lise da célula, o que causa a morte do inseto (GILL; COWLES; PIETRATONIO, 1992).

Há proteínas que não tem relação com as proteínas Cry e, são produzidas por cepas de $B t$ durante a fase vegetativa de crescimento e não formam inclusões cristalinas, sendo conhecidas como VIP. A suscetibilidade dos insetos varia em relação a essa proteína 
inseticida. As células do epitélio do intestino médio de insetos suscetíveis é o alvo primário para as proteínas VIP, e a subsequente lise destas células parece ser o mecanismo primário da causa da mortalidade. As proteínas VIP atuam de forma semelhante às proteínas Cry, contudo apresentam propriedades distintas de ligação das Cry, indicando baixo potencial de resistência cruzada entre proteínas VIP e Cry (JACKSON et al., 2007). Há consenso em toda a literatura de que o potencial dessas proteínas inseticidas ainda não foi totalmente elucidado.

No Brasil, a primeira geração de plantas Bt, especialmente milho e algodão foi composta basicamente por plantas que expressavam uma única proteína inseticida, no entanto, a segunda geração apresenta a expressão de duas ou mais proteínas inseticidas (Quadro 2.1). Sendo assim, quando os transgenes são direcionados para o controle da mesma praga-alvo, e cada um é tóxico por si só, o evento é "piramidado". No entanto, quando os dois transgenes são independentes e não atuam sobre a mesma praga-alvo, o evento é "estaqueado", e para fins de MRI funcionariam como plantas que expressam apenas uma proteína inseticida, visto os alvos serem distintos.

A segunda geração de plantas $B t$ usa a estratégia de "pirâmide de genes" para o MRI, pois quando múltiplos genes são inseridos, e não há resistência cruzada, a taxa de evolução da resistência é reduzida, principalmente devido à baixa frequência inicial dos indivíduos resistentes às múltiplas toxinas (FERRÉ; VAN RIE, 2002). Essa estratégia é baseada no conceito que a resistência para duas proteínas é conferida independentemente por diferentes genes. Sendo assim, o tempo que levaria para uma determinada praga evoluir para resistência a uma determinada proteína expressa na planta $B t$ é o produto do número de gerações que a praga levaria para evoluir a resistência a cada proteína separadamente. Por exemplo, se o tempo que uma praga levaria para evoluir a resistência à proteína $\mathrm{A}$ for de 20 gerações e para proteína B de 30 gerações, essa praga pode levar 600 gerações para evoluir a resistência para ambas as proteínas (ANDOW, 2008). Embora seja uma das melhores opções para o MRI, essa estratégia perde eficácia quando plantas transgênicas que expressam um único gene cry são cultivadas nas proximidades de plantas $B t$ expressando dois ou mais genes $c r y$, porque insetos resistentes aos dois tipos de plantas Bt podem ser selecionados (ZHAO et al., 2005). 


\begin{tabular}{|c|c|c|c|c|}
\hline Ano & Cultura & Evento & $\begin{array}{l}\text { Proteína } \\
\text { inseticida }\end{array}$ & Praga-alvo \\
\hline 2005 & Algodão & MON 531 & Cry1Ac & $\begin{array}{l}\text { A. argillacea, } P . \text { gossypiella e } H . \\
\text { virescens }\end{array}$ \\
\hline 2007 & Milho & MON 810 & Cry $1 \mathrm{Ab}$ & S. frugiperda e D. saccharalis \\
\hline \multirow{2}{*}{2008} & Milho & Bt 11 & Cry $1 \mathrm{Ab}$ & $\begin{array}{l}\text { S. frugiperda, D. saccharalis e } H \text {. } \\
\text { zea }\end{array}$ \\
\hline & Milho & TC 1507 & Cry1F & $\begin{array}{l}\text { S. frugiperda, D. saccharalis e } H \text {. } \\
\text { zea }\end{array}$ \\
\hline \multirow{4}{*}{2009} & Algodão & $\begin{array}{l}\text { Widestrike } \\
281-24-236\end{array}$ & $\begin{array}{l}\text { Cry1Ac/ } \\
\text { Cry1F }\end{array}$ & $\begin{array}{l}\text { H. virescens, } H . \text { zea, } S \text { frugiperda, } \\
\text { A. argillacea, } P . \text { gossypiella, } S . \\
\text { eridania e } P . \text { includens }\end{array}$ \\
\hline & Algodão & MON 15985 & $\begin{array}{l}\text { Cry1Ac/ } \\
\text { Cry2Ab2 }\end{array}$ & $\begin{array}{l}\text { A. argillacea, } H . \text { virescens, } P \text {. } \\
\text { gossypiella, S. frugiperda e } P \text {. } \\
\text { includens }\end{array}$ \\
\hline & Milho & MON 89034 & $\begin{array}{l}\text { Cry1A.105/ } \\
\text { Cry2Ab2 }\end{array}$ & $\begin{array}{l}\text { S. frugiperda, D. saccharalis e } H \text {. } \\
\text { zea }\end{array}$ \\
\hline & Milho & MIR 162 & VIP3Aa20 & $\begin{array}{l}\text { S. frugiperda, D. saccharalis e } H \text {. } \\
\text { zea }\end{array}$ \\
\hline \multirow{4}{*}{2010} & Milho & Bt $11 \times$ MIR 162 & $\begin{array}{l}\text { Cry1Ab/ } \\
\text { VIP3Aa20 }\end{array}$ & $\begin{array}{l}\text { S. frugiperda, D. saccharalis e } H \text {. } \\
\text { zea }\end{array}$ \\
\hline & Milho & MON 88017 & Cry3Bb1 & Espécies de Diabrotica \\
\hline & Milho & MON 89034 × TC 1507 & $\begin{array}{l}\text { Cry1A.105/ } \\
\text { Cry2Ab2/ } \\
\text { Cry1F }\end{array}$ & $\begin{array}{l}\text { S. frugiperda, D. saccharalis e } H \text {. } \\
\text { zea }\end{array}$ \\
\hline & Soja & MON $87701 \times$ MON 89788 & Cry1Ac & A. gemmatalis e $P$. includens \\
\hline \multirow{3}{*}{2011} & Algodão & TwinLink & $\begin{array}{l}\text { Cry } 1 \mathrm{Ab} / \\
\text { Cry } 2 \mathrm{Ae}\end{array}$ & $\begin{array}{l}\text { A. argillacea, } H . \text { virescens, } P . \\
\text { gossypiella, S. frugiperda e } P . \\
\text { includens }\end{array}$ \\
\hline & Milho & TC $1507 \times$ MON 810 & $\begin{array}{l}\text { Cry1F/ } \\
\text { Cry1Ab }\end{array}$ & $\begin{array}{l}\text { S. frugiperda, D. saccharalis e } H \text {. } \\
\text { zea }\end{array}$ \\
\hline & Milho & MON $89034 \times$ MON 88017 & $\begin{array}{l}\text { Cry1A.105/ } \\
\text { Cry2Ab2/ } \\
\text { Cry3Bb1 }\end{array}$ & $\begin{array}{l}\text { S. frugiperda, D. saccharalis e } H . \\
\text { zea e espécies de Diabrotica }\end{array}$ \\
\hline
\end{tabular}

Quadro 2.1 - Plantas geneticamente modificadas que expressam proteínas inseticidas de $B$. thuringiensis liberadas para cultivo no Brasil (Fonte: CTNBio, Dezembro, 2011)

\subsection{Potencial de insetos-praga para evolução da resistência a proteínas inseticidas de $B t$}

No contexto agrícola, a evolução da resistência tem sido identificada como uma das mais sérias ameaças ao desenvolvimento e à manutenção de práticas de MIP (LABBE; LENORMAND; RAYMOND, 2005). A evolução da resistência é uma consequência do 
controle de pragas, isto porque muitas das táticas de controle são idealizadas e colocadas na prática com o objetivo de reduzir a população de uma praga mediante o aumento da mortalidade ou pela diminuição da fecundidade dos insetos. Deste modo, possíveis diferenças na sobrevivência e ou fecundidade entre os indivíduos de uma população, após a utilização de alguma prática de manejo, pode resultar na seleção de insetos resistentes a táticas de controle (VIA, 1990).

Para proteínas inseticidas de $B t$, o primeiro caso de evolução da resistência de insetos foi reportado em 1985 para uma população de laboratório de Plodia interpunctella (Hübner), a qual apresentou uma razão de resistência de 100 vezes após ser criada por 15 gerações em dieta artificial tratada com inseticida biológico de Bt (MCGAUGHEY, 1985). Estudos bioquímicos indicaram que a população resistente possuía uma alteração no sítio de ligação da proteína inseticida no intestino médio (VAN RIE et al., 1990). Posteriormente, houve relatos de evolução de resistência a inseticidas biológicos de $B t$ para populações de campo de Plutella xylostella (Linnaeus) (TABASHNIK et al., 1997), sendo este considerado o primeiro caso de resistência de insetos a inseticidas biológicos em campo (FERRÉ; VAN RIE, 2002). Outro caso de evolução da resistência de insetos a inseticidas biológicos à base de $B t$ foi reportado para Trichoplusia ni (Hübner) em estufas de produção de legumes no Canadá (JANMAAT; MYERS, 2003). Ademais, na literatura foram reportados diversos casos de seleção de insetos resistentes a proteínas de Bt em condições de laboratório (Quadro 2.2).

Até o momento, todos os casos de evolução da resistência de insetos a proteínas de $B t$ restringiam-se a inseticidas biológicos de $B t$ aplicados em pulverização ou devido à seleção de linhagens resistentes em condições de laboratório. No entanto, a partir de 2007 foram reportados vários casos de evolução da resistência a campo de pragas-alvo de plantas $B t$; Busseola fusca (Fuller) à proteína Cry1Ab expressa em milho na África do Sul (VAN RENSBURG, 2007), evidência de evolução da resistência de Helicoverpa zea (Boddie) à proteína Cry1Ac expressa em algodão nos EUA (TABASHNIK et al., 2008), S. frugiperda à proteína Cry1F expressa em milho em Porto Rico (STORER et al., 2010), Pectinophora gossypiella (Saunders) à proteína Cry1Ac expressa em algodão na Índia (DUHRUA; GUJAR, 2011) e Diabrotica virgifera virgifera Le Conte à proteína Cry3Bb1 expressa em milho nos EUA (GASSMANN et al., 2011). 


\begin{tabular}{|c|c|c|c|c|c|c|c|}
\hline \multirow{2}{*}{$\begin{array}{l}\text { Espécie/ } \\
\text { Família }\end{array}$} & \multirow{2}{*}{ Origem } & \multirow{2}{*}{$\begin{array}{l}\text { Agente de } \\
\text { seleção }^{(1)}\end{array}$} & \multirow{2}{*}{ Linhagem } & \multicolumn{3}{|c|}{$\begin{array}{l}\text { Níveis de resistência e } \\
\text { resistência cruzada }\end{array}$} & \multirow{2}{*}{ Referência } \\
\hline & & & & $\mathrm{GS}^{(2)}$ & Proteína & $\mathrm{RR}^{(3)}$ & \\
\hline \multirow{4}{*}{$\begin{array}{c}\text { Heliothis } \\
\text { virescens } \\
\text { (Noctuidae) }\end{array}$} & $\begin{array}{l}\text { Carolina do } \\
\text { Norte }\end{array}$ & $\begin{array}{l}\text { Cry1Ab } \\
\text { (MR) }\end{array}$ & SEL & $\begin{array}{l}14 \\
22\end{array}$ & $\begin{array}{l}\text { Cry } 1 \mathrm{Ab} \\
\text { Cry } 1 \mathrm{Ab}\end{array}$ & $\begin{array}{l}20 \\
69\end{array}$ & $\begin{array}{c}\text { SIMS; } \\
\text { STONE, } 1991\end{array}$ \\
\hline & $\begin{array}{c}\text { Carolina do } \\
\text { Norte }\end{array}$ & $\begin{array}{l}\text { Cry1Ac } \\
\text { (T) }\end{array}$ & CP73-3 & 17 & Cry1Ab & 13 & $\begin{array}{c}\text { GOULD et al., } \\
1992\end{array}$ \\
\hline & $\begin{array}{l}\text { Carolina do } \\
\text { Norte }\end{array}$ & $\begin{array}{l}\text { Cry1Ac } \\
\text { (T/MR) }\end{array}$ & YHD2 & $\begin{array}{l}17 \\
19\end{array}$ & $\begin{array}{l}\text { Cry1Ac } \\
\text { Cry1Ac }\end{array}$ & $\begin{array}{c}50 \\
>10.000\end{array}$ & $\begin{array}{c}\text { GOULD et al., } \\
1995\end{array}$ \\
\hline & $\begin{array}{l}\text { Carolina do } \\
\text { Norte }\end{array}$ & $\begin{array}{l}\text { Cry1Ac } \\
\text { (T) }\end{array}$ & $\mathrm{KCB}$ & $\begin{array}{l}- \\
- \\
-\end{array}$ & $\begin{array}{l}\text { Cry } 1 \mathrm{Ab} \\
\text { Cry } 2 \mathrm{Aa} \\
\text { Cry1Ac }\end{array}$ & $\begin{array}{c}2300 \\
25 \\
400\end{array}$ & $\begin{array}{l}\text { FORCADA et } \\
\text { al., } 1999\end{array}$ \\
\hline $\begin{array}{c}\text { Helicoverpa } \\
\text { zea } \\
\text { (Noctuidae) }\end{array}$ & $\begin{array}{l}\text { Mississippi } \\
\text { e Texas }\end{array}$ & $\begin{array}{l}\text { Cry1Ac } \\
\text { (PT) }\end{array}$ & FZ & 7 & Cry1Ac & 119 & $\begin{array}{c}\text { LUTTRELL; } \\
\text { WAN; } \\
\text { KNIGHTEN, } \\
1999\end{array}$ \\
\hline \multirow{2}{*}{$\begin{array}{c}\text { Helicoverpa } \\
\text { armigera } \\
\text { (Noctuidae) }\end{array}$} & $\begin{array}{l}\text { Vários } \\
\text { locais da } \\
\text { India }\end{array}$ & $\begin{array}{l}\text { Cry1Ac } \\
\text { (CI) }\end{array}$ & - & 10 & Cry1Ac & 76 & $\begin{array}{c}\text { KRANTHI; } \\
\text { KRANTHI; } \\
\text { BANERJEE, } \\
2000\end{array}$ \\
\hline & $\begin{array}{l}\text { Vários } \\
\text { locais da } \\
\text { Austrália }\end{array}$ & $\begin{array}{l}\text { Cry1Ac } \\
\text { (PE) }\end{array}$ & $\mathrm{BX}$ & 21 & Cry1Ac & 321 & $\begin{array}{l}\text { AKHURST et } \\
\text { al., } 2003\end{array}$ \\
\hline \multirow{2}{*}{$\begin{array}{c}\text { Pectinophora } \\
\text { gossypiella } \\
\text { (Gelechiidae) }\end{array}$} & $\begin{array}{l}\text { Vários } \\
\text { locais dos } \\
\text { EUA }\end{array}$ & $\begin{array}{c}\text { Cry1Ac } \\
\text { (algodão } \\
B t / \mathrm{MR} \text { ) }\end{array}$ & $\begin{array}{l}\text { APHIS } \\
98 \mathrm{R}\end{array}$ & - & Cry1Ac & $>100$ & $\begin{array}{l}\text { LIU et al., } \\
2001\end{array}$ \\
\hline & Arizona & $\begin{array}{l}\text { Cry1Ac } \\
(\mathrm{MR})\end{array}$ & AZP-R & 28 & Cry1Ac & 3100 & $\begin{array}{l}\text { TABASHNIK } \\
\text { et al., } 2002\end{array}$ \\
\hline $\begin{array}{c}\text { Diatraea } \\
\text { saccharalis } \\
\text { (Crambidae) }\end{array}$ & Lousiana & $\begin{array}{l}\text { Cry1Ab } \\
\text { (MVT) }\end{array}$ & $\begin{array}{l}\text { Isolinha } \\
52\end{array}$ & - & Cry1Ab & $\begin{array}{c}\text { Larva se } \\
\text { desenvolve } \\
\text { em milho } \\
B t\end{array}$ & $\begin{array}{c}\text { HUANG; } \\
\text { LEONARD; } \\
\text { ANDOW, } \\
2007\end{array}$ \\
\hline $\begin{array}{c}\text { Ostrinia } \\
\text { nubilalis } \\
\text { (Crambidae) }\end{array}$ & $\begin{array}{l}\text { Vários } \\
\text { locais do } \\
\text { Corn Belt } \\
\text { (EUA) }\end{array}$ & $\begin{array}{l}\text { Cry1F } \\
(\mathrm{T})\end{array}$ & $\begin{array}{l}\text { Cry1F } \\
\text { Selected }\end{array}$ & $\begin{array}{c}35 \\
-\end{array}$ & $\begin{array}{l}\text { Cry1F } \\
\text { Cry1Ac }\end{array}$ & $\begin{array}{c}>3000 \\
7\end{array}$ & $\begin{array}{l}\text { PEREIRA et } \\
\text { al., } 2008\end{array}$ \\
\hline $\begin{array}{l}\text { Anticarsia } \\
\text { gemmatalis } \\
\text { (Noctuidae) }\end{array}$ & Brasil & $\begin{array}{l}\text { Cry1Ac } \\
\left(\text { Dipel }^{\circledR}\right)\end{array}$ & HD-1 & 144 & Cry1Ac & 86 & $\begin{array}{c}\text { SOSA- } \\
\text { GÓMEZ; } \\
\text { MIRANDA, } \\
2011\end{array}$ \\
\hline
\end{tabular}

Quadro 2.2 - Linhagens de insetos selecionadas em laboratório com proteínas inseticidas de Bt.

\footnotetext{
${ }^{(1)}$ Forma de seleção: microencapsulado recombinante expressando genes cry (MR); protoxina (PT); toxina ativa (T); preparação de esporos (PE); corpos de inclusão de células de Escherichia coli expressando o gene cry (CI); material vegetal transformado expressando o gene cry (MVT).

${ }^{(2)}$ GS: gerações de seleção.

${ }^{(3)} \mathrm{RR}=\mathrm{Razão}$ de Resistência $\left(\mathrm{CL}_{50}\right.$ da linhagem resistente/CL ${ }_{50}$ da linhagem suscetível).
}

A evolução da resistência em populações de $B$. fusca ao milho que expressa $\mathrm{Cy} 1 \mathrm{Ab}$ na África do Sul ocorreu em menos de 10 anos de uso da tecnologia. A evolução da resistência foi confirmada após relatos de danos de B. fusca ao milho Cry1Ab cultivado em sistema 
irrigado, esse sistema de cultivo pode ter contribuído para aumentar a pressão de seleção e favorecido à evolução da resistência, uma vez que as mariposas têm preferência por ambientes de alta umidade. A progênie de algumas populações da praga coletada em sistema de cultivo irrigado sobreviveu em vários híbridos de milho Cry1 Ab durante todo o período larval, enquanto que, a progênie de populações da praga de áreas de milho em sequeiro morreu antes do $8^{\circ}$ dia da infestação das plantas (VAN RENSBURG, 2007).

A evidência da evolução da resistência de $H$. zea à proteína Cry1Ac foi verificada a partir de dados de monitoramento da suscetibilidade, os quais revelaram que a frequência dos alelos de resistência aumentou substancialmente para algumas populações do inseto nos EUA. Embora, testes de sobrevivência de lagartas em plantas de algodão $B t$ não tenham sido realizados, as evidências disponíveis sugerem que a sobrevivência de $H$. zea em algodão $B t$ no campo é maior para populações resistentes do que para populações suscetíveis. O caso excepcional de evolução de resistência de $H$. zea ao algodão $B t$ é consistente com a teoria que envolve a estratégia de alta dose + refúgio, pois a resistência não é recessiva. Em outras palavras, a concentração de Cry1Ac em algodão $B t$ não é alta o suficiente para matar os descendentes (heterozigotos), demonstrando que o evento não atende os requisitos de alta dose (TABASHNIK et al., 2008).

A evolução da resistência de $S$. frugiperda a Cry1F ocorreu apenas quatro anos após a liberação comercial do milho $B t$, tornando esse, até o momento, o caso mais rápido de evolução da resistência a campo para uma cultura Bt. Em bioensaios com incorporação da proteína Cry1F em dieta artificial, na maior concentração testada (10 $\mu \mathrm{g}$ Cry1F/cm² dieta) não houve mortalidade significativa das lagartas neonatas. Em contraste, populações suscetíveis de $S$. frugiperda apresentaram $\mathrm{CL}_{50}=0,06 \mu \mathrm{g}$ Cry $1 \mathrm{~F} / \mathrm{cm}^{2}$ de dieta, enquanto que a $\mathrm{CL}_{50}$ das populações resistentes foi maior do que $10 \mu \mathrm{g}$ Cry $1 \mathrm{~F} / \mathrm{cm}^{2}$ de dieta, o que indica que a razão de resistência foi > 100 vezes (MATTEN et al., 2007). A possível causa da evolução da resistência em período tão curto se deve ao fato da expressão em baixa dose da proteína Cry1F, a geografia da ilha (isolamento das populações) e elevada pressão populacional da praga (STORER et al., 2010).

O caso de evolução da resistência de $P$. gossypiella ao algodão que expressa a proteína Cry1Ac foi verificada após $\approx 10$ anos de cultivo na Índia. Duas populações de $P$. gossypiella coletadas na Província de Amreli demonstraram sobrevivência em bioensaios com a proteína Cry1Ac incorporada em dieta artificial. Ambas as populações apresentaram $\mathrm{CL}_{50}, \approx 44$ vezes superior as populações suscetíveis. Entretanto essa população não demonstrou resistência 
cruzada ao algodão piramidado que expressa às proteínas Cry1Ac/Cry2Ab2 (DUHRUA; GUJAR, 2011).

Recentemente, foi reportado o primeiro caso de evolução da resistência de um coleóptero à proteína inseticida de $B t, D$. virgifera virgifera à proteína Cry3Bb1 expressa em milho Bt. As evidências da evolução da resistência ocorreram após danos significativos da praga ao milho $B t$ cultivado por três anos consecutivos em mesma área de produção nos EUA. Houve maior sobrevivência da praga nesses campos de produção, demonstrando que houve seleção de insetos que podem sobreviver em milho Cry3Bb1. Entretanto, as populações que apresentaram maior taxa de sobrevivência em milho Cry3Bb1 não apresentaram sobrevivência diferencial em milho que expressa as proteínas Cry34/35Ab1, sugerindo uma ausência de resistência cruzada (GASSMANN et al., 2011).

Para a maioria dos casos de evolução da resistência, os insetos apresentaram mutações em genes que codificam proteínas envolvidas em qualquer uma das etapas do modo de ação (HECKEL et al., 2007). Nesse contexto, vários mecanismos têm sido observados em laboratório selecionado linhagens de insetos, como: alteração nos receptores do intestino médio (FERRÉ; VAN RIE, 2002), alteração na ativação da protoxina (FORCADA et al., 1996; OPPERT et al., 1997; LI et al., 2004; KARUMBAIAH et al, 2007), degradação da proteína inseticida (FORCADA et al., 1996), maior eficiência na reposição (ou substituição) das células danificadas do intestino médio (FORCADA et al, 1999), o "sequestro" de esterases (GUNNING et al., 2005) e a elevada imunidade (MA et al., 2005). Em contraste com a variedade de mecanismos de resistência em linhagens de insetos selecionadas em laboratório, apenas um mecanismo importante, a alteração do sítio de ligação, tem sido detectada em insetos que evoluíram para resistência a campo ou casa de vegetação (FERRÉ; VAN RIE, 2002; WANG et al., 2007; TABASHNIK et al., 2011).

Para os casos de insetos que apresentaram evolução da resistência, tem sido constatado que os indivíduos resistentes apresentam um custo adaptativo, ou seja, os resistentes são menos aptos que os suscetíveis na ausência da pressão de seleção. Este menor valor adaptativo dos indivíduos resistentes normalmente está associado a uma menor viabilidade total, menor fecundidade, maior tempo de desenvolvimento, menor competitividade para o acasalamento, maior suscetibilidade aos inimigos naturais, entre outros (GEORGHIOU, 1972; ROUSH; MACKENZIE, 1987; GASSMANN; CARRIÈRE; TABASHNIK, 2009). O uso de informações sobre o custo adaptativo dos indivíduos resistentes tem sido de extrema importância para o direcionamento e refinamento das estratégias de MRI. 
Diante do grande potencial de uso de plantas $B t$ para controle de insetos-praga no Brasil, existe a necessidade de elaboração de programas de MRI para garantir a sustentabilidade dessa tecnologia para o Manejo Integrado de Pragas (MIP). Ainda existe a necessidade de que as estratégias de MRI sejam efetivamente implementadas, bem como planos de mitigação devem ser planejados para os casos em que haja aumento da frequência do alelo de resistência em populações de pragas-alvo de plantas $B t$.

\subsection{Estratégia de alta dose e refúgio para o MRI a plantas $B t$}

A sustentabilidade das plantas Bt para o MIP é extremamente dependente do estabelecimento de um programa pró-ativo. Evitar ou retardar o processo de estabelecimento de populações resistentes a uma cultura geneticamente modificada é uma etapa crítica para maximizar a durabilidade e, portanto, a sustentabilidade da tecnologia (GOULD; TABASHNIK, 1998). Nesse sentido, MRI é o termo usado para descrever um conjunto de práticas que devem ser adotadas com o objetivo de reduzir o potencial de evolução da resistência nas populações das pragas-alvo de controle. Para plantas $B t$ as estratégias de MRI são preventivas e buscam evitar ou retardar a evolução da resistência antes que haja falhas de controle no campo (DENNEHY, 1987).

Para plantas $B t$ como a soja MON $87701 \times$ MON 89788, e que expressam uma única proteína inseticida, o uso da estratégia de alta dose e áreas de refúgio tem sido preferida para o MRI de populações de insetos-praga-alvo de controle (GOULD, 1994; FIFRA SCIENTIFIC ADVISORY PANEL, 1998). A utilidade da estratégia de alta dose e refúgio para o MRI foi originalmente baseada em projeções de modelos matemáticos que simulavam o crescimento populacional dos insetos em diferentes condições. Entretanto, alguns estudos de laboratório (LIU; TABASHNIK, 1997), ensaios controlados em casa de vegetação (TANG et al., 2001) e ensaios de campo (SHELTON et al., 2000) forneceram apoio experimental para essa estratégia, tornando-a uma das mais importantes estratégias para retardar a evolução da resistência de pragas-alvo de plantas Bt (GOULD; TABASHNIK, 1998).

O conceito de alta dose foi desenvolvido a partir da análise dos níveis de resistência encontrados na literatura da geração F1 em cruzamentos de linhagens de insetos-alvo resistentes e suscetíveis a proteínas de Bt (GOULD, 1994). Operacionalmente, planta de alta dose é aquela que expressa em seus tecidos a proteína inseticida em concentração que é igual ou superior a 25 vezes a concentração letal que correspondente à mortalidade de $99 \%$ da população da praga-alvo (FIFRA SCIENTIFIC ADVISORY PANEL, 1998; CAPRIO; 
SUMMERFORD; SIMS, 2000). Uma baixa dose é qualquer quantidade que não atenda a definição de alta dose (TABASHNIK, 1994). Por sua vez, o refúgio compreende a área onde a praga não é exposta à pressão de seleção da proteína inseticida presente no campo $B t$, na qual pode sobreviver, reproduzir e acasalar-se com os indivíduos sobrevivente no campo Bt.

Desse modo, para que a soja MON 87701 × MON 89788 seja de alta dose à expressão in planta da proteína Cry1Ac deve ocorrer em um nível suficientemente alto para acarretar a mortalidade de todos os insetos-alvo homozigotos suscetíveis (SS), e também da maioria dos insetos heterozigotos (SR) que carregam o alelo de resistência presentes na população da praga (ROUSH; SHELTON, 1997). Nessa situação somente os insetos raros homozigotos resistentes (RR) são capazes de sobreviver à exposição à planta Bt. Nesse cenário, as áreas de refúgio (soja não-Bt) serão responsáveis pelo fornecimento de indivíduos suscetíveis para minimizar o acasalamento não-aleatório entre os raros indivíduos homozigotos resistentes que poderiam sobreviver na área com soja MON $87701 \times$ MON 89788 e, ao mesmo tempo, garante que a maioria da progênie seja formada por indivíduos de genótipo heterozigoto. Por sua vez, esses indivíduos heterozigotos serão fenotipicamente suscetíveis, caso a soja MON $87701 \times$ MON 89788 expressar a proteína Cry1Ac em alta dose. A alta expressão da proteína inseticida torna ineficaz qualquer mecanismo que confere ao inseto níveis de resistência baixos ou moderados e assume-se que nessa condição a maioria dos heterozigotos serão mortos (resistência recessiva) (Figura 2.1). A mortalidade dos indivíduos heterozigotos é um dos pontos fundamentais para o MRI, pois esses, no início do processo de evolução da resistência são os principais carreadores dos alelos da resistência (GOULD, 1998).

A determinação da dose da proteína inseticida expressa em soja MON $87701 \times$ MON 89788 é um importante fator para avaliação do risco de resistência. No entanto, no contexto de MRI a dose é uma propriedade de ambas, planta $B t$ e praga-alvo, e não é apenas baseada na concentração de proteína inseticida na planta $B t$. Uma forma direta de se avaliar se uma planta $B t$ é um evento de alta dose é obter os insetos-alvo resistentes à proteína inseticida, os quais poderiam ser cruzados com os insetos homozigotos suscetíveis para obtenção dos heterozigotos que poderiam ser testados diretamente sobre a planta $B t$. Nessa situação se a sobrevivência dos heterozigotos for $<5 \%$ o evento atende ao conceito de alta dose (GOULD, 1998; GHIMIRE et al., 2011). No entanto, na maioria dos casos antes da liberação comercial de uma planta $B t$, não terão sido detectados insetos resistentes, pois a frequência dos alelos que conferem resistência é inicialmente baixa. 
A (resistência recessiva)
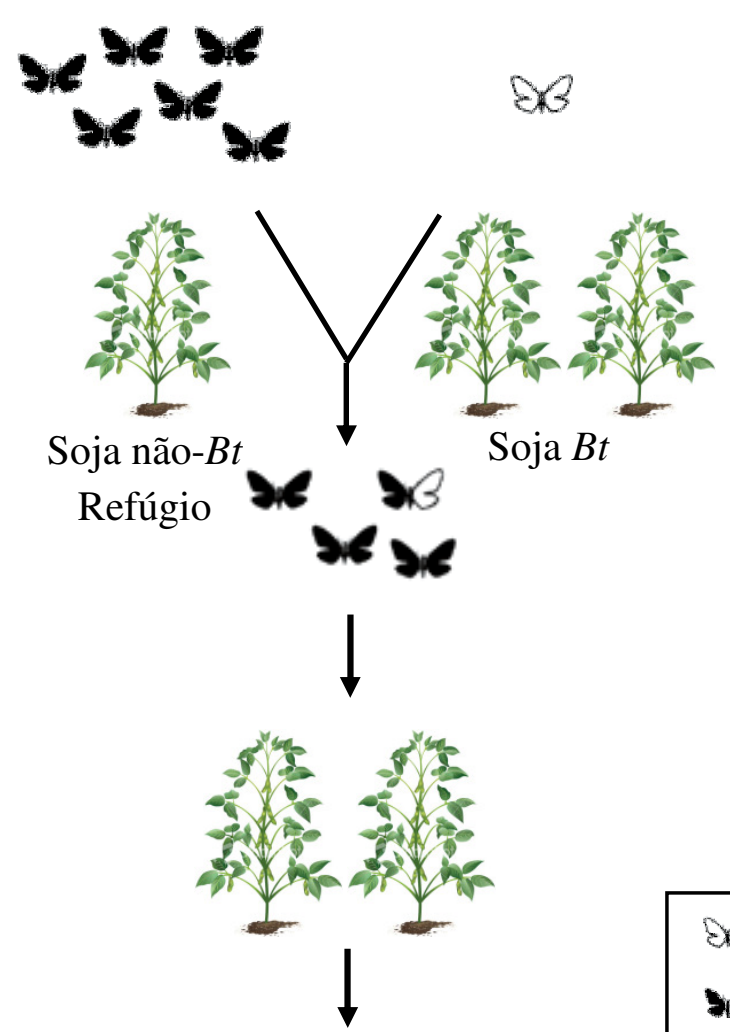

Sem sobreviventes

83
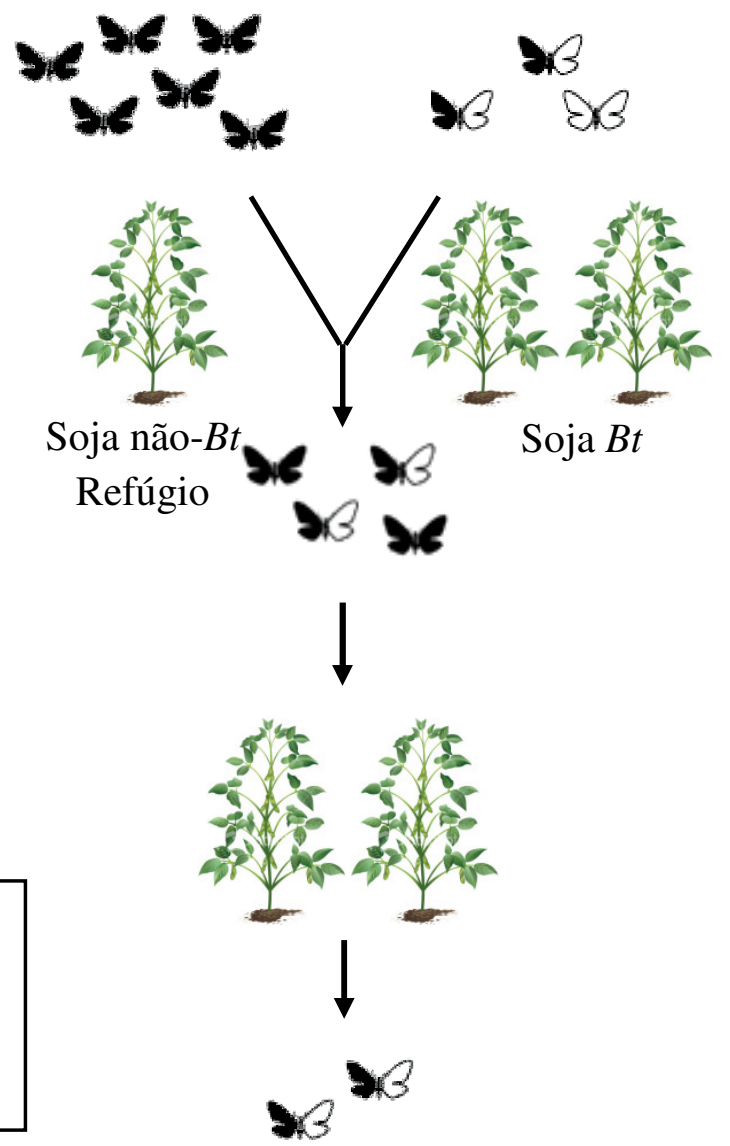

Figura 2.1 - Representação esquemática da estratégia de alta dose e refúgio para o MRI a soja MON $87701 \times$ MON 89788 sob dois pressupostos: resistência recessiva (A) ou dominante (B). Mariposas representam os sobreviventes adultos de diferentes genótipos: RR, homozigoto resistente; RS, heterozigoto; SS, homozigoto suscetível

Para a avaliação da expressão da proteína inseticida em alta dose, a Agência de Proteção Ambiental Americana (US-EPA) indica cinco métodos distintos. Estes métodos foram descritos por Caprio, Summerford e Sims (2000) e são apresentados a seguir:

\section{Bioensaios com diluições do tecido liofilizado da planta $B t$ em dieta artificial (tecido} liofilizado da isolinha não-Bt como tratamento controle).

Esse método é indicado em situações que a expressão da proteína inseticida na planta $B t$ e a suscetibilidade da praga-alvo forem altas. Quando a suscetibilidade da praga-alvo for baixa é difícil incorporar a quantidade requerida de tecido liofilizado na dieta artificial. Uma quantidade excessivamente elevada de tecido liofilizado em dieta artificial pode ocasionar mortalidade e enfezamento larval em níveis inaceitáveis, devido a efeitos de compostos secundários da planta. Outro problema potencial dos bioensaios com tecido liofilizado 
incorporado à dieta artificial é que a mortalidade e o enfezamento podem ser minimizados devido à umidade relativa ser de $\approx 100 \%$ no interior dos recipientes e/ou placas de bioensaio, reduzindo a mortalidade larval devido à dessecação e afetando a verificação da adequabilidade da planta $B t$ ao conceito de alta dose.

2. Avaliar cultivares com expressão da proteína inseticida em nível 25 vezes menor do que no evento comercial.

Este método é complexo, pois a expressão da proteína inseticida no evento comercial e no evento com baixa expressão é dinâmico, variando com a estrutura da planta e estádio de desenvolvimento. Nessa situação, para avaliar se um evento é de alta dose é utilizar o tecido liofilizado de folhas de plantas jovens, desde que, o evento comercial e o evento com baixa expressão sejam isolinhas ou linhagens com constituição genética semelhante.

3. Avaliar um grande número de cultivares comerciais a campo para determinar uma larva (1 em 10.000) derivada de oviposição natural que sobreviveu à proteína inseticida.

Esse método é dificultado por alguns aspectos como a falta de informações sobre o local de oviposição na planta e a dificuldade de se estimar o tamanho inicial da população, neste caso do número de ovos ovipositados. Em uma safra com população extremamente elevada da praga-alvo, um grande número de ovos podem ser ovipositados nas variedades comerciais resultando em número relativamente elevado de lagartas sobreviventes, apesar da não haver mudança na suscetibilidade da população à proteína inseticida. Portanto, isso pode gerar uma falsa inferência, não permitindo verificar com clareza se a planta $B t$ é de alta dose.

\section{Avaliar um grande número de cultivares comerciais à campo para determinar aquela}

larva (1 em 10.000) derivada de infestação artificialmente que sobreviveu à proteína inseticida.

Esse método pode ser útil se uma amostra suficientemente diversificada de larvas for obtida. Isso significa que no mínimo um grande número de fêmeas e uma amostra da progênie de cada fêmea devem ser testados sobre a planta $B t$.

5. Bioensaios com larvas de ínstar avançado com uma tolerância à proteína inseticida 25 vezes maior daquela de larvas neonatas.

Um problema potencial desse tipo de bioensaio é que é pouco provável que um ínstar inicial de uma praga-alvo de uma planta $B t$ seja 25 vezes menos suscetível à proteína inseticida. Além disso, ainda não está claro que a tolerância a proteína inseticida depende ou independe do peso larval, uma vez que grande quantidade de insetos suscetíveis não apresenta redução na tolerância a proteínas de $B t$ se o incremento de peso larval for considerado. 
De acordo com Gould (1998), para o sucesso da estratégia da alta dose + áreas de refúgio, para o MRI de insetos-alvo de plantas $B t$ existe a necessidade da satisfação de uma série de premissas envolvendo questões operacionais da planta $B t$ e aspectos bioecológicos das pragas-alvo de controle, tais como: (i) a planta $B t$ devem produzir a proteína inseticida em dose igual ou superior a 25 vezes o necessário para matar 99\% dos insetos suscetíveis; (ii) a frequência inicial dos genes de resistência deve ser baixa; (iii) o padrão de herança da resistência deve ser recessivo; (iv) deve haver sincronia de emergência dos insetos entre a área $B t$ e áreas de refúgio (não- $B t$ ) e (v) o refúgio deve estar localizado de modo a assegurar o acasalamento aleatório entre os possíveis indivíduos homozigotos resistentes na área $B t$ e suscetíveis das áreas de refúgio.

Uma importante premissa da estratégia de alta dose é a ocorrência de uma baixa frequência inicial de alelos de resistência. Freqüência inicial é a frequência do alelo responsável pela expressão da resistência à proteína $B t$ numa população não exposta anteriormente à proteína inseticida. Resultados de modelos matemáticos demonstram que para uma praga qualquer com frequência inicial do alelo de resistência de 0,001 a resistência pode ser adiada por mais de 20 anos com refúgios de 5\%, se a resistência for totalmente recessiva $(\mathrm{h}=0)^{1}$ e com refúgios maiores de $50 \%$ se a resistência é parcialmente dominante $(\mathrm{h}=0,4)$ (TABASHNIK; RENSBURG; CARRIÈRE, 2009). A frequência do alelo de resistência deve ser baixa, de modo que a frequência de homozigotos resistentes, seja baixa o suficiente para tornar extremamente improvável que dois indivíduos resistentes possam se encontrar, acasalarem e gerar descendentes.

Para a estratégia de alta dose e refúgio, outra característica a ser considerada no MRI é a recessividade do alelo da resistência. Neste contexto, a expressão da proteína inseticida deve ser alta o suficiente para que a resistência seja recessiva, ou seja, fazendo com que os indivíduos heterozigotos tenham fenótipo semelhante aos homozigotos suscetíveis não sobrevivendo àquela dose (GOULD, 1998). Um alelo que confere resistência a uma determinada proteína inseticida pode ser recessivo para alta dose e dominante para uma dose moderada ou baixa (Figura 2.1). Por essa razão, pode-se dizer que as plantas $B t$ com expressão em alta dose da proteína inseticida permitem que a resistência seja funcionalmente recessiva (CAPRIO; SUMMERFORD; SIMS, 2000).

Atendidas as premissas relacionadas à planta $B t$ e à praga-alvo, compete às áreas de refúgio ser suficientemente atrativas para a oviposição, e deste modo servirem como um

\footnotetext{
${ }^{1} \mathrm{~h}=$ Herdabilidade do alelo $(\mathrm{R})$ responsável pela resistência de insetos.
} 
"reservatório" de insetos suscetíveis. Para que a estratégia seja eficiente, os insetos da área de refúgio (soja não-Bt) devem imigrar para toda a área cultivada com soja MON $87701 \times$ MON 89788. Logo, espera-se que os raros indivíduos homozigotos resistentes acasalem com indivíduos homozigotos suscetíveis advindos das áreas de refúgio. Portanto, a geração subsequente será composta em sua maioria por indivíduos heterozigotos que serão suscetíveis devido à expressão da proteína $B t$ em alta dose.

Nesse cenário, o MRI à soja MON $87701 \times$ MON 89788 deve contemplar diversos componentes como o monitoramento da suscetibilidade das populações das pragas-alvo submetidas ao fator de seleção, instalação de áreas de refúgio e ações educacionais para incentivar os agricultores a implementar as áreas de refúgio em suas áreas de produção.

\section{Referências}

AKHURST, R.J.; JAMES, W.; BIRD, L.J.; BEARD, C. Resistance to the Cry1Ac $\delta$ endotoxin of Bacillus thuringiensis in the cotton bollworm, Helicoverpa armigera (Lepidoptera: Noctuidae). Journal of Economic Entomology, Lanham, v. 96, n. 4, p. 12901299, 2003.

\section{ALBERNAZ, K.C. Suscetibilidade à proteína Cry1Ac e estrutura genética em} populações de Heliothis virescens (Fabricius) (Lepidoptera: Noctuidae) no Brasil. 2011. 85 p. Dissertação (Mestrado em Entomologia) - Escola Superior de Agricultura "Luiz de Queiroz", Universidade de São Paulo, Piracicaba, 2011.

ALFORD, A.R.; HAMMOND JUNIOR, A.M. Plusiinae (Lepidoptera: Noctuidae) populations in Lousiana soybeans ecossystems as determined with looplure-baited traps. Journal of Economic Entomology, Lanham, v. 75, n. 4, p. 647-650, 1982.

ANDOW, D.A. The risk of resistance evolution in insects to transgenic insecticidal crops. Collection of Biosafety Reviews, Trieste, v. 4, p. 142-199, 2008.

BAVARESCO, A.; GARCIA, M.S.; GRÜTZMACHER, A.D.; RINGENBERG, R.; FORESTI, J. Adequação de uma dieta artificial para a criação de Spodoptera cosmioides (Walk.) (Lepidoptera: Noctuidae) em laboratório. Neotropical Entomology, Londrina, v. 33, n. 2, p. 155-161, 2004.

BOTTON, M.; CARBONARI, J.J.; GARCIA, M.S.; MARTINS, J.F. Preferência alimentar de Spodoptera frugiperda (J.E. Smith, 1797) (Lepidoptera: Noctuidae) em arroz e capim-arroz. Anais da Sociedade Entomológica do Brasil, Jaboticabal, v. 27, p. 207-212, 1998.

BRAGA, D.P.V.; OLIVEIRA, W.S.; MARTINELLI, S.; SOSA-GÓMEZ, D.R.; OLIVEIRA, M.F. Estudo de caso da Soja MON $87701 \times$ MON 89788 (Bt/RR2). In: BORÉM, A.; ALMEIDA, G. (Ed.). Plantas geneticamente modificadas: desafios e oportunidades para regiões tropicais. Visconde do Rio Branco: Suprema, 2011. cap. 17 p. 347-390. 
BRAVO, A.; GILL, S.S.; SOBERÓN, M. Bacillus thuringiensis mechanisms and use. In: GILBERT L.I.; IATROU K.; GILL, S.S. (Ed.). Comprehensive Molecular Insect Science. Amsterdam: Elsevier BV, 2005. p. 175-206.

BUSATO, G.R.; GRUTZMACHER, A.D.; OLIVEIRA, A.C.; VIEIRA, E.A.; ZIMMER, P.D.; KOPP, M.M.; BANDEIRA, J.M.; MAGALHÃES, T.R. Análise da estrutura e diversidade molecular de populações de Spodoptera frugiperda (J.E. Smith) (Lepidoptera: Noctuidae) associadas às culturas do milho e arroz no Rio Grande do Sul. Neotropical Entomology, Londrina, v. 33, n. 6, p. 709-716, 2004.

CAPINERA, J.L. Tobacco Budworm, Heliothis virescens (Fabricius) (Insecta:

Lepidoptera: Noctuidae). Gainesville: Univers, 2001. 7 p.(EENY-219). Disponível em: $<$ http://www.edis.ifas.ufl.edu.>. Acesso em: 23 mar. 2010.

CAPRIO, M.A.; TABASHNIK, B.E. Gene flow accelerates local adaptation among finite populations: simulating the evolution of insecticide resistance. Journal of Economic Entomology, Lanham, v. 85, n. 3, p. 611-620, 1992.

CAPRIO, M.A.; SUMMERFORD, D.V.; SIMS, S.R. Evaluating transgenic plants for suitability in pest and resistance management programs. In: LACEY, L.A.; KAYA, H.K. (Ed.). Field manual of techniques in invertebrate pathology. Dordrecht: Kluwer Academic, 2000.cap. 8 p. $805-828$.

CORTEZ, M.G.R.; WAQUIL, J.M. Influência de cultivar e nível d infestação de Spodoptera frugiperda (J.E. Smith) (Lepidoptera: Noctuidae) no rendimento sorgo. Anais da Sociedade Entomológica Brasileira, Jaboticabal, v. 26, n. 2, p. 407-410, 1997.

CROCOMO, W.B.; PARRA, J.R.P. Desenvolvimento de Spodoptera frugiperda (J.E. Smith, 1797) (Lepidoptera: Noctuidae) sobre milho, trigo e sorgo. Revista Brasileira de Entomologia, Curitiba, v. 29, n. 2, p. 363-368, 1985.

DEGRANDE, P.E. Guia prático de controle de pragas do algodoeiro. Dourados: UFM, 1998. 60p.

DENNEHY, T.J. Decision-making for managing pest resistance to pesticides. In: FORD, M.G.; HOLLOMAN, D.W.; KHANBAY, B.P.S.; SAWICKI, R.M. (Ed.). Combating resistance to xenobiotics: biological and chemical approaches. Chichester: Ellis Horwood, 1987. cap. 7 p. $118-126$.

DOMINGUES, F.A. Variabilidade genética de Heliothis virescens (Lepidoptera Noctuidae) no Brasil inferida por marcadores microssatálites. 2011. 85p.Dissertação (Mestrado em Entomologia) - Escola Superior de Agricultura "Luiz de Queiroz", Universidade de São Paulo, Piracicaba, 2011.

DUHRUA, S.; GUJAR, G.T. Field-evolved resistance to $B t$ toxin Cry1Ac in the pink bollworm, Pectinophora gossypiella (Saunders) (Lepidoptera: Gelechiidae), from India. Pest Management Science, Sussex, v. 67, n. 8, p. 898-803, 2011.

ELLISOR, L.O.; GRAHAM, L.T. A recent pest of alfafa. Journal of Economic Entomology, Baltimore, v. 30, n. 2, p. 278-280, 1937. 
FERREIRA, B.S.C.; PANIZZI, A.R. Distribuição de ovos e lagartas de Anticarsia gemmatalis Hübner em plantas de soja. Anais da Sociedade Entomológica do Brasil, Jaboticabal, v. 7, n. 1, p. 54-59, 1978.

FERRÉ, J.; VAN RIE, J. Biochemistry and genetics of insect resistance to Bacillus thuringiensis. Annual Review of Entomology, Stanford, v. 47, p. 501-543, 2002.

FIFRA SCIENTIFIC ADVISORY PANEL. Transmittal of the final report of the FIFRA Scientific Advisory Panel subpanel on Bacillus thuringiensis $(B t)$ plant-pesticides and resistance management. 9-10 February 1998. Docket $N^{0}$. OPPTS-00231:59, 1998.

Disponível em: <http://www.mindfully.org/GE/FIFRA-SAP-Bt.htm>. Acesso em: 15 mar. 2008.

FISCHHOFF, D.A. Insect tolerant transgenic tomato plants. Nature Biotechnology, London, v. 5, n. 8. p. 807-813, 1987.

FITT, G.P. The ecology of Heliothis species in relation to agroecosystems. Annual Review of Entomology, Stanford, v. 34, p. 17-52, 1989.

FORCADA, C.; ALCÁCER, E.; GARCERÁ, M.D.; MARTÍNEZ, R. Differences in the midgut proteolytic activity of two Heliothis virescens strains, one susceptible and one resistant to Bacillus thuringiensis toxins. Archives of Insect Biochemistry and Physiology, New York, v. 31, n. 2, p. 257-272, 1996.

FORCADA, C.; ALCÁCER, E.; GARCERÁ, M.D.; TATO, A.; MARTÍNEZ, R. Resistance to Bacillus thuringiensis Cry1Ac toxin in three strains of Heliothis virescens: Proteolytic and SEM study of the larval midgut. Archives of Insect Biochemistry and Physiology, New York, v. 42, n. 1, p. 51-63, 1999.

GAMUNDI, J.C. Biologia comparada e nutrição quantitativa de Anticarsia gemmatalis Hübner, 1818 (Lepidoptera: Noctuidae) em folhas e vagens de soja. 137p.Dissertação (Mestrado em Entomologia) - Escola Superior de Agricultura "Luiz de Queiroz", Universidade de São Paulo, Piracicaba, 1988.

GASSMANN, A.J.; CARRIÈRE, Y.; TABASHNIK, B.E. Fitness costs of insect resistance to Bacillus thuringiensis. Annual Review of Entomology, Stanford, v. 54, p. 147-163, 2009.

GASSMANN, A.J.; PETZOLD-MAXWELL, J.L.; KEWESHAN, R.S.; DUNBAR, M.W. Field-evolved resistance to $B t$ maize by Western Corn Rootworm. Plos One, Berkeley, v. 6, n. 7, e22629, 2011.

GAZZONI, D.L.; OLIVEIRA, E.B.; CORSO, I.C.; CORRÊA-FERREIRA, B.S.; VILLAS BOAS, G.L.; MOSCARDI, F.; PANIZZI, A.R. Manejo de pragas da soja. Londrina: Embrapa Centro Nacional de Pesquisa de Soja, 1981, 44 p. (Embrapa CNPSo, Circular Técnica,5).

GEORGHIOU, G.P. The evolution of resistance to pesticides. Annual Review of Ecological Systematics, Stanford, v. 3, p. 133-168, 1972. 
GEORGHIOU, G.P.; TAYLOR, C.E. Factors influencing the evolution of resistance. In: NATIONAL ACADEMIC OF SCIENCES. Pesticides resistance: strategies and tactics for management. Washington: National Academic Press, 1986. p. 157-169.

GHIMIRE, M.N.; HUANG, F.; LEONARD, R.; HEAD, G.P.; YANG, Y. Susceptibility of Cry1 Ab susceptible and resistant sugarcane borer to transgenic corn plants containing single or pyramided Bacillus thuringiensis genes. Crop Protection, Guildford, v. 30, n. 1, p. 74-81, 2011.

GILL, S.S.; COWLES, E.A.; PIETRATONIO, P.V. The mode of action of Bacillus thuringiensis endotoxins. Annual Review of Entomology, Stanford, v. 37, p. 615-636, 1992.

GOULD, F.; MARTÍNEZ-RAMÍREZ, A.; ANDERSON, A.; FERRÉ, J.; SILVA, F.J.; MOAR, W.J. Broad spectrum resistance to Bacillus thuringiensis toxins in Heliothis virescens. Proceedings of the National Academy of Sciences of the United States of America, Washington, v. 89, n. 17, p. 7986-7990, 1992.

GOULD F. Potential and problems with high-dose strategies for pesticidal engineered crops. Biocontrol Science and Technology, Oxford, v. 4, n. 4, p. 451-461, 1994.

GOULD, F.; ANDERSON, A.; REYNOLDS, A.L.; BUNGARNER, L.; MOAR, W. Selection and genetic analysis of a Heliothis virescens (Lepidoptera: Noctuidae) strain with high levels of resistance to Bacillus thuringiensis toxins. Journal of Economic Entomology, Lanham, v. 88 , n. 6, p. 1545-1559, 1995.

GOULD, F. Sustainability of transgenic insecticidal cultivars: integrating pest genetics and ecology. Annual Review of Entomology, Standfort, v. 43, p. 701-26, 1998.

GOULD, F.; TABASHNIK, B.E. Bt-cotton resistance management. In: RISSLER, J. (Ed.). Now or Never: Serious new plans to save natural pest control. Cambridge: Union of Concerned Scientists of USA, 1998. Disponível em: < http://www.ucsusa.org/publications/now.ch4.pdf>. Acesso em: 15 mar. 2008.

GUNNING, R.V.; DANG, H.T.; KEMP, F.C.; NICHOLSON, I.C.; MOORES, G.D. New resistance mechanism in Helicoverpa armigera threatens transgenic crops expressing Bacillus thuringiensis Cry1 Ac toxin. Applied and Environmental Microbiology, Washington, v. 71, n. 5, p. 2558-2563, 2005.

HABIB, M.E.M.; PALEARI, M.L.; AMARAL, M.E.C. Effect of three larval diets on the development of the armyworm, Spodoptera latifascia Walker, 1856 (Lepidoptera: Noctuidae). Revista Brasileira de Zoologia, Curitiba, v. 1, p. 177-182, 1983.

HECKEL, D.G.; GAHAN, L.J.; BAXTER, S.W.; ZHAO, J.Z.; SHELTON, A.M.; GOULD, F.; TABASHNIK, B.E. The diversity of $B t$ resistance genes in species of Lepidoptera. Journal of Invertebrate Pathology, San Diego, v. 95, n. 3; p. 192-197, 2007.

HERZOG, D.C.; TODD, J.W. Samplig velvetbean caterpillar on soybean. In: KOOGAN, M.; HERZOG, D.C. (Ed.). Sampling methods in soybean entomology. New York: Springer, 1980. p. 107-140. 
HINDS, W.E.; OSTERBERGER, B.A. The soybean caterpillar in Lousiana. Journal of Economic Entomology, Baltimore, v. 24, n. 6, p. 1168-1173, 1931.

HOFFMANN-CAMPO, C.B.; MOSCRADI, F.; CORREAA-FERREIRA, B.; OLIVEIRA, L.J.; SOSA-GÓMEZ, D.; PANIZZI, A.R.; CORSO, I.C.; GAZZONI, D.L.; OLIVEIRA, E.B. Pragas da soja no Brasil e seu manejo integrado. Londrina: Embrapa Centro Nacional de Pesquisa de Soja, 2000. 70p. (Embrapa CNPSo, Circular Técnica, 30).

HOMRICH, M.S.; PASSAGLIA, L.M.P.; PEREIRA, J.F.; BERTAGNOLLI, P.F.; SALVADORI, JR.; NICOLAU, M.; KALTCHUK-SANTOS, E.; ALVES, L.B.; BODANESE-ZANETTINI, M.H. Agronomic performance, chromosomal stability and resistance to velvetbean caterpillar of transgenic soybean expressing crylAc gene. Pesquisa Agropecuária Brasileira, Brasília, v. 43, n. 7, p. 801-807, 2008.

HUANG, F.; LEONARD, B.R; ANDOW, D.A. Sugarcane borer (Lepidoptera: Crambidae) resistance to transgenic Bacillus thuringiensis maize. Journal of Economic Entomology, Lanham, v. 100, n. 1, p. 164-171, 2007.

ISIDRO, R.; DE ALMEIRA, R.P.; PEREIRA, J.O.V. Consumo foliar de Spodoptera frugiperda em amendoim cultivares Tatu e CNPA BR-1. Revista de Oleaginosas e Fibrosas, Campina Grande, v. 1, p. 37-42, 1997.

JACKSON, R.E.; MARCUS, M.A.; GOULD, F.; BRADLEY JUNIOR, J.R.; VAN DUYN, J.W. Cross-resistance responses of CrylAc-selected Heliothis virescens (Lepidoptera: Noctuidae) to the Bacillus thuringiensis protein VIP3A. Journal of Economic Entomology, Lanham, v. 100, n. 1, p. 180-186. 2007.

JANMAAT, A.F.; MYERS, J. Rapid evolution and the cost of resistance to Bacillus thuringiensis in greenhouse populations of cabbage loopers, Trichoplusia ni. Proceedings of the Royal Society of London, Series B, London, v. 270, n. 1530, p. 2263-2270, 2003.

JENSEN, R.L.; NEWSON, L.D.; GIBBENS, J. The Soybean Looper; effects of adult nutrition on oviposition, mating frequency and longevity. Journal of Economic Entomology, Lanham, v. 67, n. 4, p. 467-470, 1974.

JOST, D.J.; PITRE, H.N. Soybean Looper (Lepidoptera: Noctuidae) oviposition on cotton and soybean of different growth stages: Influence of olfactory stimuli. Journal of Economic Entomology, Lanham, v. 95, n. 2, p. 286-293, 2002.

JOUANIN, L.; BONADÉ-BOTTINO, M.; GIRARD, C.; MORROTO, G.; GIBAND, M. Transgenic plants for insect resistance. Plant Science, Shannom, v. 131, n. 1, p. 1-11, 1998.

KARUMBAIAH, L.; OPPERT, B.; JURAT-FUENTES, J.L.; ADANG, M.J. Analysis of midgut proteinases from Bacillus thuringiensis susceptible and resistant Heliothis virescens (Lepidoptera: Noctuidae). Comparative Biochemistry and Physiology B, Oxford, v. 146, n. 1, p. 139-146, 2007.

KHALSA, M.S.; KOGAN, M.; LUCKMANN, W.H. Autographa precationis in relation to soybean: Life history, and food intake and utilization under controlled conditions.

Environmental Entomology, Lanham, v. 8, n. 1, p. 117-122, 1979. 
KOZIEL, M.G.; BELAND, G.L.; BOWMAN, C.; CAROZZI, N.B.; CRENSHAW, R.; CROSSLAND, L.; DAWSON, J; DESAI, N.; HILL, M.; KADWELL, S.; LAUNIS, K; LEWIS, K.; MADDOX, D.; MCPHERSON, K.; MEGHJI, M.R.; MERLIN, E.; RHODES, R.; WARREN, G.W.; WRIGHT, M.; EVOLA, S.V. Field performance of elite transgenic maize plants expressing an insecticidal protein derived from Bacillus thuringiensis. Nature Biotechnology, London, v. 11, n. 2, p. 194-200, 1993.

KRANTHI, K.R.; KRANTHI, S.; ALI, S.; BANERJEE, S.K. Resistance to "Cry1Ac $\delta$ endotoxin of Bacillus thuringiensis" in a laboratory selected strain of Helicoverpa armigera (Hübner). Current Science, Columbus, v. 78, n. 6, p. 1001-1004, 2000.

LABBE, P.; LENORMAND, T.; RAYMOND, E.M. On the world wide spread of an insect resistance gene: a role for local selection. Journal of Evolutionary Biology, Basel, v. 18, n. 6, p. 1471-1484, 2005.

LEPPLA, N.C. Circadian rhytms of locomotion and reproductive behavior in adult velvetbean caterpillar. Annals of the Entomological Society of America, Columbus, v. 69, n. 1, p. 4548, 1976.

LI, H.; OPPERT, B.; HIGGINS, R.A.; HUANG, F.; ZHU, K.Y.; BUSCHMAN, L.L. Comparative analysis of proteinase activities of Bacillus thuringiensis resistant and susceptible Ostrinia nubilalis (Lepidoptera: Crambidae). Insect Biochemistry and Molecular Biology, Oxford, v. 34, n. 8, p. 753-762, 2004.

LIU, Y.B.; TABASHNIK, B.E. Experimental evidence that refuges delay insect adaptation to Bacillus thuringiensis. Proceedings of the Royal Society of London, Series B, London, v. 264, n. 1381, p. 605-610, 1997.

LIU, Y.B.; TABASHNIK, B.E.; MAYER, S.K.; CARRIÉRE, Y.; BARTLETT, A.C. Genetics of pink bollworm resistance to Bacillus thuringiensis toxin Cry1Ac. Journal of Economic Entomology, Lanham, v. 94, n. 1, p. 248-252, 2001.

LUTTRELL R.G.; WAN L.; KNIGHTEN K. Variation in susceptibility of Noctuid (Lepidoptera) larvae attacking cotton and soybean to purified endotoxin proteins and commercial formulations of Bacillus thuringiensis. Journal of Economic Entomology, Lanham, v. 92, n. 1, p. 21-32, 1999.

LYNCH, R.E.; PAIR, S.D.; JOHNSON, R. Fall armyworm fecundity: relationships of egg mass weight to number of eggs. Journal of the Georgia Entomological Society, Athens, v. 18, n. 4 , p. $507-513,1983$.

MA, G.; ROBERTS, H.; SARJAN, M.; FEATHERSTONE, N.; LAHNSTEIN, J.; AKHURST, R.; SCHMIDT, O. Is the mature endotoxin Cry1Ac from Bacillus thuringiensis inactivated by a coagulation reaction in the gut lumen of resistant Helicoverpa armigera larvae? Insect Biochemistry and Molecular Biology, Oxford, v. 35, n. 7, p. 729-739, 2005. 
MACRAE, T.C.; BAUR, M.E.; BOETHEL, D.J.; FITZPATRICK, B.J.; GAO, A.G.; GAMUNDI, J.C.; HARRISON, L.A.; KABUYE, V.T.; MCPHERSON, R.M.; MIKLOS, J.A.; PARADISE, M.S.; TOEDEBUSCH, A.S.; VIEGAS, A. Laboratory and field evaluations of transgenic soybean exhibiting high dose expression of a synthetic Bacillus thuringiensis crylA gene for control of Lepidoptera. Journal of Economic Entomology, Lanham, v. 98, n. 2, p. 577-587, 2005.

MARTINELLI, S.; MONTRAZI, R.B.; ZUCHI, M.I.; SILVA-FILHO, M.C; OMOTO, C. Molecular variability of Spodoptera frugiperda (Lepidoptera: Noctuidae) populations associated to maize and cotton crops in Brazil. Journal of Economic Entomology, Lanham, v. 99, p. 519-526, 2006.

MATTEN, S. Review of Dow AgroSciences (and Pioneer HiBreds). Submission (dated July 12, 2007). Regarding Fall Armyworm resistance to the Cry1F protein expressed in TC1507 Herculex I ${ }^{\circledR}$ Insect Protection Maize in Puerto Rico. MRID\#: 471760-01. 2007.

MCGAUGHEY, W.H. Insect resistance to the biological insecticide Bacillus thuringiensis. Science, Washington, v. 229, n. 4709, p. 193-195, 1985.

MITCHEL, E.R. Life history of Pseudoplusia includens (Walker) (Lepidoptera: Noctuidae). Journal of the Georgia Entomological Society, Tifton, v. 2, n. 2, p. 53-57, 1967.

MORETI, A.C.C.C. Biologia comparada e controle de qualidade de Heliothis virescens (Fabr., 1781) (Lepidoptera:Noctuidae) em dieta natural e artificial. Dissertação (Mestrado em Entomologia) - Escola Superior de Agricultura "Luiz de Queiroz", Universidade de São Paulo, Piracicaba, 1980. 80 p.

MOSCARDI, F.; KASTELIC, J.G. Ocorrência de vírus de poliedrose nuclear e vírus de granulose em populações de Spodoptera frugiperda atacando soja na região de Sertaneja/ PR. In: EMBRAPA. Centro Nacional de Soja. Resultados da pesquisa de soja 1984/85. Londrina, 1985. p.128. (EMBRAPA CNPSo. Documento, 15).

OPPERT, B.; KRAMER, K.J.; BEEMAN, R.W.; JOHNSON, D.; MCGAUGHEY, W.H. Proteinase mediated insect resistance to Bacillus thuringiensis toxins. Journal of Biological Chemistry, Bethesda, v. 272, n. 38, p. 23473-23476, 1997.

PARROTT, W.A.; ALL, J.N.; ADANG, M.J.; BAILEY, M.A.; BOERMA, H.R.; STEWART C.N. Recovery and evaluation of soybean plants transgenic for a Bacillus thuringiensis var. kurstaki insecticidal gene. In Vitro Cellular \& Developmental Biology, Columbia, v. 30P, n. 4, p. 144-149, 1994.

PASHLEY, D.P.; JOHNSON, S.J.; SPARKS, A.N. Genetic population structure of migratory moths: the fall armyworm (Lepidoptera: Noctuidae). Annals of the Entomological Society of America, Columbus, v. 78, n. 6, p. 756-762, 1985.

PASHLEY, D.P.; MARTIN, J.A. Reproductive incompatibility between host strains of the fall armyworm (Lepidoptera: Noctuidae). Annals of Entomological Society of America, Columbus, v. 80, n. 6, p. 731-733, 1987. 
PEREIRA, E.J.G.; LANG, B.A.; STORER, N.P.; SIEGFRIED, B.D. Selection for Cry1F resistance in the European corn borer and cross-resistance to other Cry toxins. Entomologia Experimentalis et Applicata, Dordrecht, v. 126, n. 2, p. 115-121, 2008.

PITRE, H.N.; HOGG, D.B. Development of the fall armyworm on cotton, soybean and corn. Journal of the Georgia Entomological Society, Athens, v. 18, n. 2, p. 182-187, 1983.

POOLE, R.W.; MITTER, C.; HUETTEL, M. A revision and cladistic analysis of the Heliothis virescens species group (Lepidoptera: Noctuidae) with a preliminary morphometric analysis of Heliothis virescens. Minnesota: Mississipi Agricultural \& Forestry Experiment Station, 1993. 185 p. (Technical Bulletin, 185).

ROUSH, R.T.; MCKENZIE, J.A. Ecological genetics of insecticide and acaricide resistance. Annual Review of Entomology, Stanford, v. 32, p. 361-380, 1987.

ROUSH, R.T.; SHELTON, E.A.M. Assessing the odds: The emergence of resistance to Bt transgenic plants. Nature Biotechnology, New York, v. 15, n. 9, p. 816-817, 1997.

SANTOS, K. B. DOS; MENEGUIM, A.M.; NEVES, P.M.O.J. Biologia de Spodoptera eridania (Cramer) (Lepidoptera: Noctuidae) em diferentes hospedeiros. Neotropical Entomology, Vacaria, v. 34, n. 6, p. 903-910, 2005.

SCHNEIDER, J.C. Dispersal of a highly vagile insect in a heterogeneous environment. Ecology, Tempe, v. 80, n. 8, p. 2740-2749, 1999.

SCHNEPF, E.; WHITELEY, H.R. Cloning and expression of the Bacillus thuringiensis crystal protein gene in Escherichia coli. Proceedings of the National Academy of Sciences of the United States of America, Washington, v. 78, n. 5, p. 2893-2897, 1981.

SHELTON, A.M.; TANG, J.D.; ROUSH, R.T.; METZ, T.D.; EARLE, E.D. Field tests on managing resistance to $B t$-engineered plants. Nature Biotechnology, New York, v. 18, n. 3, p. 339-342, 2000.

SILVA, A.G.D’A.; GONÇALVES, C.R.; GALVÃO, D.M.; GONÇALVES , A.J.L.; GOMES, J.; SILVA, M.N. ; SIMONI, L. Lab. In: CENTRAL PATOLOGIA VEGETAL, MA. Quarto catálogo dos insetos que vivem nas plantas do Brasil. Seus parasitos e predadores. (Ed.) Rio de Janeiro :Ministério da Agricultura, 1968. v.1 pt.2, 622 p.

SILVEIRA NETO, S.; BERTI FILHO, E.R.; CARVALHO, P.L. Flutuação populacional de algumas pragas da soja em Assis, SP. O Solo, Piracicaba, v. 65, n. 1, p. 21-25, 1973.

SIMS, S.R.; STONE, T.B. Genetic basis of tobacco budworm resistance to an engineered Pseudomonas fluorescens expressing the ä-endotoxin of Bacillus thuringiensis kurstaki. Journal of Invertebrate Pathology, San Diego, v. 57, n. 2, p. 206-210, 1991.

SOSA-GÓMEZ, D. Intraspecific variation and population structure of the velvetbean caterpillar, Anticarsia gemmatalis Hübner, 1818 (Insecta: Lepidoptera: Noctuidae). Genetics and Molecular Biology, Ribeirão Preto, v. 27, n. 3, p. 378-384, 2004. 
SOSA-GÓMEZ, D.; MIRANDA, J.E. Custo adaptativo da resistência de Bacillus thuringiensis na lagarta-da-soja, Anticarsia gemmatalis. In: REUNIÃO DA PESQUISA DE SOJA DA REGIÃO CENTRAL DO BRASIL,32., 2011, São Pedro. Resumos...São Pedro: EMBRAPA SOJA, 2011. Resumo 18.

SPARKS, A.N. A review of the biology of the fall armyworm. Florida Entomologist, Vickery, v. 62, p. 82-87, 1979.

STEWART, C.N.; ADANG, M.J.; ALL, J.N.; BOERMA, H.R.; CARDINEAU, G; TUCKER, D.; PARROTT, W.A. Genetic transformation, recovery, and characterization of fertile soybean transgenic for a synthetic Bacillus thuringiensis cryIAc gene. Plant Physiology, Washington, v. 112, n. 1, p. 121-129, 1996.

STORER N.P.; BABCOCK J.M.; SCHLENZ M.; MEADE T.; THOMPSON G.D.; BING J.W.; HUCKABA R.M. Discovery and characterization of field resistance to $B t$ maize: Spodoptera frugiperda (Lepidoptera: Noctuidae) in Puerto Rico. Journal of Economic Entomology, Lanham, v. 103, n. 4, p. 1031-1038, 2010.

TABASHINIK, B. Evolution to resistence to Bacillus thurigiensis. Annual Review of Entomology, Stanford, v. 39, p. 47-79, 1994.

TABASHNIK, B.E.; LIU, Y.B.; DENNEHY, T.J.; SIMS, M.A.; SISTERSON, M.S.; BIGGS, R.W.; CARRIÈRE, Y. Inheritance of resistance to $B t$ toxin CrylAc in a field-derived strain of pink bollworm (Lepidoptera: Gelechiidae). Journal of Economic Entomology, Lanham, v.95, n. 5, p. 1018-1026. 2002.

TABASHINIK, B.C.; LIU, Y.B.; MALVAR, T.; HECKEL, D.G.; MASSON, L.; BALLESTER, V.; GRANELO, F.; MENSURA, J.L.; FERRÉ, J. Global variation in the genetic and biochemical basis of diamondback moth resitence to Bacillus thuringiensis.

Proceedings of the National Academy of Sciences of the United States of America, Washington, n. 94, n. 24, p. 12780-12785, 1997.

TABASHNIK, B.E.; GASSMANN, A.J.; CROWDER, D.W.; CARRIÈRE, Y. Insect resistance to $B t$ crops: evidence versus theory. Nature Biotechnology, New York, v. 26, n. 2, p. 1999-2002, 2008.

TABASHNIK, B.E.; RENSBURG, V.J.B.J.; CARRIÈRE, Y. Field-evolved insect resistance to $B t$ crops: Definition, theory, and data. Journal of Economic Entomology, Lanham, v. 102, n. 6, p. 2011-2025, 2009.

TABASHNIK, B.E.; HUANG, F.; GHIMIRE, M.N.; LEONARD, B.R.; SIEGFRIED, B.D.; RANGASAMY, M.; YANG, Y.; WU, Y.; GAHAN, L.J.; HECKEL, D.G.; BRAVO, A.; SOBERON, M. Efficacy of genetically modified Bt toxins against insects with different genetic mechanisms of resistance. Nature Biotechnology, New York, advance online publication, 2011.

TAKAHASHI, M.K.; NAKANO, O.; OSI, J.R. Avaliação de danos causados por Spodoptera frugiperda (J.E. Smith, 1797) (Lepidoptera: Noctuidae) em cultura de trigo. Solo, Piracicaba, v. 72 , p. 43-44, 1980. 
TANG, J.D.; COLLINS, H.L.; METZ, T.D.; EARLE, E.D.; ZHAO, J.Z.; ROUSH, R.T.; SHELTON, A.M. Greenhouse tests on resistance management of $B t$ transgenic plants using refuge strategies. Journal of Economic Entomology, Lanham, v. 94, n. 1, p. 240-247, 2001.

TARRAGÓ, M.F.S.; SILVEIRA NETO, S.; CARVALHO, S.; BARBIN, D. Influência de fatores ecológicos na flutuação populacional das lagartas da soja, Anticarsia gemmatalis Hübner e Rachiplusia nu (Guen.) em Santa Maria/RS. Anais da Sociedade Entomológica do Brasil, Jaboticabal, v. 6, n. 2, p. 180-193, 1977.

TOMQUELSKI, G.V.; MARUYAMA, L.C.T. Lagarta-da-maçã em soja. Revista Cultivar, Pelotas, v. 117, p. 20-22, 2009.

TURNIPSSED, S.G.; KOGAN, M. Soybean entomology. Annual Review of Entomology, Stanford, v. 21, p. 247-282, 1976.

VALICENTE, F.H.; COSTA, E.F. DA. Controle da lagarta do cartucho Spodoptera frugiperda (J.E. Smith), com o Baculovírus spodoptera, aplicado via água de irrigação. Anais da Sociedade Entomológica Brasileira, Jaboticabal, v. 24, n. 1, p. 61-67, 1991.

VAN RENSBURG, J.B.J. First report of field resistance by stem borer, Busseola fusca (Fuller) to Bt-transgenic maize. South African Journal of Plant and Soil, Pretoria, v. 24, n. 3, p. 147-151, 2007.

VAN RIE, J.; MCGAUGHEY, W.H.; JOHNSON, D.E.; BARNETT, B.D.; VAN MELLAERT, H. Mechanism of insect resistance to the microbial insecticide Bacillus thuringiensis. Science, Washington, v. 247, n. 4938, p. 72-74, 1990.

VIA, S. Ecological genetics and host adaptation in herbivorous insects: the experimental study of evolution in natural and agricultural systems. Annual Review of Entomology, Stanford, v. 35, p. 421-446, 1990.

ZHAO, J.Z.; CAO, J.; COLLINS, H.L.; BATES, S.L.; ROUSH, R.T.; EARLE, E.D.; SHELTON, A.M. Concurrent use of transgenic plants expressing a single and two Bacillus thuringiensis genes speeds insect adaptation to pyramided plants. Proceedings of the National Academy of Sciences of the United States of America, Washington, v. 102, n. 24, p. 8426-8430, 2005.

WANG, P.; ZHAO, J.Z.; RODRIGO-SIMÓN, A.; KAIN, W.; JANMAAT, A.F.; SHELTON, A.M.; FERRÉ, J.; MYERS, J. Mechanism of resistance to Bacillus thuringiensis toxin Cry1Ac in a greenhouse population of cabbage looper, Trichoplusia ni. Applied and Environmental Microbiology, Washington, v. 73, n. 4, p. 1199-1207, 2007. 


\title{
3 AVALIAÇÃO DO CONCEITO DE ALTA DOSE E EFICÁCIA DA SOJA MON $87701 \times$ MON 89788 CONTRA $A$. gemmatalis E $P$. includens (LEPIDOPTERA: NOCTUIDAE) NO BRASIL
}

\section{Resumo}

A soja geneticamente modificada MON $87701 \times$ MON 89788, Glycine max (L.) Merrill que expressa genes que codificam a proteína Cry1Ac de Bacillus thuringiensis var. kurstaki Berliner e a proteína 5-enolpiruvilchiquimato-3-fosfato sintase de Agrobacterium sp. foi registrada para uso no Brasil. Para subsidiar um programa de Manejo da Resistência de Insetos (MRI) foram conduzidos estudos em laboratório e campo para avaliar a expressão de alta-dose da proteína Cry1Ac em soja MON $87701 \times$ MON 89788 para Anticarsia gemmatalis Hübner e Pseudoplusia includens (Walker) para a proteína Cry1Ac. Em bioensaios com a proteína Cry1Ac purificada incorporada à dieta artificial, verificou-se que Cry1Ac foi mais ativa para A. gemmatalis $\left[\mathrm{CL}_{50}(\mathrm{IC} 95 \%)=0,23(0,15-0,34) \mu \mathrm{g}\right.$ Cry $1 \mathrm{Ac} / \mathrm{mL}$ de dieta] que para $P$. includens $\left[\mathrm{CL}_{50}(\mathrm{IC} 95 \%)=3,72(2,65-4,86) \mu \mathrm{g}\right.$ Cry1 Ac/mL de dieta]. Em bioensaios com tecido liofilizado da soja MON $87701 \times$ MON 89788, diluído 25 vezes em dieta artificial constatou-se $100 \%$ de mortalidade para $A$. gemmatalis e de 86,14 a 95,79\% para $P$. includens. Entretanto, as lagartas sobreviventes de $P$. includens apresentaram enfezamento larval $>95 \%$. Em bioensaios com discos de folha em laboratório, elevada infestação em condições de casa de vegetação e de infestação natural em campo foi obtida alta eficácia da soja MON $87701 \times$ MON 89788 no controle de ambas as pragas-alvo. A soja MON $87701 \times$ MON 89788 apresenta um elevado nível de controle de A. gemmatalis e $P$. includens, mas é um evento de alta dose somente para A. gemmatalis.

Palavras-chave: Soja transgênica; Lagarta-da-soja; Lagarta-falsa-medideira; Alta dose; Manejo de Resistência de Insetos

\begin{abstract}
Genetically modified MON $87701 \times$ MON 89788 soybean, Glycine max (L.) Merrill, expressing genes that code for the Cry1Ac protein of Bacillus thuringiensis var. kurstaki Berliner and the 5-enolpyruvylshikimate-3-phosphate synthase protein of Agrobacterium sp. has been registered for commercial use in Brazil. To develop an Insect Resistance Management (IRM) program for this event, we conducted laboratory and field studies to assess the high-dose concept and level of control it provides against Anticarsia gemmatalis and Pseudoplusia includens. The purified Cry1Ac protein in artificial diet showed that Cry1Ac was more active for A. gemmatalis [LC $\operatorname{LC}_{50}(\mathrm{FL} 95 \%)=0.23(0.15-0.34) \mu \mathrm{g}$ Cry $1 \mathrm{Ac} / \mathrm{mL}$ of diet] than for $P$. includens $\left[\mathrm{LC}_{50}(\mathrm{FL} \mathrm{95 \% )}=3.72(2.65-4.86) \mu \mathrm{g}\right.$ Cry $1 \mathrm{Ac} / \mathrm{mL}$ of diet]. In bioassays with freeze-dried MON $87701 \times$ MON 89788 soybean tissue diluted 25 times in an artificial diet, there was $100 \%$ mortality of A. gemmatalis and up to $95.79 \%$ mortality for $P$. includens. However, the surviving $P$. includens larvae showed $>95 \%$ larval stunting. In leaf discs bioassays in the laboratory and in high pest infestation studies under greenhouse conditions and in natural infestations in the field, MON $87701 \times$ MON 89788 soybean showed a very high level of efficacy against both target pests. The MON $87701 \times$ MON 89788 soybean provides a high level of control against A. gemmatalis and $P$. includes, but a high-dose event only to $A$. gemmatalis.
\end{abstract}

Keywords: Transgenic soybean; Velvetbean caterpillar; Soybean looper; High-dose; Insect Resistance Management 


\subsection{Introdução}

No Brasil, a soja Glycine max (L.) Merrill (Fabaceae: Phaseoleae) é cultivada em mais de 20 milhões de hectares e tem como principais insetos desfolhadores a lagarta-da-soja, Anticarsia gemmatalis Hübner e a lagarta-falsa-medideira, Pseudoplusia includens (Walker). A lagarta-da-soja é o inseto que acarreta os maiores prejuízos à cultura, causando desfolhamentos severos em todas as regiões produtoras de soja. No entanto, nos últimos anos, a lagarta-falsa-medideira tem assumido o status de principal inseto desfolhador da soja. Isso possivelmente se deve ao aumento do número de aplicações de agroquímicos, especialmente fungicidas para o controle da ferrugem asiática da soja, Phakopsora pachyrhizi Sydow, que tem comprometido a ação de agentes do controle biológico natural, principalmente a do fungo entomopatogênico Nomuraea rileyi (Farlow).

Atualmente o controle da lagarta-da-soja e da lagarta-falsa-medideira tem sido baseado principalmente no uso de inseticidas sintéticos. A lagarta-da-soja tem sido eficientemente controlada com inseticidas, entretanto, $P$. includens é de difícil controle por ser mais tolerante a inseticidas e por ficar menos exposta às pulverizações devido ao hábito de permanecer na parte inferior do dossel da planta. Estratégias alternativas de controle tais como o uso de inseticidas biológicos e de inimigos naturais estão disponíveis (LUTTRELL et al., 1999; MOSCARDI, 1999) mas são raramente utilizadas. Além disso, linhagens de soja resistentes, desenvolvidas através do melhoramento genético clássico tiveram um impacto limitado e não são amplamente incorporadas em programas de Manejo Integrado de Pragas (MIP) da soja.

A partir dos anos 90, alternativas promissoras para o controle de lagartas desfolhadoras da soja têm sido desenvolvidas com os avanços da biotecnologia. Em 1994, houve o primeiro relato da introgressão e expressão bem sucedida de um gene nativo crylAb de Bacillus thuringiensis Berliner (Bt) em soja (PARROTT et al., 1994). Mais recentemente foram desenvolvidas linhagens experimentais de soja que expressam um gene crylAc de $B t$ (STEWART et al., 1996; WALKER et al., 2000; HOMRICH et al., 2008a, b) e linhagens que expressam um gene sintético crylA (tic107) de Bt (MACRAE et al., 2005; MIKLOS et al., 2007; MCPHERSON; MACRAE, 2009). No último caso, as linhagens continham o evento MON 87701 que expressa a proteína sintética TIC107 que é quase idêntica a proteína nativa Cry1Ac de Bt (FISCHHOFF; PERLAK, 1995). Estas linhagens foram cruzadas através do melhoramento convencional, com linhagens que continham o evento MON 89788 para obter o evento de soja estaqueado MON $87701 \times$ MON 89788 que expressa a proteína inseticida 
Cry1Ac de $B t$, que tem como pragas-alvo primárias de controle $A$. gemmatalis e $P$. includens, e a proteína 5-enolpiruvilchiquimato-3-fosfato sintase de Agrobacterium sp. que confere tolerância ao glifosato.

A sustentabilidade dessa nova tática de MIP da soja é extremamente dependente do estabelecimento de estratégias de manejo da resistência de insetos e plantas daninhas para retardar ou impedir a evolução de resistência. Para o Manejo da Resistência de Insetos (MRI) eventos como a soja MON $87701 \times$ MON 89788, que expressam uma única proteína inseticida de $B t$, o uso da estratégia de alta dose + refúgio tem sido a preferida para o MRI (GOULD, 1994; FIFRA SCIENTIFIC ADVISORY PANEL, 1998; HUANG; ANDOW; BUSCHMAN, 2011). De um ponto de vista operacional, evento de alta dose pode ser definido como aquele que expressa a proteína inseticida em concentração que é igual ou superior a 25 vezes a concentração letal que corresponde à mortalidade de $99 \%$ da população da praga-alvo (FIFRA SCIENTIFIC ADVISORY PANEL, 1998; CAPRIO; SUMMERFORD; SIMS, 2000; ANDOW, 2008). Em outras palavras, alta dose se refere à expressão in planta de uma proteína de $B t$ em um nível suficientemente alto para acarretar a mortalidade de todos os insetos-alvo homozigotos suscetíveis, e também da maioria dos insetos heterozigotos que carregam o alelo de resistência presentes na população da praga. Nessa situação somente os insetos raros homozigotos resistentes são capazes de sobreviver à exposição à planta $B t$. Nesse cenário, as áreas de refúgio são responsáveis pelo fornecimento de indivíduos suscetíveis para minimizar o acasalamento não-aleatório entre os raros indivíduos homozigotos resistentes que sobrevivem nas plantas $B t$ e, ao mesmo tempo, garante que a maioria da progênie seja formada por indivíduos de genótipo heterozigoto. Por sua vez, esses indivíduos heterozigotos serão fenotipicamente suscetíveis, em um cenário onde a planta $B t$ expressar a proteína inseticida em alta dose (TABASHNIK; VAN RENSBURG; CARRIÈRE, 2009).

Para entender o valor da soja MON $87701 \times$ MON 89788 para o MIP e subsidiar programas de MRI, estudos de avaliação de risco de resistência foram conduzidos para caracterizar a linha básica de suscetibilidade de A. gemmatalis e $P$. includens à proteína Cry1Ac e avaliar a adequabilidade da soja MON $87701 \times$ MON 89788 ao conceito de alta dose e a sua aficácia para essas duas pragas-alvo. 


\subsection{Material e métodos}

\subsubsection{Criação e manutenção de $P$. includens}

As lagartas de $P$. includens foram mantidas em dieta artificial (Tabela 3.1) em copos plásticos de $50 \mathrm{~mL}$, vedados com uma placa acrílica circular. Nos copos contendo dieta artificial foram inoculadas 2 lagartas, as quais permaneceram até a fase de pupa. As pupas foram retiradas e acondicionadas em placas de Petri $(12 \mathrm{~cm}$ de diâmetro $\times 1,5 \mathrm{~cm}$ de altura) forradas com papel filtro umedecido com água destilada e acondicionadas em gaiolas cilíndricas de PVC para emergência dos adultos. Após a emergência, os adultos foram repassados para gaiolas cilíndricas de PVC $(24,0 \mathrm{~cm}$ altura $\times 14,5 \mathrm{~cm}$ de diâmetro), revestidas internamente com papel sulfite branco e fechadas na parte superior com tecido fino "voil". O alimento dos adultos foi constituído de uma solução aquosa de mel a $10 \%$ fornecido via capilaridade por algodão hidrófilo. A cada 2 dias os ovos foram coletados e acondicionados em recipientes plásticos $(250 \mathrm{~mL})$ contendo papel filtro umedecido com água destilada e incubados em câmara climatizada (temperatura $27 \pm 1{ }^{\circ} \mathrm{C}$, umidade relativa $60 \pm 10 \%$ e fotoperíodo 14: $10 \mathrm{~h}$ luz:escuro). Após a eclosão, as lagartas foram inoculadas em dieta artificial retornando à criação de manutenção, sendo o restante das neonatas utilizadas para realização dos bioensaios. A. gemmatalis foi fornecida na fase de ovo pela empresa Gravena Pesquisa Consultoria e Treinamento Agrícola Ltda para realização dos bioensaios. 
Tabela 3.1 - Composição da dieta artificial utilizada para a criação de $P$. includens e realização dos bioensaios de linha básica de suscetibilidade e alta dose (Adaptada de GREENE; LEPPLA; DICKERSON, 1976)

\begin{tabular}{|c|c|}
\hline Ingrediente & Quantidade \\
\hline Feijão branco (g) & 75,00 \\
\hline Germe de trigo (g) & 60,00 \\
\hline Proteína de soja (g) & 30,00 \\
\hline Caseína (g) & 30,00 \\
\hline Levedura de cerveja (g) & 37,50 \\
\hline Ágar (g) & 22,50 \\
\hline Ácido ascórbico (g) & 3,96 \\
\hline Ácido sórbico (g) & 1,98 \\
\hline Nipagim (g) & 3,30 \\
\hline Tetraciclina (mg) & 124,00 \\
\hline Formaldeído 10\% (mL) & 15,90 \\
\hline Complexo vitamínico (mL) & 9,90 \\
\hline Água (mL) & 1200,00 \\
\hline \multicolumn{2}{|c|}{ Composição do complexo vitamínico } \\
\hline Niacinamida $(\mathrm{g})$ & 1,00 \\
\hline Pantotenato de cálcio (g) & 1,00 \\
\hline Riboflavina (g) & 0,50 \\
\hline Tiamina $(\mathrm{g})$ & 0,25 \\
\hline Piridoxina (g) & 0,25 \\
\hline Ácido fólico (g) & 0,10 \\
\hline Biotina (mg) & 0,02 \\
\hline Vitamina B12 [1.000 mg/mL] (mL) & 2,00 \\
\hline Água (mL) & 1000,00 \\
\hline
\end{tabular}

\subsubsection{Linha básica de suscetibilidade de $A$. gemmatalis e $P$. includens à proteína Cry1Ac}

Para caracterização da atividade biológica da proteína Cry1Ac utilizou-se uma população de A. gemmatalis coletada em Sertanópolis, Paraná e, de $P$. includens coletada em Paulínia, São Paulo e mantidas em laboratório por mais de 10 anos (populações suscetíveis de referência). A proteína Cry1Ac purificada foi fornecido pela Monsanto do Brasil Ltda, na concentração de $1,4 \mathrm{mg}$ de Cry1 Ac/mL e armazenada em ultra-freezer a $-80 \pm 5^{\circ} \mathrm{C}$. A toxina foi analisada usando várias técnicas padrão, incluindo bioensaios e análise de aminoácidos, 
para determinar que continha $80 \%$ CrylAc ativa e $20 \%$ de materiais inertes. Após descongelamento, a proteína Cry1Ac foi diluída em solução tampão constituída de $50 \mathrm{mM}$ Ácido 3-(Ciclohexilamino)-1-Propanosulfônico (CAPS) à pH=10,25, 1 mM Benzomidine$\mathrm{HCl}, 1 \mathrm{mM}$ Ácido Etileno Diamino Tetra Acético (EDTA) e 2,5 mM de Ditiotreitol (DTT). Para os bioensaios, a proteína inseticida e a solução tampão foram adicionadas em dieta artificial (Tabela 3.1), quando a temperatura da dieta atingiu $45-50^{\circ} \mathrm{C}$. A incorporação da proteína Cry1Ac em dieta artificial foi realizada por um agitador de tubos do tipo Vortex por no mínimo 2 minutos. Em seguida, a dieta contendo a proteína incorporada foi mantida em banho-maria $\mathrm{a} \approx 55^{\circ} \mathrm{C}$ para posterior distribuição nas bandejas de bioensaio (BIO-BA-128, CD International Inc., Pitman, NJ), contendo 128 células (1 mL de dieta/célula) com auxílio de uma pipeta de repetição e ponteira. Para cada espécie foram testadas de 5 a 8 concentrações de Cry1Ac e como testemunha, somente a solução tampão foi adicionada à dieta. Após a geleificação e esfriamento da dieta, com auxílio de um pincel fino foi inoculado uma lagarta neonata ( 0 - 24 h de idade) de A. gemmatalis ou $P$. includens em cada célula. As bandejas foram vedadas com lâminas plásticas auto-adesivas (BIO-CV-16, CD International Inc.) que permite as trocas gasosas com o ambiente externo e acondicionadas em câmara climatizada (temperatura $27 \pm 1^{\circ} \mathrm{C}$, umidade relativa $60 \pm 10 \%$ e fotoperíodo $14: 10 \mathrm{~h}$ luz:escuro). O delineamento experimental foi inteiramente casualizado, com 5 a 8 repetições por concentração (16 lagartas/repetição). A atividade biológica da proteína Cry1Ac foi avaliada após 7 dias considerando-se como critérios de resposta a mortalidade (sendo também consideradas mortas as lagartas que não ultrapassaram o primeiro ínstar) e o peso das lagartas sobreviventes. A partir dos dados de mortalidade de cada concentração foi estimada a $\mathrm{CL}_{50} \mathrm{e}$ $\mathrm{CL}_{90}$ (CL - Concentração Letal) e respectivos intervalos de confiança (IC 95\%) usando o procedimento Probit no software SAS ${ }^{\circledR}$ (PROC PROBIT, SAS INSTITUTE, 2000). Para obtenção da $\mathrm{CL}_{99}$, os dados de mortalidade foram submetidos ao modelo binomial com função de ligação complemento log-log (gompit) no software SAS ${ }^{\circledR}$ (PROC PROBIT, SAS INSTITUTE, 2000). Para os dados de peso médio das lagartas sobreviventes foi realizada uma análise de regressão não-linear para estimação da $\mathrm{CE}_{50}$ e $\mathrm{CE}_{90}(\mathrm{CE}$ - Concentração Efetiva) e respectivos intervalos de confiança (IC 95\%) no software JMP SAS ${ }^{\circledR}$ (SAS INSTITUTE, 2010). O modelo logístico não-linear utilizado para o cálculo de $\mathrm{CE}_{50}$ foi o seguinte: peso $=\mathrm{Wo} /\left[1+\left(\operatorname{dose} / \mathrm{CE}_{50}\right)^{\mathrm{B}}\right]$, onde $\mathrm{W}_{\mathrm{o}}$ é o peso esperado no controle, dose é a concentração de Cry1 Ac/mL de dieta, $\mathrm{EC}_{50}$ é a concentração de Cry1Ac que reduz o peso larval em $50 \%$ e B é o parâmetro de inclinação, ângulo da função logística (SIMS et al., 
1996). Para o cálculo da $\mathrm{CE}_{90}$ o modelo logístico não-linear utilizado foi o seguinte: peso = Wo/[1+(dose $\left.\left./ \mathrm{CE}_{50}\right)\right]^{\left[\ln 9 /\left(\ln \left(\mathrm{CE}_{50} / \mathrm{CE}_{90}\right)\right)\right]}$ (Adaptada de SIMS et al., 1996), respectivamente.

\subsubsection{Bioensaios de alta dose}

Para avaliar a adequabilidade da soja MON $87701 \times$ MON 89788 ao conceito de alta dose foi realizada a semeadura da soja MON $87701 \times$ MON 89788 e soja isolinha não-Bt dos grupos de maturação 5.6 (recomendado para cultivo na região Sul do Brasil) e 8.3 (recomendado para cultivo na região Centro-Oeste do Brasil) a campo nas respectivas regiões de cultivo na densidade de 12 plantas/m linear. Após a emergência e antes da retirada de folhas para liofilização, uma folha de cada planta de soja MON $87701 \times$ MON 89788 e soja isolinha não- $B t$ foi macerada em tubo de $1,5 \mathrm{~mL}$ tipo Eppendorf ${ }^{\circledR} \mathrm{e}$, posteriormente, com uso de kit QuickStix ${ }^{\mathrm{TM}}$ AP checada para detecção da proteína Cry1Ac. Os bioensaios foram realizados com tecido vegetal liofilizado proveniente de quatro estádios fenológicos V2, V4, R2 e R4 que foi fornecido pela Monsanto do Brasil Ltda e, em laboratório, armazenado em ultra-freezer (temperatura $-80 \pm 5^{\circ} \mathrm{C}$ ). Posteriormente, o tecido liofilizado foi macerado com auxílio de almofariz e pistilo até a obtenção de um pó fino para posterior incorporação na dieta artificial (Tabela 1). Para cada amostra de tecido liofilizado foi calculada a quantidade de matéria seca que iria resultar em uma diluição de 25 vezes (em relação ao tecido fresco) quando incorporado (mg tecido/mL de dieta) em volume total igual a $20 \mathrm{~mL}$ de dieta (Tabela 3.1). Posteriormente, foi pesada a quantidade de tecido liofilizado calculada previamente sendo essa adicionada em dieta artificial $\mathrm{a} \approx 55^{\circ} \mathrm{C}$, em tubos graduados de polipropileno $\left(\right.$ Corning $\left.^{\circledR}\right)$ e, incorporado por meio de um agitador de tubos do tipo Vortex por no mínimo 2 minutos. Em seguida, a dieta contendo o tecido liofilizado incorporado foi mantida em banhomaria $\mathrm{a} \approx 55^{\circ} \mathrm{C}$ para posterior distribuição em bandejas de bioensaio (BIO-BA-128, CD International Inc., Pitman, NJ), contendo 128 células (1 mL de dieta/célula) com auxílio de pipeta de repetição e ponteira. Após a geleificação e esfriamento da dieta, em cada célula, com auxílio de um pincel fino foi inoculada uma lagarta neonata ( 0 - $24 \mathrm{~h}$ de idade) das pragas-alvo, A. gemmatalis ou $P$. includens. As bandejas foram vedadas com lâminas plásticas auto-adesivas (BIO-CV-16, CD International Inc.) que permitem as trocas gasosas com o ambiente externo e acondicionadas em câmara climatizada (temperatura $27 \pm 1^{\circ} \mathrm{C}$, umidade relativa $60 \pm 10 \%$ e fotoperíodo 14:10 h luz:escuro). Para cada estádio fenológico e praga-alvo foram realizadas 16 repetições por tratamento (16 neonatas/repetição), totalizando $\approx 250$ neonatas testadas por tratamento, estádio fenológico e praga-alvo. Aos 7 dias após da 
infestação avaliou-se a mortalidade (lagartas sem movimento aparente foram consideradas mortas), peso e ínstar das lagartas sobreviventes. Os dados de mortalidade e enfezamento das lagartas sobreviventes nas repetições experimentais com tecido liofilizado de soja MON $87701 \times$ MON 89788 foram corrigidos com a soja isolinha não-Bt (ABBOTT, 1925).

\subsubsection{Bioensaios com discos de folha}

Em casa de vegetação foi realizada a semeadura da soja MON $87701 \times$ MON 89788 e soja isolinha não-Bt dos grupos de maturação 5.5 (recomendado para cultivo na região Sul do Brasil) e 8.3 na densidade de 12 plantas/m linear. Quando as plantas atingiram os estádios fenológicos V3-V4, V5-V6, R1-R2 e R3-R4 foram retiradas folhas completamente expandidas do terço superior e, em laboratório, com auxílio de um vasador metálico, discos de folha de $1,2 \mathrm{~cm}$ de diâmetro foram obtidos e acondicionados sobre uma mistura não geleificada de Ágar-água a 2,5\% (0,7 mL/célula) em placas de acrílico (Costar $\left.{ }^{\circledR}\right)$ com 24 células. Os discos de folha de soja foram separados da camada Ágar-água por um disco de papel filtro. Posteriormente, em cada disco de folha de soja foi inoculada uma lagarta neonata (0 - 24h de idade) de A. gemmatalis ou P. includens com auxílio de um pincel fino. As placas foram vedadas com filme plástico $\left(\right.$ Magipack $^{\circledR}$ ) e, em seguida pela tampa da placa, sendo acondicionadas em câmara climatizada (temperatura de $27 \pm 1^{\circ} \mathrm{C}$, umidade relativa $60 \pm 10 \%$ e fotoperíodo 14:10 h luz:escuro). O delineamento experimental foi inteiramente casualizado com 5 repetições/tratamento, sendo cada repetição constituída de 24 lagartas neonatas, totalizando 120 neonatas testadas para cada praga-alvo e estádio fenológico da soja. Aos 4 dias após a infestação dos discos de folha se contabilizou a mortalidade das lagartas. A mortalidade de cada praga-alvo obtida em diferentes estádios fenológicos da soja MON 87701 $\times$ MON 89788 foi corrigida a partir da respectiva isolinha não-Bt (ABBOTT, 1925). Posteriormente, os dados de mortalidade $(x)$ foram transformados em $\sqrt{x+0,5}$, submetidos à análise de variância e as médias comparadas pelo teste $t(P \leq 0,05)$ (PROC TTEST, SAS INSTITUTE, 2000).

\subsubsection{Experimentos em casa de vegetação}

A soja MON $87701 \times$ MON 89788 foi exposta à elevada infestação de A. gemmatalis ou de $P$. includens em casa de vegetação. Para cada praga-alvo foram realizados experimentos distintos, os quais foram constituídos de quatro tratamentos que consistiram de soja MON $87701 \times$ MON 89788 do grupo de maturação 5.5 e 8.3 e respectivas isolinhas não- $B t$, os quais 
foram semeados na densidade de 12 sementes/m linear, seguindo delineamento experimental de blocos casualizados. Para cada experimento foram instalados 4 blocos, com 4 linhas de soja/bloco. Dentro de cada bloco as linhas de soja (3,0 m comprimento $\times 0,5 \mathrm{~m}$ entre linhas) representaram as repetições experimentais (parcelas). A partir do estádio fenológico V5-V6, as plantas foram mantidas em sistema de contenção sob gaiolas teladas de nylon $(16 \times 18$ mesh) com 13,0 m comprimento $\times 3,5 \mathrm{~m}$ largura $\times 2,9 \mathrm{~m}$ altura, as quais permaneceram até $\mathrm{o}$ fim do estudo. Quando as plantas atingiram o estádio reprodutivo R1-R2, $\approx 2000$ pupas de $A$. gemmatalis ou de $P$. includens foram subdividas em quatro grupos de $\approx 500$ pupas, acondicionadas em caixas de acrílico $(11 \times 11 \mathrm{~cm})$, e posteriormente colocadas no interior da respectiva gaiola em quatro pontos (1 ponto de infestação/bloco) sobre suportes de madeira de $\approx 1,0 \mathrm{~m}$ de altura. As avaliações de incidência larval e desfolha foram realizadas aos 34 (A. gemmatalis) e 43 ( $P$. includens) dias após a introdução das pupas na gaiola. Para ambos os experimentos, a incidência larval foi estimada por meio da contagem do número de larvas em $1 \mathrm{~m}$ de linha de soja, sendo essa expressa em larvas/m linear. Para avaliação da desfolha foram avaliadas, aleatoriamente, cinco plantas por parcela, nas quais foi estimada a porcentagem de desfolha/planta por meio da comparação das folhas a uma escala de desfolha para a cultura da soja (Figura 3.1) (WILLSON, 2009). Os dados de incidência larval e desfolha $(x)$ foram transformados em $(x+0,1)^{1 / 2}$, submetidos à análise de variância e as médias do tratamento com soja MON $87701 \times$ MON 89788 e soja isolinha não-Bt com mesmo grupo de maturação foram comparadas pelo teste $t(P \leq 0,05)$ (PROC TTEST, SAS INSTITUTE, 2000).

\subsubsection{Experimento a campo}

Para avaliar eficácia agronômica da soja MON $87701 \times$ MON 89788 no controle de infestações naturais das pragas-alvo, em condições de campo em Santa Cruz das Palmeiras, São Paulo realizou-se a semeadura da soja MON $87701 \times$ MON 89788 e soja isolinha não-Bt do grupo de maturação 8.3 (16 de novembro de 2009) em 4 blocos idênticos ordenados em delineamento experimental de blocos casualizados com 3 parcelas/bloco (1,0 $\mathrm{m}$ entre parcelas $\times$ 2,0 m entre blocos). Os tratamentos (parcelas) consistiram de soja MON $87701 \times$ MON 89788 e soja isolinha não- $B t$ pulverizada e não-pulverizada. A área útil de cada tratamento foi de $24 \mathrm{~m}^{2}$ (6,0 m comprimento $\times$ 4,0 m largura) com 8 linhas de soja (6,0 m comprimento $\times$ $0,5 \mathrm{~m}$ entre linhas). No tratamento com soja isolinha não- $B t$ pulverizada realizou-se uma pulverização de spinosad (Tracer $480 \mathrm{SC}^{\circledR}$ ) na dose $50 \mathrm{~mL} /$ ha quando a desfolha atingiu o 
nível de controle para os estádios reprodutivos (desfolha $>15 \%$ ). O monitoramento da incidência larval e danos foram realizados a cada 7 dias a partir do momento que as pragasalvo da soja MON $87701 \times$ MON 89788 foram observadas na área experimental, finalizando com a senescência das plantas. A incidência de lagartas foi determinada batendo-se as plantas de duas linhas centrais de cada parcela sobre "pano-de-batida" $(1,0 \mathrm{~m}$ comprimento $\times 0,50 \mathrm{~m}$ largura), sendo a incidência larval de cada espécie convertida em larvas/m linear. Para avaliação dos danos foram avaliadas, aleatoriamente, nas duas linhas centrais 20 plantas de soja (dois grupos de 10 plantas), nas quais foi estimada a porcentagem de desfolha por planta por meio da comparação das folhas a uma escala de desfolha para a cultura da soja (Figura 3.1) (WILLSON, 2009). Os dados de incidência larval e desfolha ( $x$ ) foram transformados em $\sqrt{x+0,1}$, e as médias dos tratamentos comparadas pelo teste de Tukey $(P \leq 0,05)$ (PROC ANOVA, SAS INSTITUTE, 2000).
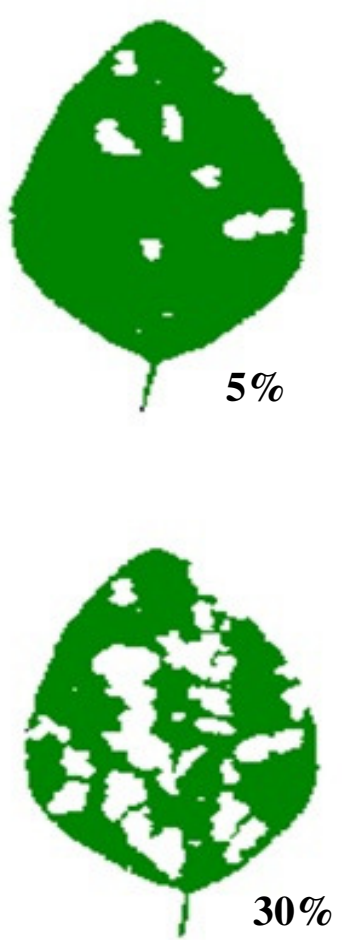

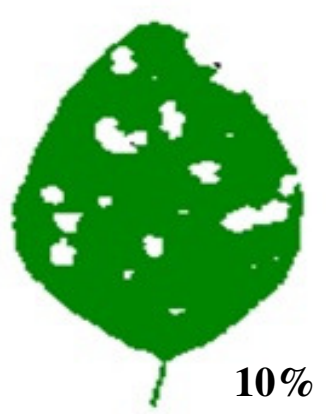

$10 \%$

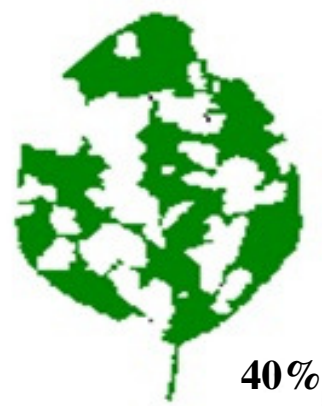

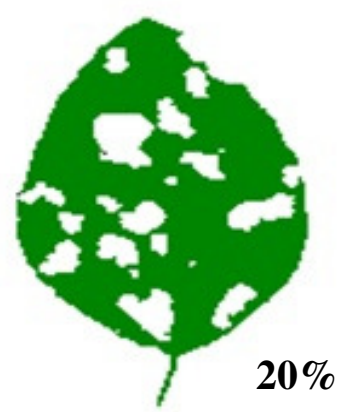

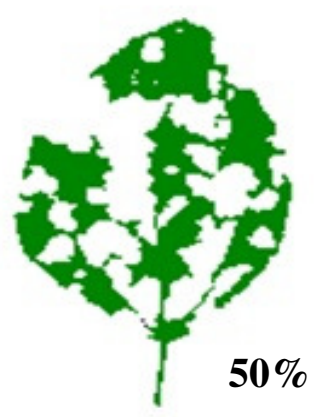

Figura 3.1 - Escala para avaliação de desfolha em soja (WILLSON, 2009)

\subsection{Resultados}

\subsubsection{Linha básica de suscetibilidade}

A proteína inseticida Cry1Ac foi mais ativa para A. gemmatalis do que para $P$. includens (Tabela 3.2, 3.3 e Figura 3.2). Para a concentração letal (CL) foram observadas repostas a partir de 0,032 e 0,1 $\mu \mathrm{g}$ Cry $1 \mathrm{Ac} / \mathrm{mL}$ de dieta para A. gemmatalis e $P$. includens, 
respectivamente (Figura 3.2). Em relação a $\mathrm{CL}_{50}$, lagartas neonatas de A. gemmatalis foram $\approx$ 16 vezes mais suscetíveis Cry1Ac que neonatas de $P$. includens (Tabela 3.2). Em relação à concentração efetiva (CE) houve resposta a partir das concentrações de 0,01 e 0,1 $\mu \mathrm{g}$ Cry1Ac/mL de dieta para A. gemmatalis e $P$. includens, respectivamente (Figura 3.2). Em termos de $\mathrm{CE}_{50}, A$. gemmatalis foi $\approx 75$ vezes mais suscetível que $P$. includens (Tabela 3.3). Entretanto, mesmo havendo diferenças na suscetibilidade, pequenas quantidades da proteína Cry1Ac em dieta artificial ocasionaram mortalidade e afetaram severamente o desenvolvimento, demonstrando que as pragas-alvo da soja MON $87701 \times$ MON 89788 apresentaram alta suscetibilidade à proteína Cry1Ac purificada, a qual compartilha mais de 99\% de identidade de aminoácidos com àquela expressa na soja MON $87701 \times$ MON 89788.

Tabela 3.2 - Concentração letal (CL ${ }^{(1)} ; \mu \mathrm{g}$ Cry1 Ac/mL de dieta) de neonatas de A. gemmatalis e $P$. includens exposta à proteína Cry1Ac purificada de $B$. thuringiensis incorporada em dieta artificial

\begin{tabular}{ccccccc}
\hline Praga-alvo & $n^{(2)}$ & $\begin{array}{c}\text { Coeficiente } \\
\text { Angular }( \pm \mathrm{EP})\end{array}$ & $\begin{array}{c}\mathrm{CL}_{50} \\
(\mathrm{IC} \mathrm{95 \% )}\end{array}$ & $\begin{array}{c}\mathrm{CL}_{90} \\
(\mathrm{IC} 95 \%)\end{array}$ & $\chi^{2}$ & g.l. $^{(3)}$ \\
\hline Anticarsia gemmatalis & 1409 & $1,99( \pm 0,10)$ & 0,23 & 1,03 & 9,76 & 5 \\
& & & $(0,15-0,34)$ & $(0,65-2,38)$ & & \\
Pseudoplusia includens & 1653 & $1,86( \pm 0,13)$ & 3,72 & 18,11 & 7,35 & 6 \\
& & & $(2,65-4,86)$ & $(12,49-33,50)$ & & \\
\hline
\end{tabular}

${ }^{(1)} \mathrm{CL}_{50}$ : concentração letal de Cry1 Ac $(\mu \mathrm{g} / \mathrm{mL}$ de dieta) que mata $50 \%$ das larvas testadas no período de observação de 7 dias. Similarmente, $\mathrm{CL}_{90}$ é a concentração de Cry1 Ac requerida para matar $90 \%$ das larvas testadas.

(2) número total de insetos testados.

${ }^{(3)}$ graus de liberdade.

Tabela 3.3 - Concentração efetiva $\left(\mathrm{CE}^{(1)} ; \mu \mathrm{g}\right.$ Cry1 $\mathrm{Ac} / \mathrm{mL}$ de dieta) que inibe o desenvolvimento de neonatas de $A$. gemmatalis e $P$. includens expostas à proteína Cry1Ac purificada de B. thuringiensis incorporada em dieta artificial

\begin{tabular}{cccc}
\hline Praga-alvo & $n^{(2)}$ & $\begin{array}{c}\mathrm{CE}_{50} \\
(\mathrm{IC} 95 \%)\end{array}$ & $\begin{array}{c}\mathrm{CE}_{90} \\
(\mathrm{IC} \mathrm{95 \% )})\end{array}$ \\
\hline Anticarsia gemmatalis & 880 & 0,017 & 1,033 \\
& & $(0.015-0,020)$ & $(0,654-2,383)$ \\
Pseudoplusia includens & 965 & 1,268 & 11,242 \\
& & $(0,889-1,647)$ & $(6,032-17,124)$ \\
\hline
\end{tabular}

${ }^{(1)} \mathrm{CE}_{50}$ : Concentração efetiva de Cry1 $\mathrm{Ac}(\mu \mathrm{g} / \mathrm{mL}$ de dieta) que causa $50 \%$ de inibição de desenvolvimento larval no período de observação de 7 dias. Similarmente, $\mathrm{CE}_{90}$ é a concentração efetiva de Cry1 Ac requerida para inibir $90 \%$ do desenvolvimento larval.

(2)número total de insetos testados. 
A partir dos dados de concentração-mortalidade foi estimada a CL99 $($ IC 95\%) $=2,08$ $(1,64$ - 2,86) e 29,13 (22,83 - 40,63) $\mu \mathrm{g}$ Cry1Ac/mL de dieta para A. gemmatalis e $P$. includens, respectivamente. Com base na $\mathrm{CL}_{99}$ foram definidas as concentrações diagnósticas potenciais de 1,8 $\mu \mathrm{g}$ Cry1 Ac/mL de dieta (valor dentro do (IC 95\%) da CL99) e 3,2 $\mu \mathrm{g}$ Cry $1 \mathrm{Ac} / \mathrm{mL}$ de dieta $\left(\approx 2\right.$ vezes a $\left.\mathrm{CL}_{99}\right)$ para o monitoramento da suscetibilidade de $A$. gemmatalis. De modo similar foram estimadas a concentração de $32 \mu \mathrm{g}$ Cry1 Ac/mL de dieta (valor dentro do (IC 95\%) da CL99) e $56 \mu$ g Cry1 Ac/mL de dieta ( $\approx 2$ vezes a CL99) para o monitoramento da suscetibilidade de P. includens. Para as ambas as pragas-alvo, as duas concentrações diagnósticas potenciais ocasionaram 100\% de mortalidade (Figura 3.2). No entanto, estudos adicionais devem se realizados para melhor avaliar a resposta natural de populações geograficamente distintas das pragas-alvo à proteína Cry1Ac purificada, para a validação dessas concentrações diagnósticas para o monitoramento da suscetibilidade.

(A)

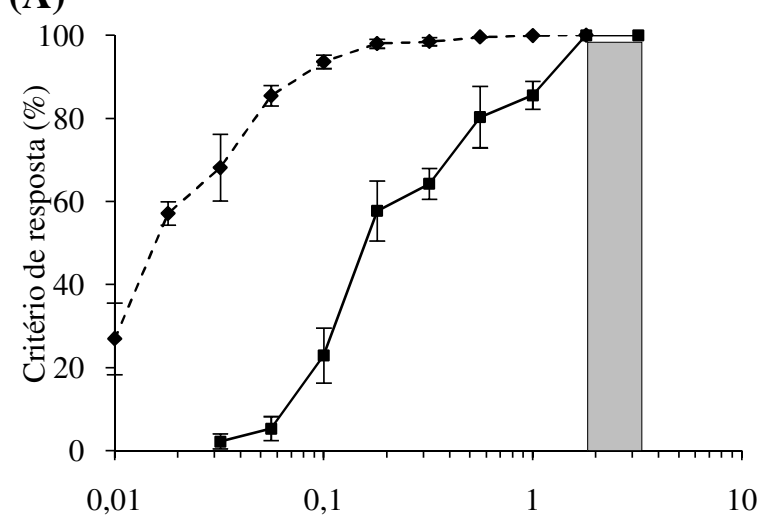

(B)

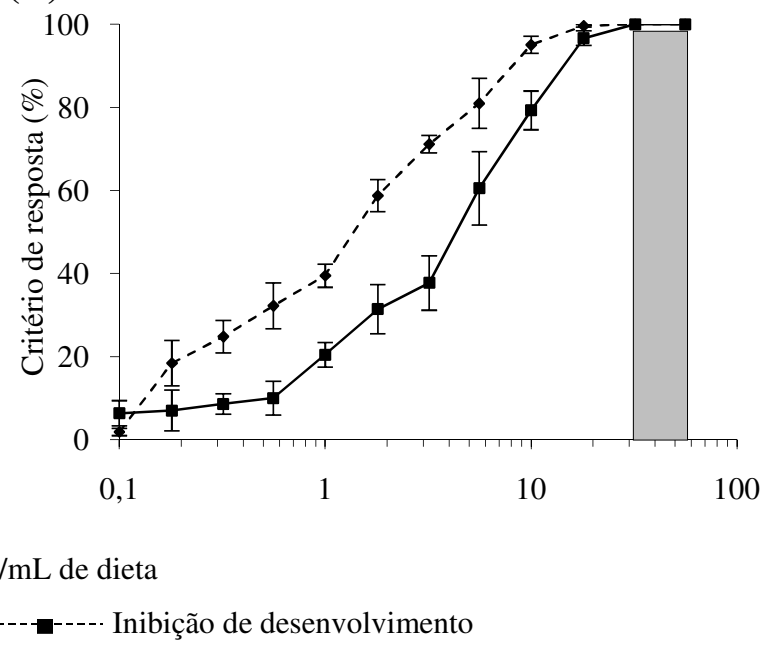

Figura 3.2 - Resposta biológica (mortalidade e inibição do desenvolvimento) de neonatas $A$. gemmatalis (A) e P. includens (B) expostas à proteína Cry1Ac purificada de $B$. thuringiensis incorporada em dieta artificial. A área hachurada indica a faixa de concentrações diagnósticas sugeridas para programas de monitoramento da resistência

\subsubsection{Bioensaios de alta dose}

O tecido liofilizado da soja MON $87701 \times$ MON 89788 dos grupos de maturação 5.6 e 8.3, em diluição de 25 vezes em dieta artificial ocasionou $100 \%$ de mortalidade para $A$. gemmatalis em todos os estádios fenológicos avaliados (Figura 3.3). 


\section{Grupo de maturação 5.6}

(A)

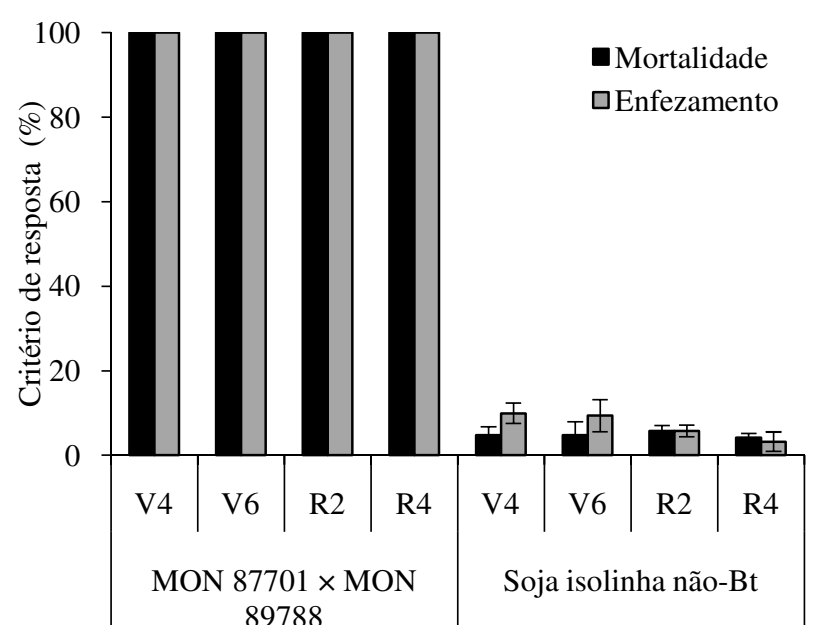

(B)

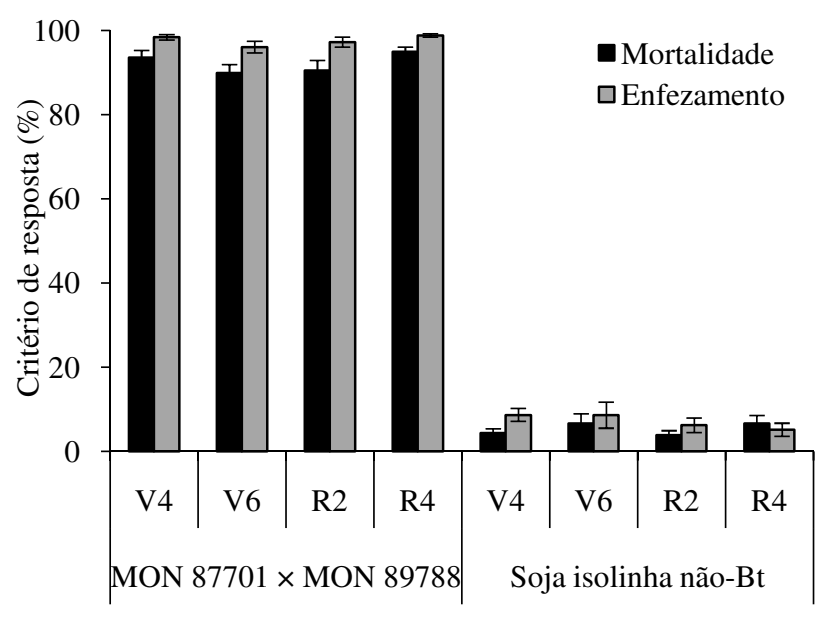

\section{Grupo de maturação 8.3}

(C)

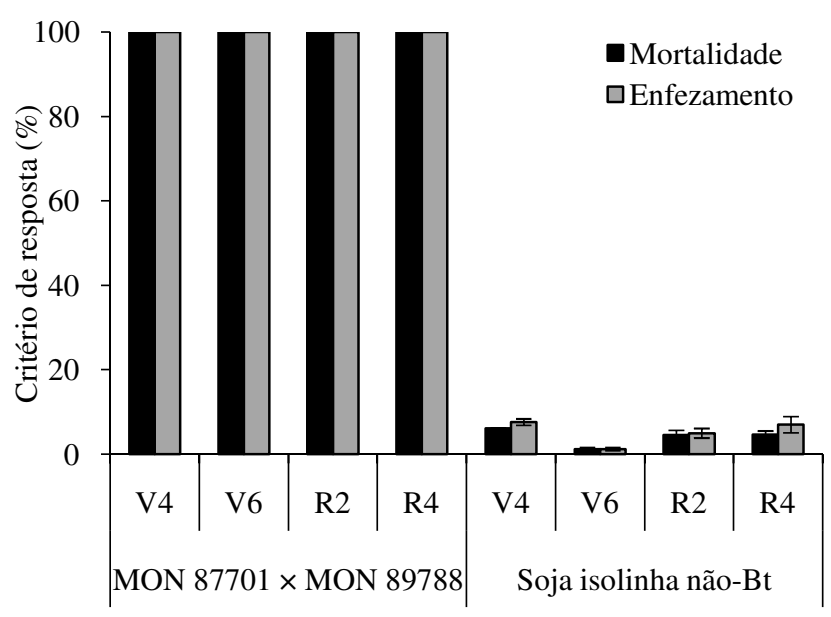

(D)

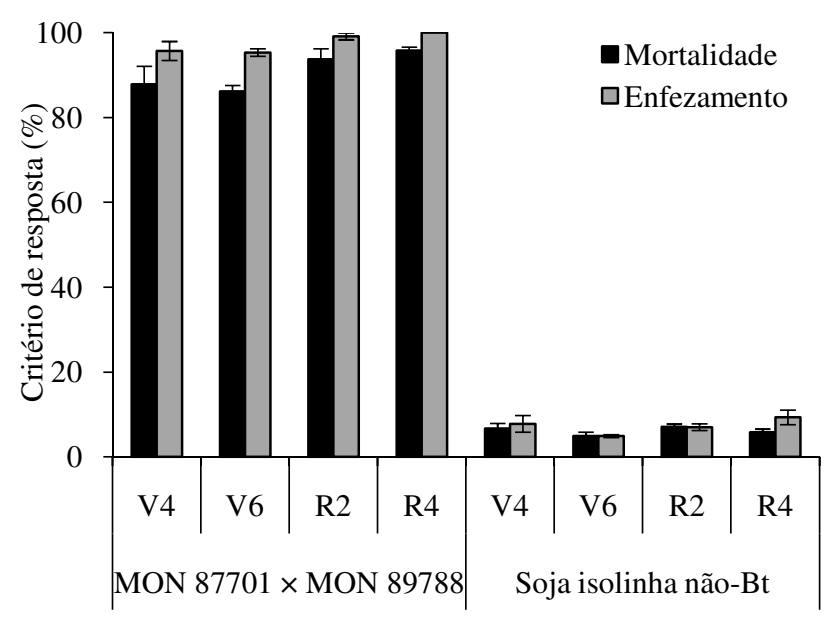

Figura 3.3 - Porcentagem de mortalidade e enfezamento (não atingiram terceiro ínstar) de neonatas de A. gemmatalis (A e C) e P. includes (B e D) após 7 dias em dieta artificial contendo tecido liofilizado de soja MON $87701 \times$ MON 89788 do grupo de maturação 5.6 e 8.3 e soja isolinha não- $B t$ em diluição de 25 vezes relativo ao tecido foliar fresco. Valores representam médias \pm EP após correção com o tecido liofilizado da soja isolinha não- $B t$

Por outro lado, a soja MON $87701 \times$ MON 89788 não ocasionou mortalidade completa de $P$. includens, que variou de 89,97 a $94,98 \%$ e 86,14 a $95,79 \%$ no grupo de maturação 5.6 e 8.3, respectivamente. Em contraste, o tecido liofilizado da soja isolinha não$B t$ ocasionou mortalidade $<8 \%$ para ambas as pragas-alvo. As lagartas sobreviventes de $P$. includens em tecido liofilizado de soja MON $87701 \times$ MON 89788 de ambos os grupos de 
maturação apresentaram enfezamento no crescimento larval $>95 \%$, quando comparados aos sobreviventes em soja isolinha não- $B t$, fato que explica a pequena quantidade de lagartas que atingiram o terceiro ínstar após sete dias (Figura 3.3). Nesse nível de inibição de desenvolvimento as lagartas sobreviventes de P. includens se mantidas em dieta artificial contendo o tecido liofilizado de soja MON $87701 \times$ MON 89788, dificilmente completariam o ciclo biológico.

\subsubsection{Bioensaios com discos de folha}

As lagartas neonatas de $A$. gemmatalis e $P$. includens foram extremamente suscetíveis à proteína Cry1Ac expressa nas folhas de soja MON $87701 \times$ MON 89788 dos grupos de maturação 5.5 e 8.3 (Tabela 3.4 e 3.5). Aos 4 dias após a infestação houve $100 \%$ de mortalidade de A. gemmatalis em discos de folha de soja MON $87701 \times$ MON 89788, sendo a mortalidade significativamente maior daquela observada na soja isolinha não- $B t$ do grupo de maturação 5.5 nos estádios V3-V4 $(t=9,77$; g.1. $=1,8 ; P<0,0001)$, V5-V6 $(t=8,88 ;$ g.1. = 1, 8; $P<0.0001)$, R1-R2 $(t=7,01 ;$ g.l. $=1,8 ; P<0,0001)$ e R3-R4 $(t=5,17 ;$ g.l. $=1,8 ; P<$ 0,0001) e grupo de maturação 8.3 nos estádios V3-V4 $(t=6,51$; g.l. $=1,8 ; P<0,0001)$, V5V6 $(t=7,65 ;$ g.l. $=1,8 ; P<0,0001), \mathrm{R} 1-\mathrm{R} 2(t=6,57$; g.l. $=1,8 ; P<0,0001)$ e R3-R4 $(t=$ 6,94; g.1. = 1, 8; $P<0,0001)($ Tabela 3.4).

Tabela 3.4 - Porcentagem de mortalidade de neonatas de A. gemmatalis após 4 dias da infestação de discos de folha da soja MON $87701 \times$ MON 89788 dos grupos de maturação 5.5 e 8.3 e soja isolinha não- $B t$ em laboratório, durante a safra $2009 / 10$ e $2010 / 11$

\begin{tabular}{|c|c|c|c|c|}
\hline \multirow{2}{*}{ Tratamento } & \multicolumn{4}{|c|}{ Estádio fenológico $^{(1)}$} \\
\hline & V3-V4 & V5-V6 & R1-R2 & R3-R4 \\
\hline & \multicolumn{4}{|c|}{ Grupo de maturação 5.5} \\
\hline Soja MON $87701 \times$ MON 89788 & $100,00 \pm 0,00$ & $100,00 \pm 0,00$ & $100,00 \pm 0,00$ & $100,00 \pm 0,00$ \\
\hline \multirow[t]{2}{*}{ Soja isolinha não- $B t$} & $19,91 \pm 4,40$ & $18,33 \pm 2,40$ & $16,66 \pm 2,94$ & $7,50 \pm 2,42$ \\
\hline & \multicolumn{4}{|c|}{ Grupo de maturação 8.3} \\
\hline Soja MON $87701 \times$ MON 89788 & $100,00 \pm 0,00$ & $100,00 \pm 0,00$ & $100,00 \pm 0,00$ & $100,00 \pm 0,00$ \\
\hline Soja isolinha não- $B t$ & $5,00 \pm 3,63$ & $19,17 \pm 2,12$ & $15,00 \pm 3,12$ & $15,98 \pm 2,31$ \\
\hline
\end{tabular}


De modo similar, também houve $100 \%$ de mortalidade de lagartas neonatas de $P$. includens em discos de folha de soja MON $87701 \times$ MON 89788 do grupo de maturação 5.5 nos estágios fenológicos V3-V4 $(t=3,65$; g.l. $=1,8 ; P<0,0001)$, V5-V6 $(t=3,86$; g.1 = 1, 8; $P<0,0001), \mathrm{R} 1-\mathrm{R} 2(t=3,85 ;$ g.1. $=1,8 ; P<0,0001)$ e R3-R4 $(t=4,00 ;$ g.l $=1,8 ; P<$ 0,0001) e grupo de maturação 8.3 nos estágios V3-V4 $(t=4,04$; g.l. $=1,8 ; P<0,0001)$, V5V6 $(t=6,99 ;$ g.1. $=1,8 ; P<0,0001)$, R1-R2 $(t=4,35 ;$ g.1. $=1,8 ; P<0,0001)$ e R3-R4 $(t=$ $6,02 ;$ g.l. $=1,8 ; P<0,0001)$, sendo a mortalidade significativamente maior daquela observada na isolinha soja não- $B t(<16 \%$ de mortalidade) em ambos os grupos de maturação avaliados (Tabela 3.5). Além disso, o consumo dos discos de folha de soja MON $87701 \times$ MON 89788 pelas pragas-alvo foi insignificante, enquanto que os discos de folha das isolinhas não- $B t$ foram quase que totalmente consumidos. Isso indica que uma pequena quantidade (raspagem) de tecido foliar foi suficiente para matar as lagartas neonatas.

Tabela 3.5 - Porcentagem de mortalidade de neonatas de $P$. includens após 4 dias da infestação de discos de folha da soja MON $87701 \times$ MON 89788 dos grupos de maturação 5.5 e 8.3 e soja isolinha não- $B t$ em laboratório, durante a safra $2009 / 10$ e $2010 / 11$

\begin{tabular}{lcccc}
\hline \multirow{2}{*}{ Tratamento } & \multicolumn{4}{c}{ Estádio fenológico $^{(1)}$} \\
\cline { 2 - 5 } & V3-V4 & V5-V6 & R1-R2 & R3-R4 \\
\hline & & Grupo de maturação 5.5 \\
Soja MON 87701 × MON 89788 & $100,00 \pm 0,00$ & $100,00 \pm 0,00$ & $100,00 \pm 0,00$ & $100,00 \pm 0,00$ \\
Soja isolinha não-Bt & $0,83 \pm 0,83$ & $1,66 \pm 1,02$ & $3,83 \pm 2,42$ & $5,70 \pm 2,42$
\end{tabular}

Grupo de maturação 8.3

Soja MON $87701 \times$ MON $89788 \quad 100,00 \pm 0,00 \quad 100,00 \pm 0,00 \quad 100,00 \pm 0,00 \quad 100,00 \pm 0,00$

$\begin{array}{llll}\text { Soja isolinha não-Bt } \quad 3,33 \pm 2,42 & 15,83 \pm 1,55 & 3,33 \pm 0,83 & 11,70 \pm 2,40\end{array}$

${ }^{(1)}$ Valores representam médias \pm EP após correção com a soja isolinha não-Bt. Houve diferença estatística significativa (teste $t$ a $P \leq 0,05$ ) entre a soja MON $87701 \times$ MON 89788 e soja isolinha não-Bt em todos os estádios fenológicos avaliados.

\subsubsection{Experimentos em casa de vegetação}

Não foram constadas lagartas sobreviventes de A. gemmatalis sobre a soja MON $87701 \times$ MON 89788 em qualquer avaliação com alta densidade populacional da praga (Tabela 3.6). Houve uma incidência larval significativamente superior (> 100 larvas/m) na isolinha não- $B t$ dos grupos de maturação $5.5(t=2,80$; g.1. $=1,6 ; P<0,0001)$ e $8.3(t=2,67$; 
g.l. = 1, 6; $P<0,0001)$. A elevada incidência larval de $A$. gemmatalis em soja isolinha não- $B t$ ocasionou desfolha significativamente superior daquela verificada na soja MON $87701 \times$ MON 89788 dos grupos de maturação $5.5(t=3,30$; g.1. = 1, 6; $P<0,0001)$ e $8.3(t=3,20$; g.l.= 1, 6; $P<0,0001)$. Os traços de desfolha na soja MON $87701 \times$ MON 89788 foram ocasionados por lagartas de ínstar avançado que migraram das parcelas com isolinha não-Bt adjacentes. A migração de lagartas de A. gemmatalis de ínstares avançados ocasionou o fim das avaliações, pois poderiam comprometer as avaliações de desfolha da soja MON $87701 \times$ MON 89788. No entanto, mesmo após o encerramento das avaliações as plantas permaneceram em casa de vegetação sob elevada infestação, a qual ocasionou desfolha de $\approx$ $100 \%$ nas parcelas com soja isolinha não-Bt. Em contraste, na soja MON $87701 \times$ MON 89788 a desfolha foi $<5 \%$.

Tabela 3.6 - Incidência larval (larvas/m linear) e danos (\% de desfolha) de A. gemmatalis e $P$. includens em soja MON $87701 \times$ MON 89788 dos grupos de maturação 5.5 e 8.3 e respectiva isolinha não- $B t$ em experimento em casa de vegetação durante a safra 2009/10. Santa Cruz das Palmeiras, São Paulo

\begin{tabular}{lrr}
\hline \multicolumn{1}{c}{ Tratamento } & Incidência larval $^{(1)}$ & \% Desfolha ${ }^{(1)}$ \\
\hline & \multicolumn{2}{c}{ A. gemmatalis } \\
Soja MON 87701 × MON 89788 (Grupo de maturação 5.5) & $0,00 \pm 0,00$ & $3,25 \pm 1,11$ \\
Soja isolinha não-Bt (Grupo de maturação 5.5) & $109,75 \pm 8,86$ & $50,00 \pm 0,00$ \\
Soja MON 87701 × MON 89788 (Grupo de maturação 8.3) & $0,00 \pm 0,00$ & $3,75 \pm 1,44$ \\
Soja isolinha não-Bt (Grupo de maturação 8.3) & $187,25 \pm 37,99$ & $50,00 \pm 0,00$ \\
& \multicolumn{1}{c}{$P$. includens } \\
& $0,00 \pm 0,00$ & $1,25 \pm 1,25$ \\
Soja MON 87701 × MON 89788 (Grupo de maturação 5.5) & $13,75 \pm 2,95$ & $39,50 \pm 5,04$ \\
Soja isolinha não-Bt (Grupo de maturação 5.5) & $0,00 \pm 0,00$ & $0,75 \pm 0,75$ \\
Soja MON 87701 × MON 89788 (Grupo de maturação 8.3) & $18,50 \pm 4,99$ & $39,00 \pm 5,26$ \\
Soja isolinha não-Bt (Grupo de maturação 8.3) & & \\
\hline
\end{tabular}

\footnotetext{
${ }^{(1)}$ Valores representam médias \pm EP. Uma análise de variância ANOVA (teste $t$ a $P \leq 0,05$ ) foi realizada entre a soja MON $87701 \times$ MON 89788 e soja isolinha não-Bt para as duas espécies avaliadas. Houve diferença estatística significativa entre a soja MON $87701 \times$ MON 89788 e soja isolinha não-Bt com mesmo grupo de maturação para as duas variáveis analisadas.
}

De modo contrário ao estudo com $A$. gemmatalis, a pressão populacional de $P$. includens em soja MON $87701 \times$ MON 89788 foi moderada. Mas também não foram constadas larvas sobreviventes de P. includens em soja MON $87701 \times$ MON 89788 em 
qualquer avaliação. Em contraste, houve uma incidência larval significativamente superior (> 13 lagartas/m linear) na isolinha não- $B t$ dos grupos de maturação $5.5(t=3,03$; g.1. $=4,7 ; P<$ $0,0001)$ e $8.3(t=2,87$; g.l. $=4,7 ; P<0,0001)$. No entanto, mesmo com pressão populacional moderada, $P$. includens ocasionou desfolha da isolinha não- $B t$ superior ao nível de dano econômico ( $15 \%$ de desfolha na fase reprodutiva), sendo significativamente maior daquela verificada em soja MON $87701 \times$ MON 89788 dos grupos de maturação 5.5 ( $t=3,30$; g.l. = $1,6 ; P<0,0001)$ e $8.3(t=3,20 ;$ g.l. $=1,6 ; P<0,0001)$. Em contraste, a desfolha da soja MON $87701 \times$ MON 89788 por $P$. includens foi $<2 \%$ (Tabela 3.6).

\subsubsection{Experimento a campo}

Nas avaliações da eficácia da soja MON 87701 × MON 89788 no controle de infestações naturais de A. gemmatalis e $P$. includens foi observada uma maior incidência endêmica de $P$. includens do que $A$. gemmatalis (Tabela 3.7). Não houve diferenças significativas na incidência larval de $A$. gemmatalis nos estádios vegetativos V2-V4 ( $F=$ 1,00; g.1. $=5,6 ; P=0,4547)$ e V6-V8 $(F=1,49 ;$ g.l. $=5,6 ; P=0,2975)$ na soja MON 87701 × MON 89788 e isolinha não-Bt pulverizada e não-pulverizada. No entanto, incidência larval significativamente menor de $A$. gemmatalis foi verificada nos estádios reprodutivos R1-R2 ( $F$ $=31,79 ;$ g.l. $=5,6 ; P=0,0006)$ e R3-R4 $(F=67,41 ;$ g.l. $=5,6 ; P<0,0001)$. De modo similar, também não houve diferenças significativas na incidência larval de $P$. includens em soja MON $87701 \times$ MON 89788 e isolinha não-Bt pulverizada e não-pulverizada nos estádios vegetativos V2-V4 $(F=0,42 ;$ g.l. $=5,6 ; P=0,6699)$ e V6-V8 $(F=0,46$; g.l. $=5,6 ; P=$ 0,6544). Incidência larval de $P$. includens significativamente menor em soja MON $87701 \times$ MON 89788 foi constatada nos estádios reprodutivos R1-R2 $(F=74,51$; g.l. $=5,6 ; P<$ 0,0001) e R3-R4 ( $F=44,54 ;$ g.l. $=5,6 ; P=0,0003)$ (Tabela 3.7). 
Tabela 3.7 - Incidência larval (larvas/m linear) de A. gemmatalis e $P$. includens em soja MON $87701 \times$ MON 89788 do grupo de maturação 8.3 e soja isolinha não- $B t$ (pulverizada e não-pulverizada), expostas a infestações naturais das pragas-alvo em experimento a campo, durante a safra 2009/10. Santa Cruz das Palmeiras, São Paulo, Brazil

\begin{tabular}{|c|c|c|c|c|}
\hline \multirow{2}{*}{ Tratamento } & \multicolumn{4}{|c|}{ Estádio fenológico $^{(1)}$} \\
\hline & $\mathrm{V} 2-\mathrm{V} 4$ & V6-V8 & $\mathrm{R} 1-\mathrm{R} 2$ & R3-R4 \\
\hline & \multicolumn{4}{|c|}{ A. gemmatalis } \\
\hline Soja MON $87701 \times$ MON 89788 & $0,00 \pm 0,00 \mathrm{a}$ & $0,00 \pm 0,00 \mathrm{a}$ & $0,00 \pm 0,00 \mathrm{~b}$ & $0,00 \pm 0,00 \mathrm{c}$ \\
\hline Controle (pulverizado) & $0,00 \pm 0,00 \mathrm{a}$ & $1,50 \pm 1,19 \mathrm{a}$ & $2,75 \pm 0,25 \mathrm{a}$ & $16,75 \pm 2,39 b$ \\
\hline \multirow[t]{2}{*}{ Controle (não-pulverizado) } & $0,25 \pm 0,25 \mathrm{a}$ & $0,25 \pm 0,25 \mathrm{a}$ & $2,75 \pm 0,85 \mathrm{a}$ & $7,25 \pm 2,21 \mathrm{a}$ \\
\hline & \multicolumn{4}{|c|}{ P. includens } \\
\hline Soja MON $87701 \times$ MON 89788 & $0,25 \pm 0,25 \mathrm{a}$ & $0,75 \pm 0,48 \mathrm{a}$ & $0,00 \pm 0,00 \mathrm{~b}$ & $0,00 \pm 0,00 \mathrm{~b}$ \\
\hline Controle (pulverizado) & $0,25 \pm 0,25 \mathrm{a}$ & $1,25 \pm 0,75 \mathrm{a}$ & $10,25 \pm 0,75 a$ & $38,50 \pm 6,12 \mathrm{a}$ \\
\hline Controle (não-pulverizado) & $0,25 \pm 0,25 \mathrm{a}$ & $1,25 \pm 0,95 \mathrm{a}$ & $7,25 \pm 1,70 \mathrm{a}$ & $36,75 \pm 10,04 \mathrm{a}$ \\
\hline
\end{tabular}

${ }^{(1)}$ Valores representam medias \pm EP. Uma análise de variância ANOVA (Tukey a $P \leq 0,05$ ) foi realizada para os tratamentos em cada estádio fenológico (médias seguidas pela mesma letra na coluna não são estatisticamente diferentes) para as duas espécies avaliadas.

Quando a infestação foi analisada conjuntamente, não se constatou diferença significativa na incidência larval das pragas-alvo em soja MON $87701 \times$ MON 89788 e isolinha não- $B t$ pulverizada e não-pulverizada nos estádios vegetativos V2-V4 $(F=0,47$; g.l. $=5,6 ; P=0,6449)$ e V6-V8 $(F=0,42 ;$ g.l. $=5,6 ; P=0,6769)$ (Tabela 3.8). Em contraste, nos estádios reprodutivos R1-R2 $(F=105,18$; g.l. $=5,6$; $P<0,0001)$ e R3-R4 $(F=147,04$; g.1. = 5, 6; $P<0,0001)$, a incidência larval das pragas-alvo foi significativamente menor em soja MON $87701 \times$ MON 89788.

Quanto à desfolha, não houve diferenças significativas entre a soja MON $87701 \times$ MON 89788 e isolinha não-Bt pulverizada e não-pulverizada somente no estádio vegetativo V2-V4 $(F=0,01 ;$ g.l. $=5,6 ; P=0,9894)$. Desfolha significativamente menor da soja MON $87701 \times$ MON 89788, comparativamente a isolinha não-Bt pulverizada e não-pulverizada ocorreu nos estádios V6-V8 $(F=8,20 ;$ g.1. = 5, 6; $P=0,0192)$, R1-R2 $(F=70,41 ;$ g.1. = 5, 6; $P<0,0001)$ e R3-R4 $(F=81,56 ;$ g.l. $=5,6 ; P<0,0001)$.

É importante destacar que mesmo durante o pico populacional das pragas-alvo que variou de $\approx 45$ a 53 lagartas/m linear na isolinha não- $B t$ pulverizada e não-pulverizada, respectivamente, a incidência larval das pragas-alvo não ultrapassou 1 larva/m linear em soja 
MON $87701 \times$ MON 89788 (Tabela 3.8). Independentemente da quantidade de desfolha exibida na isolinha não- $B t$ pulverizada e não-pulverizada, apenas traços de desfolha $(<2 \%)$ foram verificados na soja MON $87701 \times$ MON 89788. Essa aparente desfolha se deve ao ataque de lagartas de Spodoptera spp. à soja MON $87701 \times$ MON 89788, as quais esporadicamente foram constadas na área experimental.

Tabela 3.8 - Incidência larval (A. gemmatalis e $P$. includes) e porcentagem de desfolha da soja MON $87701 \times$ MON 89788 do grupo de maturação 8.3 e soja isolinha não-Bt (pulverizada e não-pulverizada) expostas a infestações naturais das pragas-alvo em experimento a campo, durante a safra 2009/10. Santa Cruz das Palmeiras, São Paulo

\begin{tabular}{|c|c|c|c|c|}
\hline \multirow{2}{*}{ Tratamento } & \multicolumn{4}{|c|}{ Estádio fenológico $^{(1)}$} \\
\hline & V2-V4 & V6-V8 & $\mathrm{R} 1-\mathrm{R} 2$ & R3-R4 \\
\hline & \multicolumn{4}{|c|}{ Larvas/m linear } \\
\hline Soja MON 87701 × MON 89788 & $0,25 \pm 0,25 \mathrm{a}$ & $0,75 \pm 0,48 \mathrm{a}$ & $0,00 \pm 0,00 \mathrm{~b}$ & $0,00 \pm 0,00 \mathrm{~b}$ \\
\hline Controle (pulverizado) & $0,50 \pm 0,50 \mathrm{a}$ & $1,50 \pm 0,65 \mathrm{a}$ & $13,00 \pm 1,47 \mathrm{a}$ & $45,75 \pm 4,37 \mathrm{a}$ \\
\hline \multirow[t]{2}{*}{ Controle (não-pulverizado) } & $0,25 \pm 0,25 \mathrm{a}$ & $2,75 \pm 1,11 \mathrm{a}$ & $10,00 \pm 1,91 \mathrm{a}$ & $53,50 \pm 7,76 a$ \\
\hline & \multicolumn{4}{|c|}{$\%$ Desfolha } \\
\hline Soja MON 87701 × MON 89788 & $0,13 \pm 0,19 \mathrm{a}$ & $0,13 \pm 0,07 \mathrm{~b}$ & $0,56 \pm 0,48 b$ & $1,94 \pm 0,28 b$ \\
\hline Controle (pulverizado) & $0,13 \pm 0,07 \mathrm{a}$ & $1,75 \pm 0,53 \mathrm{a}$ & $10,06 \pm 0,88 \mathrm{a}$ & $35,63 \pm 4,48 a$ \\
\hline Controle (não-pulverizado) & $0,13 \pm 0,07 \mathrm{a}$ & $1,25 \pm 0,23 \mathrm{a}$ & $9,88 \pm 0,31 \mathrm{a}$ & $39,75 \pm 5,32 \mathrm{a}$ \\
\hline
\end{tabular}

${ }^{(1)}$ Valores representam medias \pm EP. Uma análise de variância ANOVA (Tukey a $P \leq 0,05$ ) foi realizada para os tratamentos em cada estádio fenológico (médias seguidas pela mesma letra na coluna não são estatisticamente diferentes) para as duas espécies avaliadas.

\subsection{Discussão}

Das pragas-alvo primárias da soja MON $87701 \times$ MON 89788, A. gemmatalis foi mais suscetível à proteína Cry1Ac purificada do que $P$. includens. Em geral, A. gemmatalis é altamente suscetível a proteínas inseticidas Cry1 de B. thuringiensis (BOBROWSKI et al., 2002). Essa diferença na suscetibilidade também foi reportada para inseticidas biológicos de $B t$, sendo que $A$. gemmatalis foi de 1,5 a 5,6 vezes mais suscetível que $P$. includens (MORALES et al., 1995). Entretanto, quando a comparação é intra-específica, a população de $P$. includens foi $\approx 8$ e 15 vezes menos suscetível que populações da praga de laboratório e campo dos EUA, respectivamente (LUTTRELL; WAN; KNIGHTEN, 1999). Essa diferença na suscetibilidade pode estar relacionada à técnica de bioensaio, formulação da proteína 
inseticida, dieta artificial, população de campo ou laboratório e tempo de exposição (LUTTRELL; WAN; KNIGHTEN, 1999; DULMAGE; GRAHAM; MARTINEZ, 1978; ALI; LUTTRELL; YOUNG, 2006; BLANCO et al., 2009).

É importante destacar que o critério de resposta utilizado, representou não só a mortalidade, mas também a inibição do crescimento (lagartas de primeiro ínstar consideradas mortas). O uso desse critério de resposta possibilitou a obtenção de concentrações diagnósticas potenciais que ocasionaram mortalidade completa das pragas-alvo, fato que potencializa a detecção de pequenas mudanças na suscetibilidade das populações, e torna mais rápido e prático o monitoramento da suscetibilidade. Em estudo similar, Sims et al. (1996) desenvolveram um bioensaio diagnóstico para o monitoramento da suscetibilidade de Heliothis virescens (Fabricius) e Helicoverpa zea (Boddie) à proteína Cry1Ac, em que o critério de resposta foi semelhante ao critério de "mortalidade" utilizado neste estudo, sendo consideradas mortas as lagartas que não se desenvolveram $(<1,0 \mathrm{mg})$. Essa técnica de bioensaio com uso de concentração diagnóstica foi mais sensível que um bioensaio de mortalidade padrão, porque melhor discriminou os fenótipos suscetíveis dos resistentes.

A maior atividade biológica da proteína Cry1Ac sobre A. gemmatalis também foi verificada nos bioensaios de alta dose. O tecido liofilizado da soja MON $87701 \times$ MON 89788 diluído 25 vezes na dieta artificial ocasionou $100 \%$ de mortalidade de A. gemmatalis demonstrando que a soja MON $87701 \times$ MON 89788 atendeu ao conceito alta dose para o MRI da lagarta-da-soja. Em outras palavras, a expressão da proteína Cry1Ac in planta ocorreu em nível 25 vezes superior àquela necessária para causar mortalidade completa de neonatas e acredita-se que nessa condição a maioria dos insetos heterozigotos (indivíduos que carregam o alelo da resistência) seria morta, fazendo que o alelo da resistência seja fenotipicamente ou "funcionalmente" recessivo. No entanto, o tecido liofilizado de soja MON $87701 \times$ MON 89788 não ocasionou mortalidade completa de $P$. includens, não atendendo o conceito de alta dose para o MRI dessa praga-alvo. Em estudo semelhante, Macrae et al. (2005) utilizando tecido liofilizado da soja crylA (tic107) verificaram mortalidade completa de A. gemmatalis e mortalidade quase completa de $P$. includens. Coletivamente, estes dados indicam que $P$. includens apresenta, potencialmente, um risco maior de evoluir para resistência à soja MON $87701 \times$ MON 89788 do que A. gemmatalis. Nesse cenário, quando a alta dose não é atingida, os riscos de evolução de resistência podem ser gerenciados através do aumento do tamanho e abundância das áreas de refúgio (TABASHNIK; GOULD; CARRIÈRE, 2004). Para o MRI das pragas-alvo da soja MON $87701 \times$ MON 89788, a recomendação de pelo menos $20 \%$ de área de refúgio (soja não-Bt) estruturado localizado 
externamente à área cultivada com soja MON $87701 \times$ MON 89788 foi aprovado no Brasil (CTNBIO, 2010). O princípio do uso de refúgio (soja não-Bt) é que qualquer inseto resistente sobrevivente em soja MON $87701 \times$ MON 89788 tem maiores chances de acasalar com adultos suscetíveis presentes nos refúgios do que com outro adulto resistente. Para a soja MON $87701 \times$ MON 89788, o tamanho da área de refúgio leva em conta, principalmente, o risco de evolução de resistência de $P$. includens.

Outro aspecto a ser considerado no MRI das pragas-alvo da soja MON $87701 \times$ MON 89788 é o fato de $P$. includens usar o algodão como hospedeiro ocasional. O uso de cultivares de algodão $B t$ que também expressem a proteína Cry1Ac pode acelerar a evolução de resistência em populações de $P$. includens, especialmente em áreas de produção de soja e algodão do Brasil Central, onde ocorre sobreposição e/ou sucessão de cultivo dessas plantas hospedeiras, resultando em um período de exposição adicional à proteína Cry1Ac. A redução da suscetibilidade de $P$. includens à proteínas inseticidas de $B t$ foi demonstrada para populações da praga coletadas em algodão $B t\left(\right.$ Bollgard $\left.^{\circledR}\right)$ nos EUA, as quais em bioensaios em laboratório foram menos suscetíveis à inseticidas biológicos de B. thuringiensis var kurstaki e aizawai (MASCARENHAS et al., 1998). Diante disso, é de fundamental importância considerar o sistema de cultivo de algodão e soja para o estabelecimento das estratégias de MRI para $P$. inclundes no Brasil. Além disso, a soja no Cerrado é cultivada em grandes áreas contínuas e o estabelecimento de adequadas áreas de refúgio é particularmente importante nessa região.

Além de ser de alta dose para o MRI de A. gematalis e muito próximo à alta dose para P. includens, a soja MON $87701 \times$ MON 89788 forneceu controle completo dessas espécies quando exposta à infestação natural, demonstrando ser uma excelente tecnologia de MIP da soja. Além disso, a soja MON $87701 \times$ MON 89788 fornece controle completo das pragasalvo secundárias como a broca-das-axilas, Crocidosema aporema (Walsingham) e a outra lagarta falsa-medideira, Rachiplusia nu (Guenée) (GAMUNDI et al., 2004; MACRAE et al., 2005). A alta eficácia de controle se deve à expressão da proteína Cry1Ac em níveis elevados durante todo o desenvolvimento da planta. Adicionalmente, a soja MON $87701 \times$ MON 89788 foi mais eficaz no controle de infestações endêmicas das pragas-alvo e seus danos que a aplicação profilática de inseticidas, pois a incidência larval e os danos foram sempre menores em soja MON $87701 \times$ MON 89788 do que na isolinha não-Bt pulverizada e nãopulverizada.

A soja MON $87701 \times$ MON 89788 foi mais eficaz no controle de lagartas desfolhadoras que a soja que expressa um gene nativo crylAb e soja Jack-Bt que expressa 
uma versão sintética de um gene truncado crylAc. As linhagens de soja que expressam a proteína inseticida Cry1Ab exibiram eficácia parcial de controle de A. gemmatalis (PARROTT et al., 1994). Similarmente, a soja Jack-Bt exibiu controle moderado de $A$. gemmatalis, $P$. includens e $H$. zea em laboratório e casa de vegetação (STEWART et al., 1996; WALKER et al., 2000). P. includens, em particular, causou desfolha significativa à soja Jack-Bt (> 60\% de desfolha), sendo a desfolha atribuída a migração de lagartas de ínstares avançados do controle negativo (WALKER et al., 2000). No presente estudo, em casa de vegetação observou-se também migração de $A$. gemmatalis e $P$. includens das isolinhas nãoBt adjacentes, mas essas lagartas de ínstares avançados foram controladas pela soja MON $87701 \times$ MON 89788. Lagartas de ínstares avançados geralmente são mais tolerantes a inseticidas biológicos e proteínas purificadas de $B t$ ou expressas em plantas transgênicas (BAI et al., 1993; ALI; YOUNG, 1996; ALI; LUTTRELL, 2009). A mortalidade de A. gemmatalis e P. includens de ínstares avançados, presumivelmente mais tolerantes é, sem dúvida, reflexo da elevada expressão da proteína $B t$ em soja MON $87701 \times$ MON 89788 e da suscetibilidade dessas espécies a Cry1Ac.

Por outro lado, a soja MON $87701 \times$ MON 89788 parece ter eficácia similar a linhagens experimentais de soja com alta expressão do gene sintético crylA (tic107) de Bt e linhagens da cultivar 'IAS5' que expressam uma versão sintética de um gene truncado crylAc. A soja crylA (tic107) demonstrou a campo uma proteção completa contra $A$. gemmatalis, $P$. includens, $C$. aporema e $H$. zea, sem desfolha aparente (MACRAE et al., 2005; MIKLOS et al., 2007; MCPHERSON; MACRAE, 2009). De modo similar, as linhagens transgênicas da cultivar 'IAS5' ocasionaram mortalidade completa de $A$. gemmatalis em estudos em laboratório e casa de vegetação (HOMRICH et al., 2008a, b). No entanto, linhagens transgênicas da cultivar 'IAS5' não foram avaliadas para o controle de $P$. includens e outros lepidópteros-praga da soja.

Neste estudo fica evidente que a soja MON $87701 \times$ MON 89788 é uma excelente tática de controle da lagarta-da-soja e lagarta-falsa-medideira. Entretanto, a vida útil dessa tecnologia é extremamente dependente de eficientes programas de monitoramento da suscetibilidade de populações das pragas-alvo, A. gemmatalis e P. includens, bem como, da conscientização do uso de áreas de refúgio para o MRI. A aplicação cuidadosa da estratégia de MRI como a de alta dose e áreas de refúgio deve salvaguardar o valor da soja MON 87701 $\times$ MON 89788 para o MIP da soja no Brasil. 


\subsection{Conclusões}

- A proteína inseticida Cry1Ac é mais ativa para A. gemmatalis do que para $P$. includens.

- A soja MON $87701 \times$ MON 89788 expressa a proteína Cry1Ac em alta dose para o MRI de A. gemmatalis e muito próximo à alta dose para o MRI de $P$. includens.

- A soja MON $87701 \times$ MON 89788 é de alta eficácia no controle das pragas-alvo primárias, A. gemmatalis e $P$. includens.

\section{Referências}

ABBOTT, W.S. A method of computing the effectiveness of an insecticide. Journal of Economic Entomology, Lanham, v. 18, n. 1, p. 265-266, 1925.

ALI, M.I.; YOUNG, S.Y. Activity of Bacillus thuringiensis Berliner against different ages and stages of Helicoverpa zea (Lepidoptera: Noctuidae) on cotton. Journal of Entomological Science, Tifton, v. 31, p. 1-8, 1996.

ALI, M.I.; LUTTRELL, R.G.; YOUNG, S.Y. Susceptibilities of Helicoverpa zea and Heliothis virescens (Lepidoptera: Noctuidae) populations to Cry1 Ac insecticidal protein. Journal of Economic Entomology, Lanham, v. 99, n. 1, p. 64-175, 2006.

ALI, M.I.; LUTTRELL, R.G. Response estimates for assessing Heliothine susceptibility to $B t$ toxins. Journal of Economic Entomology, Lanham, v. 102, n. 5, p. 935-1947, 2009.

ANDOW, D.A. The risk of resistance evolution in insects to transgenic insecticidal crops. Collection of Biosafety Reviews, Trieste, v. 4, p. 142-199, 2008.

BAI, C.; DEGHEELE, D.; JANSENS, S.; LAMBERT, B. Activity of insecticidal crystal proteins and strains of Bacillus thuringiensis against Spodoptera exempta (Walker). Journal of Invertebrate Pathology, San Diego, v. 62, n. 3, p. 211-215, 1993.

BLANCO, C.A.; GOULD, F.; VEGA-AQUINO, P.; JURAT-FUENTES, J.L.; PERERA, O.P.; ABEL, C.A. Response of Heliothis virescens (Lepidoptera: Noctuidae) strains to Bacillus thuringiensis Cry1Ac incorporated into different insect artificial diets. Journal of Economic Entomology, Lanham, v. 102, n. 4, p. 1599-1606, 2009.

BOBROWSKI, V.L.; PASQUALI, G.; BODANESE-ZANETTINI, M.H.; PINTO, L.M.N.; FIUZA, L.M. Characterization of two Bacillus thuringiensis isolates from South Brazil and their toxicity against Anticarsia gemmatalis (Lepidoptera : Noctuidae). Biological Control, Orlando, v. 25, n. 2, p. 129-135, 2002. 
CAPRIO, M.A.; SUMMERFORD, D.V.; SIMS, S.R. Evaluating transgenic plants for suitability in pest and resistance management programs. In: LACEY, L.A.; KAYA, H.K. (Ed.). Field manual of techniques in invertebrate pathology. Dordrecht: Kluwer Academic, 2000. cap. 8, p. 805-828.

CTNBIO, Comissão Técnica Nacional de Biossegurança. Liberação comercial de soja geneticamente modificada resistente a insetos e tolerante a herbicida, soja MON 87701 $\times$ MON 89788. In: Parecer Técnico $n^{\circ}$ 2542/2010. Disponível em:

<http://www.ctnbio.gov.br/index.php/content/view/15558.html>. Acesso em: 15 dez. 2010.

DULMAGE, H.T.; GRAHAM, H.M.; MARTINEZ, E. Interactions between the tobacco budworm, Heliothis virescens, and the $\alpha$-endotoxin produced by the HD-1 isolate of Bacillus thuringiensis var. kurstaki: relationship between length of exposure to the toxin and survival. Journal of Invertebrate Pathology, San Diego, v.32, n.1, p.40-50, 1978.

FIFRA SCIENTIFIC ADVISORY PANEL. Transmittal of the final report of the FIFRA Scientific Advisory Panel subpanel on Bacillus thuringiensis (Bt) plant-pesticides and resistance management. 9-10 February 1998. Docket $\mathrm{N}^{\mathrm{O}}$. OPPTS-00231:59, 1998. Disponível em: <http://www.mindfully.org/GE/FIFRA-SAP-Bt.htm>. Acesso em: 15 mar. 2008.

FISCHHOFF, D.A.; PERLAK, F.J. Synthetic plant genes. U.S. Patent 5-500-365, 1995.

GAMUNDI, J.C.; RIART, S.M.; MACRAE, T.C.; ZAMPIERIN, S. Geographic variation in susceptibility of Epinotia aporema (Lepidoptera: Olethreutidae) and Rachiplusia nu (Lepidoptera: Noctuidae) to Bacillus thuringiensis toxin Cry1Ac in Argentina. In: WORLD SOYBEAN RESEARCH CONGRESS,7., 2004. Iguassu Falls. Proceedings...Iguassu Falls, Brazil, 2004. March 1-6, p. 56.

GOULD F. Potential and problems with high-dose strategies for pesticidal engineered crops. Biocontrol Science and Technology, Oxford, v. 4, n. 4, p. 451-461, 1994.

GOULD F. Sustainability of transgenic insecticidal cultivars: integrating pest genetics and ecology. Annual Review of Entomology, Standfort, v. 43, p. 701-26, 1998.

GREENE, G.L.; LEPPLA, N.C.; DICKERSON, W.A. Velvetbean caterpillar: a rearing procedure and artificial medium. Journal of Economic Entomology, Lanham, v. 69, n. 4, p. 488-497, 1976.

HOMRICH, M.S.; PASSAGLIA, L.M.P.; PEREIRA, J.F.; BERTAGNOLLI, P.F.; PASQUALI G.; ZAIDI, M.A.; ALTOSAAR, I.; BODANESE-ZANETTINI, M.H. Resistance to Anticarsia gemmatalis Hübner (Lepidoptera, Noctuidae) in transgenic soybean (Glycine $\max ($ L.) Merrill Fabales, Fabaceae) cultivar IAS5 expressing a modified Cry1Ac endotoxin. Genetics and Molecular Biology, Ribeirão Preto, v. 31, n. 2, p. 522-531, $2008 \mathrm{a}$.

HOMRICH, M.S.; PASSAGLIA, L.M.P.; PEREIRA, J.F.; BERTAGNOLLI, P.F.; SALVADORI, JR.; NICOLAU, M.; KALTCHUK-SANTOS, E.; ALVES, L.B.; BODANESE-ZANETTINI, M.H. Agronomic performance, chromosomal stability and resistance to velvetbean caterpillar of transgenic soybean expressing crylAc gene. Pesquisa Agropecuária Brasileira, Brasília, v. 43, n. 7, p. 801-807, 2008b. 
HUANG, F.; ANDOW, D.A.; BUSCHMAN, L.L. Success of the high-dose/refuge resistance management strategy after 15 years of $B t$ crop use in North America. Entomologia Experimentalis et Applicata, Dordrecht, v. 140, n. 1, p. 1-16, 2011.

LUTTRELL R.G.; WAN L.; KNIGHTEN K. Variation in susceptibility of Noctuid (Lepidoptera) larvae attacking cotton and soybean to purified endotoxin proteins and commercial formulations of Bacillus thuringiensis. Journal of Economic Entomology, Lanham, v. 92, n. 1, p. 21-32, 1999.

MACRAE, T.C.; BAUR, M.E.; BOETHEL, D.J.; FITZPATRICK, B.J.; GAO, A.G.; GAMUNDI, J.C.; HARRISON, L.A.; KABUYE, V.T.; MCPHERSON, R.M.; MIKLOS, J.A.; PARADISE, M.S.; TOEDEBUSCH, A.S.; VIEGAS, A. Laboratory and field evaluations of transgenic soybean exhibiting high dose expression of a synthetic Bacillus thuringiensis crylA gene for control of Lepidoptera. Journal of Economic Entomology, Lanham, v. 98, n. 2, p. 577-587, 2005.

MASCARENHAS, R.N.; BOETHEL, D.J.; LEONARD, B.R.; BOYD, M.L.; CLEMENS, C.G. Resistance monitoring to Bacillus thuringiensis for soybean loopers (Lepidoptera: Noctuidae) collected from soybean and transgenic Bt-cotton. Journal of Economic Entomology, Lanham, v. 91, n. 5, p. 1044-1050, 1998.

MCPHERSON, R.M.; MACRAE, T.C. Evaluation of transgenic soybean exhibiting high expression of a synthetic Bacillus thuringiensis crylA transgene for suppressing lepidopteran population densities and crop injury. Journal of Economic Entomology, Lanham, v. 102, n. 4, p. 1640-1648, 2009.

MIKLOS, J.A.; ALIBHAI, M.F.; BLEDING, S.A.; CONNOR-WARD, D.C.; GAO, A.; HOLMES, B.A.; KOLACZ, K.H.; KABUYE, V.T.; MACRAE, T.C.; PARADISE, M.S.; TOEDEBUSCH, A.S.; HARRISON, L.A. Characterization of soybean exhibiting high expression of a synthetic Bacillus thuringiensis crylA transgene that confers a high degree of resistance to lepidopteran pests. Crop Science, Washington, v. 47, n. 1, p. 148-157, 2007.

MORALES, L.; MOSCARDI, F.; KASTELIC, J.G.; SOSA-GÓMEZ, D.R.; PARO, F.E.; SOLDORIO, E.I.L. Suscetibilidade de Anticarsia gemmatalis Hübner e Chrysodeixis includens (Walker) (Lepidoptera: Noctuidae), a Bacillus thuringiensis Berliner. Annais da Sociedade Entomológica do Brasil, Londrina, v. 24, n. 3, p. 593-598, 1995.

MOSCARDI, F. Assessment of the application of baculoviruses for control of Lepidoptera. Annual Review of Entomology, Standford, v. 44, p. 257-289, 1999.

PARROTT, W.A.; ALL, J.N.; ADANG, M.J.; BAILEY, M.A.; BOERMA, H.R.; STEWART C.N. Recovery and evaluation of soybean plants transgenic for a Bacillus thuringiensis var. kurstaki insecticidal gene. In Vitro Cellular \& Developmental Biology, Columbia, v. 30P, n. 4, p. 144-149, 1994.

SAS INSTITUTE INC. 2000. SAS/STAT: Statistical Analysis System: getting started with the SAS learning. Version 9.1. Cary, NC: SAS Institute, 2000.

SAS INSTITUTE INC. 2010. SAS JMP: Introductory guide, Version 9.0. Cary, NC: SAS Institute, 2010. 
SIMS, S.R.; GREENPLATE, J.T.; STONE, T.B.; CAPRIO, M.A.; GOULD, F.L. Monitoring strategies for early detection of Lepidoptera resistance to Bacillus thuringiensis insecticidal proteins. In: BROWN T.M. (Ed). Molecular genetics and evolution of pesticide resistance. Washington: American Chemical Society, 1996. cap. 23 p. 229-242.

STEWART, C.N.; ADANG, M.J.; ALL, J.N.; BOERMA, H.R.; CARDINEAU, G; TUCKER, D.; PARROTT, W.A. Genetic transformation, recovery, and characterization of fertile soybean transgenic for a synthetic Bacillus thuringiensis cryIAc gene. Plant Physiology, Washington, v. 112, n. 1, p. 121-129, 1996.

TABASHNIK, B.E.; GOULD, F.; CARRIÈRE, Y. Delaying evolution of insect resistance to transgenic crops by decreasing dominance and heritability. Journal of Evolutionary Biology, Basel, v. 17, n. 4, p. 904-912, 2004.

TABASHNIK, B.E.; VAN RENSBURG, J.B.J.; CARRIÈRE, Y. Field-evolved insect resistance to $B t$ crops: Definition, theory and data. Journal of Economic Entomology, Lanham, v. 102, n. 6, p. 2011-2025, 2009.

WALKER, D.R.; ALL, J.N.; MCPHERSON R.M.; BOERMA H.R.; PARROTT, W.A. Field evaluation of soybean engineered with a synthetic crylAc transgene for resistance to corn earworm, soybean looper, velvetbean caterpillar (Lepidoptera: Noctuidae) and lesser cornstalk borer (Lepidoptera: Pyralidae). Journal of Economic Entomology, Lanham, v. 93, n. 3, p. 613-622, 2000.

WILLSON, H.R. Soybean insect defoliation assessment. The Ohio State University Extension, OPMS, Circular FC-22. Disponível em: <http://www.ag.ohiostate.edu/ ohioline/icm-fact/fc-22.html>. Acesso em: 15 mar. 2009. 


\title{
4 ATIVIdAde BIOLÓgICA DA PROTEÍNA Cry1Ac EXPRESSA EM SOJA MON $87701 \times$ MON 89788 CONTRA Heliothis virescens NO BRASIL
}

\section{Resumo}

No Brasil, Heliothis virescens (Fabricius) é uma praga-chave do algodão, Gossypium hirsutum L.. Entretanto, nos últimos anos, $H$. virescens tem ocasionado danos severos na cultura da soja, Glycine max (L.) Merrill. Nesse cenário, a soja MON 87701 × MON 89788 que expressa genes que codificam a proteína Cry1Ac de Bacillus thuringiensis var. kurstaki Berliner, pode ser uma ferramenta de controle de H. virescens. Para subsidiar programas de Manejo da Resistência de Insetos (MRI) avaliou-se a atividade biológica da proteína Cry1Ac expressa em soja MON $87701 \times$ MON 89788 contra $H$. virescens. A proteína Cry1Ac purificada incorporada à dieta artificial apresentou elevada atividade biológica para $H$. virescens $\left[\mathrm{CL}_{50}(\mathrm{IC} 95 \%)=0,026(0,021-0,033) \mu \mathrm{g}\right.$ de Cry1 Ac/mL de dieta]. Em bioensaios com tecido liofilizado da soja MON $87701 \times$ MON 89788, diluído 25 vezes em dieta artificial, ocasionou $100 \%$ de mortalidade de $H$. virescens. A eficácia da soja MON $87701 \times$ MON 89788 contra $H$. virescens foi confirmada em bioensaios com discos de folha, trifólios e vagens. Portanto, soja MON $87701 \times$ MON 89788 pode ser considerada um evento de alta eficácia e de alta dose para $H$. virescens. Porém, existe a necessidade implementação de estratégias de MRI para preservar a durabilidade dessa tecnologia.

Palavras-chave: Soja transgênica; Lagarta-das-maçãs; Alta dose; Manejo da Resistência de Insetos

\begin{abstract}
In Brazil, Heliothis virescens (Fabricius) is a key pest of cotton, Gossypium hirsutum L.. However, in recent years, $H$. virescens has caused severe damage to soybean, Glycine max (L.) Merrill. Therefore, MON $87701 \times$ MON 89788 soybean expressing genes that code for the Cry1Ac protein from Bacillus thuringiensis var. kurstaki Berliner can be an important tool for controlling $H$. virescens. In order to implement Insect Resistance Management (IRM) programs, we evaluated the biological activity of Cry1Ac protein expressed in MON $87701 \times$ MON 89788 soybean against $H$. virescens. The Cry1Ac purified protein incorporated into artificial diet showed high biological activity for $H$. virescens $\left[\mathrm{LC}_{50}(95 \% \mathrm{FL})=0.026(0.021\right.$ - 0.033) of Cry1Ac $\mathrm{mg} / \mathrm{mL}$ of diet]. In bioassays with freeze-dried tissue of soybean MON $87701 \times$ MON 89788, diluted 25 times in artificial diet, there was $100 \%$ mortality of $H$. virescens. The high efficacy of MON $87701 \times$ MON 89788 soybean against $H$. virescens was confirmed in bioassays with leaf discs, trifoliate leaves and pods. Therefore, the MON 87701 $\times$ MON 89788 soybean can be considered an event of high efficacy and high dose to $H$. virescens. However, there is a need for an effective implementation of IRM strategies to preserve the durability of this technology.
\end{abstract}

Keywords: Transgenic soybean; Tobacco budworm; High-dose; Insect Resistance Management 


\subsection{Introdução}

No Brasil, a cultura da soja Glycine max (L.) Merrill (Fabaceae: Phaseoleae) tem como principais insetos desfolhadores a lagarta-da-soja, Anticarsia gemmatalis Hübner e a lagarta-falsa-medideira, Pseudoplusia includens (Walker). Entretanto, nos últimos anos, um dos principais insetos-praga da cultura do algodão, a lagarta-das-maçãs, Heliothis virescens (Fabricius) se tornou um sério problema fitossanitário em soja com ataques severos em áreas de produção de soja no Brasil. Os adultos de $H$. virescens concentram a oviposição nos trifólios da soja em início da expansão foliar. No entanto, após a eclosão, as lagartas além de danificar as folhas, também atacam estruturas de reprodução como flores e vagens, nas quais se abrigam, dificultando a amostragem por meio de "pano-de-batida", comumente utilizado para levantamento populacional de lagartas em soja, prejudicando a estimativa de infestação e a tomada de decisão para o controle (TOMQUELSKI; MARUYAMA, 2009).

Em soja, $H$. virescens tem sido controlada por inseticidas, muitas vezes direcionados ao controle da lagarta-da-soja e da lagarta-falsa-medideira. No entanto, devido a sua importância recente em soja, especificamente para o controle de $H$. virescens, até o momento, não há nenhum inseticida registrado no Ministério da Agricultura, Pecuária e Abastecimento (MAPA) para controle desse inseto-praga na cultura da soja no Brasil. Por outro lado, na cultura do algodão, $H$. virescens tem sido eficientemente controlada por eventos de algodão que expressam a proteína Cry1Ac de Bacillus thuringiensis Berliner (Bt) (SIEBERT et al., 2008; SIVASUPRAMANIAM et al., 2008).

No Brasil, em 2010 houve a liberação para cultivo comercial da primeira variedade de soja geneticamente modificada resistente a insetos e tolerante ao glifosato ( evento MON $87701 \times$ MON 89788$)($ CTNBio, 2010). A soja MON $87701 \times$ MON 89788 expressa genes que codificam a produção da proteína inseticida Cry1Ac de $B t$, que tem como pragas-alvo primárias A. gemmatalis e $P$. includens e, a proteína 5-enolpiruvilchiquimato-3-fosfato sintase (EPSPS) de Agrobacterium sp. que confere tolerância ao glifosato. Embora, H. virescens seja considerada praga-alvo secundária da soja MON $87701 \times$ MON 89788 essa tecnologia se apresenta como uma alternativa promissora para o MIP desse inseto-praga em soja, uma vez que H. virescens tem demonstrado alta suscetibilidade a Cry1 Ac (ALI et al., 2006; BLANCO et al., 2009a; ALI; LUTTRELL, 2009).

No Brasil, a sobreposição e/ou sucessão dos cultivos de algodão e soja expõe as populações de $H$. virescens à intensa pressão de seleção pela proteína Cry1Ac, aumentando o risco de seleção de indivíduos resistentes. A evolução da resistência de $H$. virescens a Cry1Ac 
foi reportada para uma linhagem de laboratório da praga (YHD-2), a qual apresentou razão de resistência > 10.000 vezes, após 19 gerações de pressão de seleção com Cry1Ac incorporada em dieta artificial (GOULD et al., 1995). Para outra linhagem de H. virescens (KCB) a razão de resistência a Cry1Ac foi de $\approx 400$ vezes (FORCADA et al., 1999). Adicionalmente, estudos de estimativa da frequência inicial de alelos que conferem resistência de $H$. virescens a Cry1Ac nos EUA, constataram uma frequência inicial relativamente alta de $1,5 \times 10^{-3}$ (GOULD et al., 1997) e de 0,0036 a 0,0263 (BLANCO et al., 2009b), evidenciando a possibilidade de rápida evolução da resistência a campo, caso estratégias de Manejo da Resistência de Insetos (MRI) não sejam implementadas. Diante da possibibilidade de evolução de resistência de $H$. virescens a Cry1Ac expressa em soja MON $87701 \times$ MON 89788, é de extrema importância o estabelecimento de estratégias de MRI para esse insetopraga.

O estabelecimento de estratégias de MRI não é um condicionante para a aprovação de plantas $B t$ no Brasil. No entanto, esse é um dos aspectos que tem recebido muita atenção de acadêmicos e especialistas da indústria na formulação de estratégias para impedir ou retardar a evolução da resistência de insetos a proteínas de $B t$ expressas em plantas transgênicas (TABASHNIK; GOULD; CARRIÈRE, 2004). Dentre as estratégias de MRI a culturas que expressam uma única proteína de $B t$, como a soja MON $87701 \times$ MON 89788, uma das principais tem sido a estratégia de alta dose + áreas de refúgio (GOULD, 1994; FIFRA SCIENTIFIC ADVISORY PANEL, 1998; TABASHNIK; VAN RENSBURG; CARRIÈRE, 2009; HUANG; ANDOW; BUSCHMAN, 2011). De um ponto de vista operacional, planta de alta dose é aquela que expressa a proteína inseticida em concentração que é igual ou superior a 25 vezes a concentração letal que correspondente à mortalidade de $99 \%$ da população da praga-alvo (FIFRA SCIENTIFIC ADVISORY PANEL, 1998; CAPRIO; SUMMERFORD; SIMS, 2000; ANDOW, 2008). A expressão da proteína inseticida em alta dose torna qualquer alelo de resistência, nas populações das pragas-alvo, funcionalmente recessivo, e com o fornecimento de genótipos suscetíveis pelas áreas de refúgio impedindo o acasalamento entre os raros homozigotos resistentes sobreviventes na cultura transgênica, a evolução da resistência pode ser retardada.

Nesse sentido, para subsidiar programas de MRI e entender o valor da soja MON $87701 \times$ MON 89788 para o MIP de H. virescens foram conduzidos estudos para caracterizar a atividade biológica da proteína Cry1Ac expressa em soja MON 87701 × MON 89788 contra H. virescens. 


\subsection{Material e métodos}

\subsubsection{Linha básica de suscetibilidade}

Para caracterização da atividade biológica da proteína Cry1Ac purificada utilizou-se uma população de $H$. virescens coletada em algodão, em Sapezal, Mato Grosso e mantida em laboratório por no mínimo 6 anos (população suscetível de referência). Para obtenção da linha básica de suscetibilidade, a proteína Cry1Ac purificada na concentração de 1,4 mg de Cry1Ac ativo/mL e pureza de $80 \%$, foi fornecida pela empresa Monsanto do Brasil Ltda e armazenada em ultra-frezer (temperatura $-80 \pm 5^{\circ} \mathrm{C}$ ). Após descongelamento, a proteína Cry1Ac foi diluída em solução tampão constituída de 50 mM Ácido 3-(Ciclohexilamino)-1Propanosulfônico (CAPS) à pH=10,25, $1 \mathrm{mM}$ Benzomidine-HCl, $1 \mathrm{mM}$ Ácido Etileno Diamino Tetra Acético (EDTA) e 2,5 mM de Ditiotreitol (DTT). Para os bioensaios, a proteína inseticida e a solução tampão foram adicionadas em dieta artificial à base de feijão branco, germe de trigo e caseína (Adaptada de Greene; Leppla; Dickerson, 1976) (Capítulo 3, Tabela 3.1), quando a temperatura da dieta atingiu $45-50^{\circ} \mathrm{C}$. A incorporação da proteína Cry1Ac em dieta artificial foi realizada por um agitador de tubos do tipo Vortex por no mínimo 2 minutos. Em seguida, a dieta contendo a proteína incorporada foi mantida em banho-maria $\mathrm{a} \approx 55^{\circ} \mathrm{C}$ para posterior distribuição nas bandejas de bioensaio (BIO-BA-128, CD International Inc., Pitman, NJ), contendo 128 células (1 mL de dieta/célula) com auxílio de uma pipeta de repetição e ponteira. Para cada espécie foram testadas de 5 a 8 concentrações de Cry1Ac e como testemunha, somente a solução tampão foi adicionada à dieta. Após a geleificação e esfriamento da dieta, com auxílio de um pincel fino foi inoculada uma neonata ( 0 - $24 \mathrm{~h}$ de idade) de $H$. virescens em cada célula. As bandejas foram vedadas com lâminas plásticas auto-adesivas (BIO-CV-16, CD International Inc.) que permite as trocas gasosas com o ambiente externo e acondicionadas em câmara climatizada (temperatura $27 \pm 1{ }^{\circ} \mathrm{C}$, umidade relativa $60 \pm 10 \%$ e fotoperíodo $14: 10 \mathrm{~h}$ luz:escuro). O delineamento experimental foi inteiramente casualizado, com 5 a 8 repetições por concentração (16 lagartas/repetição). A atividade biológica da proteína Cry1Ac foi avaliada após 7 dias considerando-se como critérios de resposta a mortalidade (sendo também consideradas mortas as lagartas que não ultrapassaram o primeiro ínstar) e o peso das lagartas sobreviventes. A partir dos dados de mortalidade e ínstar sobrevivente foi estimada a $\mathrm{CL}_{50}$ e $\mathrm{CL}_{90}$ (CL Concentração Letal) e $\mathrm{CIM}_{50}$ e $\mathrm{CIM}_{90}$ (Concentração que Inibe a Muda) e respectivos intervalos de confiança (IC 95\%) usando o procedimento Probit (PROC PROBIT, SAS 
INSTITUTE, 2000). Para obtenção da CL 99 , os dados de mortalidade foram submetidos ao modelo binomial com função de ligação complemento log-log (gompit) (SAS PROC PROBIT, SAS Institute, 2000). Para os dados de peso médio das lagartas sobreviventes foi realizada uma análise de regressão não-linear para estimação da $\mathrm{CE}_{50}$ e $\mathrm{CE}_{90}$ (CE Concentração Efetiva) e respectivos intervalos de confiança (IC 95\%) no software JMP SAS ${ }^{\circledR}$ (SAS INSTITUTE, 2010). Os modelos logísticos não-lineares utilizados para o cálculo de $\mathrm{CE}_{50}$ e $\mathrm{CE}_{90}$ foram os seguintes: peso $=\mathrm{Wo} /\left[1+\left(\text { dose }_{C} \mathrm{CE}_{50}\right)^{\mathrm{B}}\right](\mathrm{SIMS}$ et al. 1996) e peso $=$ Wo $/\left[1+\left(\text { dose }_{C} \mathrm{CE}_{50}\right)\right]^{\left[\ln 9 /\left(\ln \left(\mathrm{CE}_{50} / \mathrm{CE}_{90}\right)\right)\right]}(\mathrm{SIMS}$ et al. 1996) respectivamente.

\subsubsection{Bioensaios de alta dose}

Para avaliar a adequabilidade da soja MON $87701 \times$ MON 89788 ao conceito de alta dose foi realizada a semeadura da soja MON $87701 \times$ MON 89788 e soja isolinha não-Bt dos grupos de maturação 5.5 (recomendado para cultivo na região Sul do Brasil) e 8.3 (recomendado para cultivo na região Centro-Oeste do Brasil) a campo nas respectivas regiões de cultivo na densidade de 12 plantas/m linear. Após a emergência e antes da retirada de folhas para liofilização, uma folha de cada planta de soja MON $87701 \times$ MON 89788 e soja isolinha não- $B t$ foi macerada em tubo de 1,5 mL tipo Eppendorf ${ }^{\circledR} \mathrm{e}$, posteriormente, com uso de kit QuickStix ${ }^{\mathrm{TM}}$ AP checada para detecção da proteína Cry1Ac. Os bioensaios foram realizados com tecido vegetal liofilizado proveniente de quatro estádios fenológicos V2, V4, R2 e R4 que foi fornecido pela Monsanto do Brasil Ltda e, em laboratório, armazenado em ultra-freezer (temperatura $-80 \pm 5^{\circ} \mathrm{C}$ ). Posteriormente, o tecido liofilizado foi macerado com auxílio de almofariz e pistilo até a obtenção de um pó fino para posterior incorporação na dieta artificial. Para cada amostra de tecido liofilizado foi calculada a quantidade de matéria seca que iria resultar em uma diluição de 25 vezes (em relação ao tecido fresco) quando incorporado ( $\mathrm{mg}$ tecido/mL de dieta) em volume total igual a $20 \mathrm{~mL}$ de dieta artificial (Adaptada Greene; Leppla; Dickerson, 1976) (Capítulo 3, Tabela 3.1). Posteriormente, foi pesada a quantidade de tecido liofilizado calculada previamente sendo essa adicionada em dieta artificial $\mathrm{a} \approx 55^{\circ} \mathrm{C}$, em tubos graduados de polipropileno (Corning ${ }^{\circledR}$ ) e, incorporado por meio de um agitador de tubos do tipo Vortex por no mínimo 2 minutos. Em seguida, a dieta contendo o tecido liofilizado incorporado foi mantida em banho-maria $\mathrm{a} \approx 55^{\circ} \mathrm{C}$ para posterior distribuição em bandejas de bioensaio (BIO-BA-128, CD International Inc., Pitman, NJ), contendo 128 células ( $1 \mathrm{~mL}$ de dieta/célula) com auxílio de pipeta de repetição e ponteira. Após a geleificação e esfriamento da dieta, em cada célula, com auxílio de um pincel fino foi 
inoculada uma lagarta neonata (0 - $24 \mathrm{~h}$ de idade) de H. virescens. As bandejas foram vedadas com lâminas plásticas auto-adesivas (BIO-CV-16, CD International Inc.) que permitem as trocas gasosas com o ambiente externo e acondicionadas em câmara climatizada (temperatura $27 \pm 1^{\circ} \mathrm{C}$, umidade relativa $60 \pm 10 \%$ e fotoperíodo $14: 10 \mathrm{~h}$ luz:escuro). Para cada estádio fenológico e praga-alvo foram realizadas 16 repetições por tratamento (16 neonatas/repetição), totalizando $\approx 250$ neonatas testadas por tratamento, estádio fenológico e praga-alvo. Aos 7 dias após da infestação avaliou-se a mortalidade, peso e ínstar das lagartas sobreviventes. As lagartas sem movimento aparente após leve toque com estilete foram consideradas mortas. Os dados de mortalidade e enfezamento das lagartas sobreviventes nas repetições experimentais com tecido liofilizado de soja MON $87701 \times$ MON 89788 foram corrigidos com a soja isolinha não-Bt (ABBOTT, 1925).

\subsubsection{Bioensaios com discos de folha, trifólios e vagens}

Em casa de vegetação foi realizada a semeadura da soja MON $87701 \times$ MON 89788 e soja isolinha não- $B t$ dos grupos de maturação 5.5 e 8.3 na densidade de 12 plantas/m linear. Quando as plantas atingiram os estádios fenológicos V3-V4, V5-V6, R1-R2 e R3-R4 foram retiradas folhas completamente expandidas do terço superior e, em laboratório, com auxílio de um vasador metálico foram obtidos discos de folha de $1,2 \mathrm{~cm}$ de diâmetro. Os trifólios em fase inicial de expansão foliar (bordas se encostando) foram retirados de plantas nos estádio fenológicos V5-V6 e R1-R2. Por sua vez, as vagens foram retiradas do terço superior da plantas de soja quando essas atingiram o estádio fenológico R4. Os discos de folha, trifólios e vagens foram acondicionados sobre uma mistura não geleificada de Ágar-água a 2,5\% (1 $\mathrm{mL} /$ célula) em placas de acrílico $\left(\right.$ Costar $\left.^{\circledR}\right)$ com 24, 12 e 6 células, respectivamente, sendo essas estruturas vegetativas separadas da camada Ágar-água por um disco de papel filtro. Posteriormente, em cada disco de folha, trifólio e vagem foram inoculadas 1 , 3 e 3 neonatas ( 0 - $24 \mathrm{~h}$ de idade) de H. virescens, respectivamente. As placas foram vedadas com filme plástico (Magipack ${ }^{\circledR}$ ) e, em seguida pela tampa da placa, sendo acondicionadas em câmara climatizada (temperatura de $27 \pm 1{ }^{\circ} \mathrm{C}$, umidade relativa $60 \pm 10 \%$ e fotoperíodo $14: 10 \mathrm{~h}$ luz:escuro). Em todos os bioensaios, o delineamento experimental foi inteiramente casualizado com 5, 4 e 7 repetições por tratamento, sendo cada repetição constituída de 24, 36 e 18 neonatas no bioensaios com discos de folha, trifólios e vagens, respectivamente. Aos 4 dias após a infestação dos discos de folha, trifólios e vagens avaliou-se a mortalidade das lagartas. Adicionalmente, avaliou-se o dano de $H$. virescens a cada disco de folha, mediante 
comparação a uma escala de dano (Tabela 4.1). A mortalidade nos tratamentos com soja MON $87701 \times$ MON 89788 foi corrigida a partir da respectiva isolinha não-Bt (ABBOTT, 1925). Os dados de mortalidade e danos aos discos de folha $(x)$ foram transformados em $\sqrt{x+0,5}$ e $\sqrt{x+0,1}$, respectivamente. Em seguida, os dados foram submetidos à análise de variância e as médias comparadas pelo teste $t(P \leq 0,05)$ (PROC TTEST, SAS INSTITUTE, 2000).

Tabela 4.1 - Escala de avaliação de danos de H. virescens aos discos de folha de soja MON $87701 \times$ MON 89788

\begin{tabular}{cr}
\hline Escala & Dano \\
\hline 0 & 1 a $5 \%$ da área do disco foliar consumida ou danificada. \\
2 & $>5$ a $10 \%$ da área do disco foliar consumida ou danificada. \\
3 & $>10$ a $15 \%$ da área do disco foliar consumida ou danificada. \\
4 & $>15$ a $20 \%$ da área do disco foliar consumida ou danificada. \\
5 & $>20$ a $25 \%$ da área do disco foliar consumida ou danificada. \\
6 & $>25$ a $30 \%$ da área do disco foliar consumida ou danificada. \\
7 & $>30$ a $35 \%$ da área do disco foliar consumida ou danificada. \\
8 & $>35$ a $40 \%$ da área do disco foliar consumida ou danificada. \\
9 & $>40$ a $45 \%$ da área do disco foliar consumida ou danificada. \\
10 & $>45$ a $50 \%$ da área do disco foliar consumida ou danificada. \\
11 & $>50 \%$ da área do disco foliar consumida ou danificada. \\
\hline
\end{tabular}

\subsection{Resultados}

\subsubsection{Linha básica de suscetibilidade}

A praga-alvo secundária da soja MON $87701 \times$ MON 89788, H. virescens foi extremamente suscetível à proteína Cry1Ac de B. thuringiensis. Para a concentração letal (CL) foram observadas repostas a partir de 0,001 $\mu \mathrm{g}$ Cry1Ac/mL de dieta e mortalidade completa a partir da concentração de $0,56 \mu \mathrm{g}$ Cry $1 \mathrm{Ac} / \mathrm{mL}$ de dieta (Tabela 4.2 e Figura 4.1). Em relação à concentração que inibe a muda (CIM) verificou-se que 0,021 e 0,106 $\mu \mathrm{g}$ Cry $1 \mathrm{Ac} / \mathrm{mL}$ dieta foram suficientes para inibir em 50 e $90 \%$ o progresso das lagartas do $1^{\circ}$ para o $2^{\circ}$ ínstar, respectivamente (Tabela 4.3). Para a concentração efetiva (CE), houve 
elevada inibição do desenvolvimento de $H$. virescens, com $90 \%$ de redução do peso larval na concentração de 0,0038 $\mu \mathrm{g}$ Cry1 Ac/mL de dieta (Tabela 4.3).

Tabela 4.2 - Concentração letal $\left(\mathrm{CL}^{(1)} ; \mu \mathrm{g}\right.$ Cry1 Ac/mL de dieta) de neonatas de H. virescens expostas à proteína Cry1 Ac purificada de B. thuringiensis incorporada em dieta artificial

\begin{tabular}{ccccccc}
\hline Praga-alvo & $n^{(2)}$ & $\begin{array}{c}\text { Coeficiente } \\
\text { Angular ( } \pm \text { EP })\end{array}$ & $\begin{array}{c}\mathrm{CL}_{50} \\
(\mathrm{IC} 95 \%)\end{array}$ & $\begin{array}{c}\mathrm{CL}_{90} \\
(\mathrm{IC} 95 \%)\end{array}$ & $\chi^{2}$ & g.l. $^{(3)}$ \\
\hline Heliothis virescens & 955 & $1,98( \pm 0,14)$ & $\begin{array}{c}0,026 \\
(0,021-0,033)\end{array}$ & $\begin{array}{c}0,145 \\
(0,115-0,184)\end{array}$ & 9,96 & 8 \\
\hline
\end{tabular}

${ }^{(1)} \mathrm{CL}_{50}$ : concentração letal de Cry1 Ac $(\mu \mathrm{g} / \mathrm{mL}$ de dieta) que mata $50 \%$ das larvas testadas no período de observação de 7 dias. Similarmente, $\mathrm{CL}_{90}$ é a concentração de Cry1 Ac requerida para matar $90 \%$ das larvas testadas.

(2) número total de insetos testados.

${ }^{(3)}$ graus de liberdade.

Tabela 4.3 - Concentração que inibe a muda $\left(\mathrm{CIM}^{(1)} ; \mu \mathrm{g}\right.$ Cry1 Ac/mL de dieta) e concentração efetiva $\left(\mathrm{CE}^{(2)} ; \mu \mathrm{g}\right.$ Cry1 Ac/mL de dieta) que inibe o desenvolvimento de neonatas de $H$. virescens expostas à proteína Cry1Ac purificada de B. thuringiensis incorporada em dieta artificial

\begin{tabular}{cccccc}
\hline Praga-alvo & $n^{(3)}$ & $\begin{array}{c}\mathrm{CIM}_{50} \\
(\mathrm{IC} \mathrm{95 \% )}\end{array}$ & $\begin{array}{c}\mathrm{CIM}_{90} \\
(\mathrm{IC} 95 \%)\end{array}$ & $\begin{array}{c}\mathrm{CE}_{50} \\
(\mathrm{IC} \mathrm{95 \% )}\end{array}$ & $\begin{array}{c}\mathrm{CE}_{90} \\
(\mathrm{IC} 95 \%)\end{array}$ \\
\hline Heliothis & 536 & 0,021 & 0,106 & 0,00088 & 0,0038 \\
virescens & & $(0,014-0,029)$ & $(0,070-0,198)$ & $(0,00068-0,00108)$ & $(0,0033-0,0044)$ \\
\hline
\end{tabular}

${ }^{(1)} \mathrm{CIM}_{50}$ : Concentração de Cry1 Ac ( $\mu \mathrm{g} / \mathrm{mL}$ de dieta) que inibe a muda do I para o II ínstar de $50 \%$ larvas testadas no período de observação de 7 dias. Similarmente, CIM $_{90}$ é a concentração de Cry1 Ac que inibe a muda de $90 \%$ das larvas testadas.

${ }^{(2)} \mathrm{CE}_{50}$ : Concentração efetiva de Cry1 $\mathrm{Ac}(\mu \mathrm{g} / \mathrm{mL}$ de dieta) que causa $50 \%$ de inibição de desenvolvimento larval no período de observação de 7 dias. Similarmente, $\mathrm{CE}_{90}$ é a concentração efetiva de Cry1 Ac requerida para inibir $90 \%$ do desenvolvimento larval.

${ }^{(3)}$ número total de insetos testados.

A partir dos dados de concentração-mortalidade foi estimada a CL99 (IC 95\%) =0,40 $(0,30$ - 0,60) $\mu \mathrm{g}$ Cry1 Ac/mL de dieta. Com base na CL99 foram definidas as concentrações diagnósticas potenciais de $0,56 \mu \mathrm{g}$ de Cry $1 \mathrm{Ac} / \mathrm{mL}$ de dieta (valor dentro do IC (95\%) da $\left.\mathrm{CL}_{99}\right)$ e $1,0 \mu \mathrm{g}$ de $\mathrm{Cry} 1 \mathrm{Ac} / \mathrm{mL}$ de $\operatorname{dieta}\left(\approx 2\right.$ vezes a $\left.\mathrm{CL}_{99}\right)$ para o monitoramento da suscetibilidade de populações de $H$. virescens que infestam a cultura da soja. As duas concentrações diagnósticas potenciais ocasionaram 100\% de mortalidade nos bioensaios de concentração-resposta para a caracterização da linha básica de suscetibilidade (Figura 4.1). 


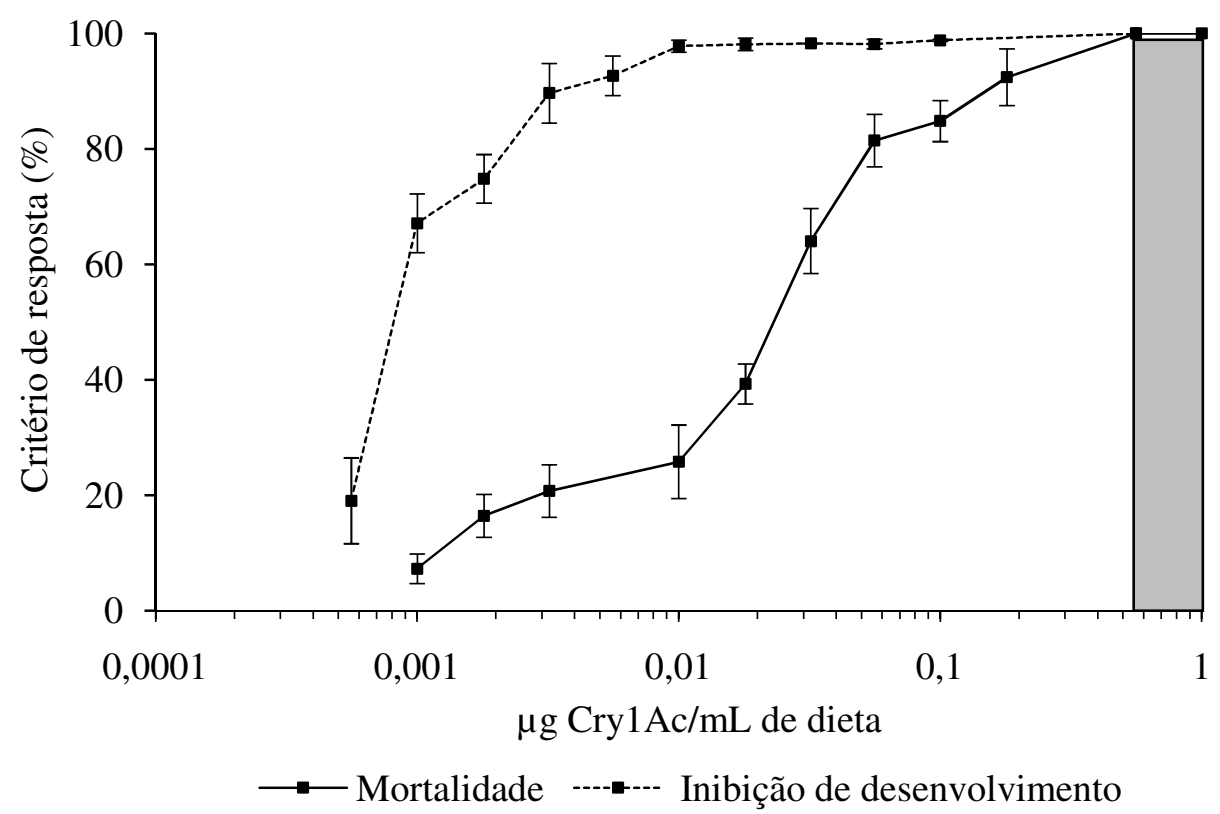

Figura 4.1 - Mortalidade e inibição do desenvolvimento de neonatas de $H$. virescens expostas à proteína Cry1Ac purificada de B. thuringiensis incorporada em dieta artificial. A área hachurada indica a faixa de concentrações diagnósticas sugeridas para programas de monitoramento da resistência

\subsubsection{Bioensaios de alta dose}

O tecido liofilizado da soja MON $87701 \times$ MON 89788 dos grupos de maturação 5.5 e 8.3 quando incorporado à dieta artificial, em diluição de 25 vezes, ocasionou $100 \%$ de mortalidade de $H$. virescens em todos os estádios fenológicos avaliados (Figura 4.2). Em contraste, o tecido liofilizado da soja isolinha não-Bt ocasionou baixa mortalidade, variando de 3,03 a 9,95\% em ambos os grupos de maturação e estados fenológicos. Em consequência da mortalidade completa, o enfezamento de neonatas de $H$. virescens em dieta artificial contendo tecido liofilizado de soja MON $87701 \times$ MON 89788 também foi de 100\% (Figura 4.2). Por outro lado, o tecido liofilizado de soja isolinha não- $B t$ ocasionou enfezamento inferior a $10 \%$ em ambos os grupos de maturação e estados fenológicos avaliados. Em outras palavras, a maioria das lagartas expostas ao tecido liofilizado de soja isolinha não-Bt, após 7 dias, ultrapassaram o $2^{\circ}$ ínstar larval. 
(A)

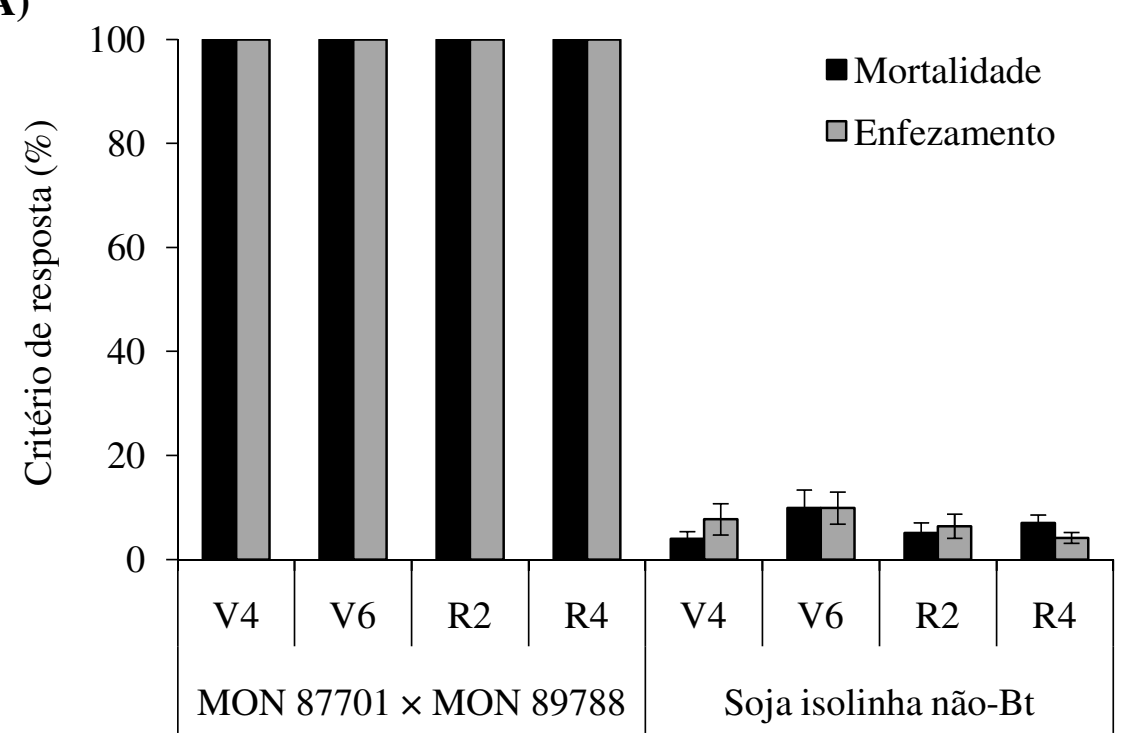

(B)

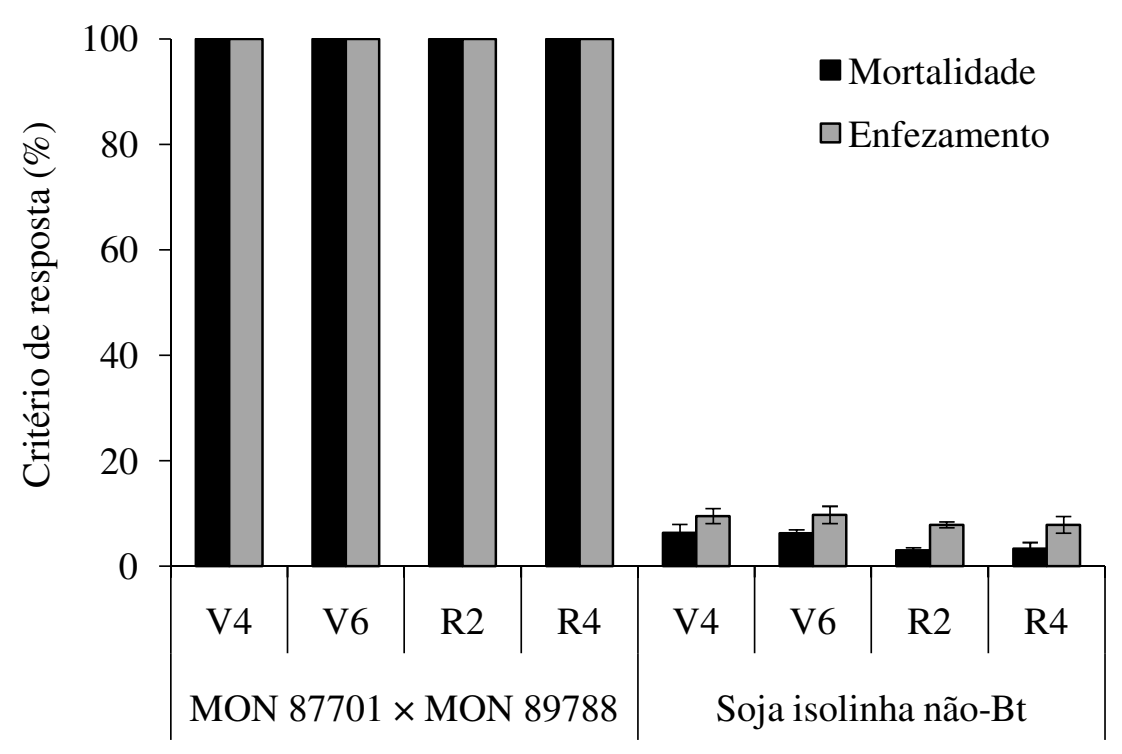

Figura 4.2 - Porcentagem de mortalidade e enfezamento (não atingiram terceiro ínstar) de neonatas de $H$. virescens após 7 dias em dieta artificial contendo tecido liofilizado de soja MON 87701 × MON 89788 do grupo de maturação 5.5 (A) e 8.3 (B) e soja isolinha não-Bt em diluição de 25 vezes relativo ao tecido foliar fresco. Valores representam médias \pm EP após correção com o tecido liofilizado da soja isolinha não- $B t$

\subsubsection{Bioensaios com discos de folha, trifólios e vagens}

As neonatas de $H$. virescens foram extremamente suscetíveis à dose da proteína Cry1Ac expressa em folhas de soja MON $87701 \times$ MON 89788 dos grupos de maturação 5.5 e 8.3 (Tabela 4.4). Aos 4 dias após a infestação, houve 100\% de mortalidade de $H$. virescens em discos de folha de soja MON $87701 \times$ MON 89788, sendo a mortalidade 
significativamente maior daquela verificada na soja isolinha não- $B t$ dos grupos de maturação 5.5 nos estádios V3-V4 $(t=5,69 ;$ g.1. $=1,8 ; P<0,0001)$, V5-V6 $(t=5,16 ;$ g.1. $=1,8 ; P<$ 0,0001), R1-R2 $(t=5,40 ;$ g.1. $=1,8 ; P<0,0001)$ e R3-R4 $(t=2,79 ;$ g.1. $=1,5 ; P<0,0001)$ e grupo de maturação 8.3 nos estádios V3-V4 $(t=5,27$; g.l. $=1,8 ; P<0,0001)$, V5-V6 $(t=$ 5,54; g.l. $=1,8 ; P<0,0001), \mathrm{R} 1-\mathrm{R} 2(t=5,56 ;$ g.l. $=1,8 ; P<0,0001)$ e R3-R4 $(t=4,42 ;$ g.l. $=$ $1,8 ; P<0,0001)($ Tabela 4.4).

Tabela 4.4 - Porcentagem de mortalidade de neonatas de $H$. virescens após quatro dias da infestação de discos de folha da soja MON $87701 \times$ MON 89788 dos grupos de maturação 5.5 e 8.3 e soja isolinha não-Bt em laboratório, durante a safra $2011 / 12$

\begin{tabular}{lrrrr}
\hline \multirow{2}{*}{ Tratamento } & \multicolumn{4}{c}{ Estádio fenológico $^{(1)}$} \\
\cline { 2 - 5 } & \multicolumn{1}{c}{ V3-V4 } & V5-V6 & R1-R2 & R3-R4 ${ }^{(2)}$ \\
\hline \multirow{3}{*}{ Soja MON 87701 × MON 89788 de maturação 5.5 } \\
Soja isolinha não- $B t$ & $100,00 \pm 0,00$ & $100,00 \pm 0,00$ & $100,00 \pm 0,00$ & $100,00 \pm 0,00$ \\
& $10,74 \pm 3,27$ & $9,09 \pm 3,45$ & $9,92 \pm 2,75$ & $11,11 \pm 1,39$ \\
& & & & \\
Soja MON 87701 $\times$ MON 89788 & $100,00 \pm 0,00$ & $100,00 \pm 0,00$ & $100,00 \pm 0,00$ & $100,00 \pm 0,00$ \\
Soja isolinha não- $B t$ & $7,50 \pm 1,56$ & $9,17 \pm 2,04$ & $9,09 \pm 2,05$ & $4,96 \pm 2,35$ \\
\hline
\end{tabular}

${ }^{(1)}$ Valores representam médias \pm EP após correção com a soja isolinha não-Bt. Houve diferença estatística significativa (teste $t$ a $P \leq 0,05$ ) entre a soja MON $87701 \times$ MON 89788 e soja isolinha não-Bt em todos os estádios fenológicos avaliados.

${ }^{(2)}$ No estádio fenológico R3-R4 do grupo de maturação 5.5 foram testadas 72 neonatas/tratamento.

Outro resultado relevante foi o inexpressivo dano de $H$. virescens aos discos de folha de soja MON $87701 \times$ MON 89788 (< $1 \%$ de consumo do disco foliar) (Tabela 4.5). Os discos de folha da soja MON $87701 \times$ MON 89788, após 4 dias de infestação com $H$. virescens foram significativamente menos danificados daqueles de soja isolinha não- $B t$ dos grupos de maturação 5.5 nos estádios V3-V4 $(t=4,09 ;$ g.l. $=1,8 ; P<0,0001)$, V5-V6 $(t=$ 4,18; g.1. = 1, 8; $P<0.0001)$, R1-R2 $(t=4,14$; g.1. $=1,8 ; P<0,0001)$ e R3-R4 $(t=3,10$; g.1. $=$ $1,5 ; P<0,0001)$ e grupo de maturação 8.3 nos estádios V3-V4 $(t=4,04 ;$ g.l. $=1,8 ; P<$ 0,0001), V5-V6 ( $t=4,00 ;$ g.l. $=1,8 ; P<0,0001), \mathrm{R} 1-\mathrm{R} 2(t=3,25 ; \mathrm{g} .1 .=1,8 ; P<0,0001) \mathrm{e}$ R3-R4 ( $t=4,15 ;$ g.l. $=1,8 ; P<0,0001)$. Isso demonstra que uma pequena ingestão de tecido foliar de soja MON $87701 \times$ MON 89788 foi suficiente para ocasionar a morte de neonatas. Por outro lado, os discos de soja da isolinha não- $B t$ apresentaram nota média de dano $>5$, que 
equivale a mais de $20 \%$ de consumo do disco foliar, em todos os estágios fenológicos avaliados.

Tabela 4.5 - Nota média de dano de neonatas de H. virescens após quatro dias da infestação de discos de folha da soja MON $87701 \times$ MON 89788 dos grupos de maturação 5.5 e 8.3 e soja isolinha não- $B t$ em laboratório, durante a safra 2011/12

\begin{tabular}{lcccc}
\hline \multirow{2}{*}{ Tratamento } & \multicolumn{4}{c}{ Estádio fenológico $^{(1)}$} \\
\cline { 2 - 5 } & V3-V4 & V5-V6 & R1-R2 & R3-R4 \\
\cline { 2 - 5 } Soja MON 87701 × MON 89788 & $0,05 \pm 0,02$ & $0,08 \pm 0,03$ & $0,05 \pm 0,02$ & $0,06 \pm 0,02$ \\
Soja isolinha não-Bt & $5,79 \pm 0,37$ & $6,39 \pm 0,13$ & $5,33 \pm 0,44$ & $5,71 \pm 0,31$ \\
& & & & \\
Soja MON 87701 × MON 89788 & $0,04 \pm 0,02$ & $0,03 \pm 0,02$ & $0,00 \pm 0,00$ & $0,07 \pm 0.02$ \\
Soja isolinha não-Bt & $6,33 \pm 0,17$ & $6,23 \pm 0,15$ & $5,69 \pm 0,43$ & $6,46 \pm 0.42$
\end{tabular}

${ }^{(1)}$ Valores representam médias \pm EP após correção com a soja isolinha não-Bt. Houve diferença estatística significativa (teste $t$ a $P \leq 0,05$ ) entre a soja MON $87701 \times$ MON 89788 e soja isolinha não-Bt em todos os estádios fenológicos avaliados.

De modo similar aos bioensaios com discos de folha, também houve $100 \%$ de mortalidade de neonatas de $H$. virescens quando expostas a alimentação em trifólios de soja MON $87701 \times$ MON 89788 do grupo de maturação 5.5 nos estádios V5 ( $t=5,17$; g.l. = 1, 6; $P<0,0001)$ e R1 $(t=5,41 ;$ g.l. $=1,6 ; P<0,0001)$ e grupo de maturação 8.3 nos estádios V5 $(t=4,69 ;$ g.l. $=1,6 ; P<0,0001)$ e R1 ( $t=5,10 ;$ g.l. $=1,6 ; P<0,0001)$, sendo a mortalidade significativamente superior daquela verificada na isolinha não-Bt (Tabela 6).

Nos bioensaios com vagens de soja MON $87701 \times$ MON 89788 do grupo de maturação $5.5(t=9,80 ;$ g.l. $=1,12 ; P<0,0001)$ e $8.3(t=10.87$; g.1. $=1,12 ; P<0,0001)$ também houve $100 \%$ de mortalidade de H. virescens (Tabela 4.6). A elevada mortalidade de neonatas (> 25\%) na soja isolinha não-Bt em ambos os grupos de maturação é uma evidência direta da dificuldade que neonatas de $H$. virescens possuem para se alimentar de vagens de soja, as quais além de possuir grande pilosidade apresentam tecido vegetal de difícil ingestão e digestão. Dessa forma, os danos de $H$. virescens em vagens a campo são ocasionados por lagartas de ínstares avançados que se desenvolveram alimentando-se em folhas de soja. No caso da soja MON $87701 \times$ MON 89788, a alimentação em folhas ocasionará a mortalidade completa de neonatas de $H$. virescens e, consequentemente irá reduzir os danos às vagens. 
Tabela 4.6 - Porcentagem de mortalidade de neonatas de $H$. virescens após quatro dias da infestação de trifólios (bordas se encostando) e vagens da soja MON $87701 \times$ MON 89788 dos grupos de maturação 5.5 e 8.3 e soja isolinha não-Bt em laboratório, durante a safra 2011/12

\begin{tabular}{|c|c|c|c|}
\hline \multirow{2}{*}{ Tratamento } & \multicolumn{2}{|c|}{ Trifólios $^{(1)}$} & \multirow{2}{*}{$\begin{array}{c}\text { Vagens }^{(1} \\
\text { R4 }\end{array}$} \\
\hline & V5 & R1 & \\
\hline
\end{tabular}

\begin{tabular}{lrcr}
\hline & \multicolumn{3}{c}{ Grupo de maturação 5.5 } \\
Soja MON 87701 × MON 89788 & $100,00 \pm 0,00$ & $100,00 \pm 0,00$ & $100,00 \pm 0,00$ \\
Soja isolinha não-Bt & $8,33 \pm 2,62$ & $4,68 \pm 2,69$ & $29,37 \pm 3,72$
\end{tabular}

Grupo de maturação 8.3

$\begin{array}{lrrr}\text { Soja MON 87701 × MON 89788 } & 100,00 \pm 0,00 & 100,00 \pm 0,00 & 100,00 \pm 0,00 \\ \text { Soja isolinha não-Bt } & 9,72 \pm 2,08 & 9,03 \pm 3,40 & 32,54 \pm 3,14\end{array}$

(1) Valores representam médias \pm EP após correção com a soja isolinha não- $B t$. Houve diferença estatística
significativa (teste $t$ a $P \leq 0,05)$ entre a soja MON $87701 \times$ MON 89788 e soja isolinha não- $B t$ nos bioensaios
com trifólios e vagens.

\subsection{Discussão}

H. virescens foi extremamente suscetível a Cry1Ac purificada. Essa proteína inseticida é idêntica àquela expressa em soja MON $87701 \times$ MON 89788, diferindo em apenas 7 aminoácidos no domínio altamente conservado da região Domain I da toxina ativa (FISCHHOFF; PERLAK, 1995). A atividade biológica da proteína Cry1Ac para $H$. virescens foi similar àquela reportada para populações da praga dos EUA, quando expostas a Cry1Ac purificada incorporada em dieta artificial (STONE; SIMS, 1993; LUTTRELL; WAN; KNIGHTEN, 1999). Por outro lado, populações de laboratório e campo de $H$. virescens nos EUA quando expostas a Cry1Ac (MVP II) incorporada em dieta artificial foram em termos de $\mathrm{CL}_{50}$ e $\mathrm{CIM}_{50}, \approx 3$ a 15 vezes, respectivamente, menos suscetíveis que a população de $H$. virescens deste estudo (ALI; LUTTRELL; YOUNG, 2006; BLANCO et al., 2009; ALI; LUTTRELL, 2009). De modo semelhante, populações de $H$. virescens coletadas em algodão no Brasil e expostas a Cry1Ac (MVP II) incorporada em dieta artificial em termos de $\mathrm{CL}_{50} \mathrm{e}$ $\mathrm{CE}_{50}$ foram $\approx 7$ e 6 vezes, respectivamente, menos suscetíveis que a população de $H$. virescens estudada (dados não publicados $\mathrm{SM}$ ). A variação na suscetibilidade de $H$. virescens em diferentes estudos pode estar associada à fonte da proteína Cry1Ac (purificada ou MVP II) (ALI; LUTTRELL; YOUNG, 2006). Adicionalmente, aspectos relacionados à técnica de bioensaio, população da praga (LUTTRELL; WAN; KNIGHTEN, 1999), tempo de exposição (DULMAGE; GRAHAM; MARTINEZ, 1978), temperatura (ROBERTSON et al., 1996) e 
dieta artificial (BLANCO et al., 2009) também podem afetar a suscetibilidade de $H$. virescens a proteínas inseticidas de $B t$.

O monitoramento da suscetibilidade de $H$. virescens a Cry1Ac expressa em soja MON $87701 \times$ MON 89788 deve ser realizado mediante uso de concentrações diagnósticas. As concentrações diagnósticas potencias ocasionaram mortalidade completa de $H$. virescens, fato que torna esse tipo de bioensaio um procedimento rápido, prático e compatível com a larga escala de bioensaios de um programa de monitoramento da suscetibilidade das pragas-alvo da soja MON $87701 \times$ MON 89788. Em adição, as avaliações da inibição da troca de tegumento e redução no crescimento larval são também importantes, pois potencialmente podem ser incluídas no monitoramento da suscetibilidade, e desta forma maximizar a possibilidade de detectar a evolução da resistência (SIMS et al., 1996). Contudo, estudos adicionais de linha básica de suscetibilidade de populações geograficamente distintas de $H$. virescens coletadas em soja são necessários para estimar com maior precisão as concentrações diagnósticas de Cry1Ac a serem utilizadas no monitoramento da suscetibilidade. Paralelamente, ao monitoramento da suscetibilidade de populações de $H$. virescens de soja, também se faz necessário o acompanhamento da suscetibilidade de populações de $H$. virescens que infestam o algodão $B t$, pois em ambas as culturas esse inseto-praga será exposto à pressão de seleção pela proteína Cry1Ac.

De modo similar ao estudo de linha básica, $H$. virescens demonstrou ser extremamente suscetível a Cry1Ac presente no tecido liofilizado da soja MON $87701 \times$ MON 89788. O tecido liofilizado diluído 25 vezes em dieta artificial ocasionou mortalidade completa de $H$. virescens, demonstrando que a expressão da proteína Cry1Ac em soja MON $87701 \times$ MON 89788 ocorre em níveis que constituem alta dose para o MRI desse inseto-praga. Para a soja MON $87701 \times$ MON 89788 se as áreas de refúgio forem efetivamente implementadas, é pouco provável que ocorra evolução da resistência em populações de campo das pragas-alvo de controle, pois esse evento também expressa Cry1Ac em alta dose para A. gemmatalis e muito próximo a alta dose para $P$. includens (BERNARDI et al., 2012). Um exemplo da eficiência da estratégia de alta dose para o MRI tem sido verificado para as principais pragasalvo de culturas $B t$ nos EUA e Canadá, Ostrinia nubilalis (Hübner) (Lepidoptera: Pyralidae), Diatraea grandiosella Dyar (Lepidoptera: Crambidae), H. virescens e Pectinophora gossypiella (Saunders) (Lepidoptera: Gelechiidae), as quais após 15 anos de uso intensivo de milho e algodão $B t$ permanecem suscetíveis as proteínas inseticidas expressas nessas plantas transgênicas (HUANG; ANDOW; BUSCHMAN, 2011). 
Entretanto, para ser eficiente a estratégia de alta dose é dependente do uso de áreas de refúgio para evitar ou retardar a evolução da resistência das pragas-alvo. Para o MRI das pragas-alvo primárias da soja MON $87701 \times$ MON 89788, A. gemmatalis e $P$. includens a recomendação de pelo menos $20 \%$ de área de refúgio (soja não- $B t$ ) estruturado localizado externamente a área cultivada com soja MON $87701 \times$ MON 89788 foi aprovado no Brasil (CTNBio, 2010). Acredita-se que essa área de refúgio seja suficiente para assegurar o MRI de H. virescens à soja MON $87701 \times$ MON 89788, uma vez que, na cultura do algodão, onde a expressão de Cry1Ac também é de alta dose para $H$. virescens, a recomendação de $20 \%$ de refúgio, até o momento, tem sido eficiente para retardar ou evitar a evolução da resistência em populações desse inseto-praga.

A soja MON $87701 \times$ MON 89788, além de ser de alta dose para o MRI de $H$. virescens, se apresenta como uma excelente alternativa para o controle desse inseto-praga. Em bioensaios com discos de folha, trifólios em expansão e vagens, a soja MON $87701 \times$ MON 89788 ocasionou controle completo de $H$. virescens. Esses resultados fornecem evidências suficientes para afirmar que a soja MON $87701 \times$ MON 89788 fornecerá controle completo de $H$. virescens a campo. Isso é reforçado pela elevada eficácia de controle de $H$. virescens pelo algodão Bollgard $^{\circledR}$ que também expressa Cry1Ac (SIEBERT et al., 2008; SIVASUPRAMANIAM et al., 2008), cuja proteína inseticida é idêntica àquela expressa em soja MON $87701 \times$ MON 89788 .

No contexto do MRI, por ser praga-chave da cultura do algodão e ser um recente problema fitossanitário em soja, $H$. virescens será exposta a intensa pressão de seleção pela proteína Cry1Ac em soja MON $87701 \times$ MON 89788 e algodão Bt Bollgard $^{\circledR}$, Bollgard II $^{\circledR}$ e Widestrike $^{\circledR}$ ). Em áreas de cultivo do Brasil Central e Cerrado, a sobreposição e/ou sucessão de cultivos de algodão e soja pode favorecer a seleção de insetos com genótipo resistente e aumentar o risco de resistência de $H$. virescens a Cry1Ac. Outro aspecto a ser considerado para o MRI é a ausência de estruturação genética entre populações de $H$. virescens de algodão e soja no Brasil, fato que pode favorecer a dispersão dos alelos que conferem resistência entre as populações desse inseto-praga e acelerar o processo de evolução da resistência (ALBERNAZ, 2011; DOMINGUES, 2011). Nesse cenário, é de extrema importância considerar as particularidades dos diferentes regimes de seleção que $H$. virescens será exposta devido ao sistema de produção para refinar as estratégias de MRI. Contudo, a efetiva implementação de áreas de refúgio para o MRI das pragas-alvo primárias da soja MON 87701 $\times$ MON 89788 deve assegurar refúgio suficiente para $H$. virescens e garantir a 
sustentabilidade dessa tecnologia para o MIP desse inseto-praga nos diferentes agroecossistemas de cultivo de soja no Brasil.

\subsection{Conclusões}

- A proteína inseticida Cry1Ac apresenta alta atividade biológica contra H. virescens.

- A soja MON $87701 \times$ MON 89788 expressa a proteína Cry1Ac em alta dose para o MRI de H. virescens.

- A soja MON 87701 × MON 89788 é eficiente no controle de $H$. virescens.

\section{Referências}

ABBOTT, W.S. A method of computing the effectiveness of an insecticide. Journal of Economic Entomology, Lanham, v. 18, n. 1, p. 265-266, 1925.

ALBERNAZ, K.C. Suscetibilidade à proteína Cry1Ac e estrutura genética em populações de Heliothis virescens (Fabricius) (Lepidoptera: Noctuidae) no Brasil.2011. 85p. Dissertação (Mestrado em Entomologia) - Escola Superior de Agricultura "Luiz de Queiroz", Universidade de São Paulo, Piracicaba, 2011.

ALI, M.I.; LUTTRELL, R.G.; YOUNG, S.Y. Susceptibilities of Helicoverpa zea and Heliothis virescens (Lepidoptera: Noctuidae) populations to Cry1 Ac insecticidal protein. Journal of Economic Entomology, Lanham, v. 99, n. 1, p. 64-175, 2006.

ALI, M.I.; LUTTRELL, R.G. Response estimates for assessing Heliothine susceptibility to $B t$ toxins. Journal of Economic Entomology, Lanham, v. 102, n. 5, p. 935-1947, 2009.

ANDOW, D.A. The risk of resistance evolution in insects to transgenic insecticidal crops. Collection of Biosafety Reviews, Trieste, v. 4, p. 142-199, 2008.

BERNARDI, O.; MALVESTITI, G.S.; DOURADO, P.M.; OLIVEIRA, W.S.;

MARTINELLI, S.; BERGER, G.U.; HEAD, G.P.; OMOTO, C. Assessment of the high-dose concept and level of control provided by MON $87701 \times$ MON 89788 soybean against Anticarsia gemmatalis and Pseudoplusia includens (Lepidoptera: Noctuidae) in Brazil. Pest Management Science, Sussex, In press., 2012.

BLANCO, C.A.; GOULD, F.; VEGA-AQUINO, P.; JURAT-FUENTES, J.L.; PERERA, O.P.; ABEL, C.A. Response of Heliothis virescens (Lepidoptera: Noctuidae) strains to Bacillus thuringiensis cry1 Ac incorporated into different insect artificial diets. Journal of Economic Entomology, Lanham, v. 102, n. 4, p. 1599-1606, 2009a. 
BLANCO, C.A.; ANDOW, D.A.; ABEL, C.A.; SUMERFORD, D.V.; HERNANDEZ, G.; LÓPEZ JR, J.D.; ADAMS, L.; GROOT, A.; LEONARD, R.; PARKER, R.; PAYNE, G.; PERERA, O.P.; TERÁN-VARGAS, A.P.; AZUARA-DOMÍNGUEZ, A. Bacillus thuringiensis Cry1Ac resistance frequency in tobacco budworm (Lepidoptera: Noctuidae). Journal of Economic Entomology, Lanham, v. 102, n. 4, p. 381-387 2009 b.

CAPRIO, M.A.; SUMMERFORD, D.V.; SIMS, S.R. Evaluating transgenic plants for suitability in pest and resistance management programs. In: LACEY, L.A.; KAYA, H.K. (Ed.). Field manual of techniques in invertebrate pathology. Dordrecht: Kluwer Academic, 2000. cap. 8, p. 805-828.

CTNBIO, Comissão Técnica Nacional de Biossegurança. Liberação comercial de soja geneticamente modificada resistente a insetos e tolerante a herbicida, soja MON $87701 \times$ MON 89788. In: Parecer Técnico $n^{\circ}$ 2542/2010. Disponível em:

<http://www.ctnbio.gov.br/index.php/content/view/15558.html>. Acesso em: 15 dez. 2010.

DOMINGUES, F.A. Variabilidade genética de Heliothis virescens (Lepidoptera Noctuidae) no Brasil inferida por marcadores microssatálites. 2011. 85p. Dissertação (Mestrado em Entomologia) - Escola Superior de Agricultura "Luiz de Queiroz", Universidade de São Paulo, Piracicaba, 2011.

DULMAGE, H.T.; GRAHAM, H.M.; MARTINEZ, E. Interactions between the tobacco budworm, Heliothis virescens, and the $\alpha$-endotoxin produced by the HD-1 isolate of Bacillus thuringiensis var. kurstaki: relationship between length of exposure to the toxin and survival. Journal of Invertebrate Pathology, San Diego, v.32, n.1, p.40-50, 1978.

FIFRA SCIENTIFIC ADVISORY PANEL. Transmittal of the final report of the FIFRA Scientific Advisory Panel subpanel on Bacillus thuringiensis $(B t)$ plant-pesticides and resistance management. 9-10 February 1998. Docket $\mathrm{N}^{\mathrm{O}}$. OPPTS-00231:59, 1998.

Disponível em: <http://www.mindfully.org/GE/FIFRA-SAP-Bt.htm>. Acesso em: 15 mar. 2008.

FISCHHOFF, D.A.; PERLAK, F.J. Synthetic plant genes. U.S. Patent 5-500-365, 1995.

FORCADA, C.; ALCÁCER, E.; GARCERÁ, M.D.; TATO, A.; MARTÍNEZ, R. Resistance to Bacillus thuringiensis Cry1Ac toxin in three strains of Heliothis virescens: Proteolytic and SEM study of the larval midgut. Archives of Insect Biochemistry and Physiology, New York, v. 42, n. 1, p. 51-63, 1999.

GOULD F. Potential and problems with high-dose strategies for pesticidal engineered crops. Biocontrol Science and Technology, Oxford, v. 4, n. 4, p. 451-461, 1994.

GOULD, F.; ANDERSON, A.; REYNOLDS, A.L.; BUNGARNER, L.; MOAR, W. Selection and genetic analysis of a Heliothis virescens (Lepidoptera: Noctuidae) strain with high levels of resistance to Bacillus thuringiensis toxins. Journal of Economic Entomology, Lanham, v. 88, n. 6, p. 1545-1559, 1995. 
GOULD, F.; ANDERSON, A.; JONES, A.; SUMERFORD, D.; HECKEL, D.G.; LOPEZ, J.; MICINSKI, S.; LEONARDI, R.; LASTER, M. Initial frequency of alleles for resistance to Bacillus thuringiensis toxins in field populations of Heliothis virescens. Proceedings of the National Academy of Sciences of the United States of America, Washington, v. 94, n. 8, p. 3519-3523, 1997.

GREENE, G.L.; LEPPLA, N.C.; DICKERSON, W.A. Velvetbean caterpillar: a rearing procedure and artificial medium. Journal of Economic Entomology, Lanham, v. 69, n. 4, p. 488-497, 1976.

HUANG, F.; ANDOW, D.A.; BUSCHMAN, L.L. Success of the high-dose/refuge resistance management strategy after 15 years of $B t$ crop use in North America. Entomologia Experimentalis et Applicata, Dordrecht, v. 140, n. 1, p. 1-16, 2011.

LUTTRELL R.G.; WAN L.; KNIGHTEN K. Variation in susceptibility of Noctuid (Lepidoptera) larvae attacking cotton and soybean to purified endotoxin proteins and commercial formulations of Bacillus thuringiensis. Journal of Economic Entomology, Lanham, v. 92, n. 1, p. 21-32, 1999.

ROBERTSON, J.L.; PREISLER, H.K.; NG S.S.; HICKLE, L.A.; BERDEJA, A.; GELERNTER, W.D. Comparative effect of temperature and time on activity of Dipel $2 \mathrm{X}$ and MPV preparations of Bacillus thuringiensis subsp. kurstaki on diamondback moth (Lepidoptera: Plutellidae). Journal of Economic Entomology, Lanham, v. 89, n. 5, p. 10841087, 1996.

SAS INSTITUTE INC. 2000. SAS/STAT: Statistical Analysis System: getting started with the SAS learning. Version 9.1. Cary, NC: SAS Institute, 2000.

SAS INSTITUTE INC. 2010. SAS JMP: Introductory guide, Version 9.0. Cary, NC: SAS Institute, 2010.

SIEBERT, M.W.; NOLTING, S.; LEONARD, B.R.; BRAXTON, L.B.; ALL, J.N.; VAN DUYN, J.W.; BRADLEY, J.R.; BACHELER, J.; HUCKABA, R.M. Efficacy of transgenic cotton expressing Cry1 Ac and Cry1F insecticidal protein against Heliothines (Lepidoptera: Noctuidae). Journal of Economic Entomology, Lanham, v. 101, n. 6, p. 1950-1959, 2008.

SIMS, S.R.; GREENPLATE, J.T.; STONE, T.B.; CAPRIO, M.A.; GOULD, F.L. Monitoring strategies for early detection of Lepidoptera resistance to Bacillus thuringiensis insecticidal proteins. In: BROWN T.M. (Ed). Molecular genetics and evolution of pesticide resistance. Washington: American Chemical Society, 1996. cap. 23 p. 229-242.

SIVASUPRAMANIAM, S.; MOAR, W. J.; RUSCHKE, L.G.; OSBORN, J. A.; JIANG, C.; SEBAUGH, J.L.; BROWN G.R.; SHAPPLEY, Z.W.; OPPENHUIZEN, M.E.; MULLINS, J.W.; GREENPLATE, J.T. Toxicity and characterization of cotton expressing Bacillus thuringiensis Cry1 Ac and Cry2Ab2 proteins for control of lepidopteran pests. Journal of Economic Entomology, Lanham, v. 101, n. 2, p.546-554, 2008.

STONE, T.B.; SIMS, S.R. Geographic susceptibility of Heliothis virescens and Helicoverpa zea (Lepidoptera: Noctuidae) to Bacillus thuringiensis. Journal of Economic Entomology, Lanham, v. 86, n. 4, p. 989-994, 1993. 
TABASHNIK, B.E.; GOULD, F.; CARRIÈRE, Y. Delaying evolution of insect resistance to transgenic crops by decreasing dominance and heritability. Journal of Evolutionary Biology, Basel, v. 86, n. 5, p. 989-994, 2004.

TABASHNIK, B.E.; VAN RENSBURG, J.B.J.; CARRIÈRE, Y. Field-evolved insect resistance to $B t$ crops: Definition, theory and data. Journal of Economic Entomology, Lanham, v. 102, n. 6, p. 904-912, 2009.

TOMQUELSKI, G.V.; MARUYAMA, L.C.T. Lagarta-da-maçã em soja. Revista Cultivar, Pelotas, v. 117, p. 20-22, 2009.

WILLSON, H.R. Soybean insect defoliation assessment. The Ohio State University Extension, OPMS, Circular FC-22. Disponível em: <http://www.ag.ohiostate.edu/ ohioline/icm-fact/fc-22.html>. Acesso em:15 mar. 2009. 


\title{
5 CARACTERIZAÇÃO DA ATIVIDADE DA SOJA MON $87701 \times$ MON 89788 CONTRA ESPÉCIES DE Spodoptera (LEPIDOPTERA: NOCTUIDAE)
}

\section{Resumo}

No Brasil, Spodotera cosmioides (Walker), Spodoptera eridania Stoll e Spodoptera frugiperda (J. E. Smith) são consideradas pragas secundárias em soja, Glicine max (L.) Merrill, mas possuem grande potencial de ocasionar danos na cultura. Mesmo não sendo pragas-alvo da soja MON $87701 \times$ MON 89788 que expressa a proteina Cry1Ac de Bacillus thuringiensis var. kurstaki Berliner, essas espécies serão expostas a essa proteína. Nesse sentido, para entender o valor da soja MON $87701 \times$ MON 89788 para o Manejo Integrado de Pragas (MIP) e Manejo da Resistência de Insetos (MRI) caracterizou-se a atividade da soja MON $87701 \times$ MON 89788 para S. cosmioides, S. eridania e S. frugiperda, mediante avaliação da toxicidade de Cry1Ac e de parâmetros biológicos dessas espécies nessa soja geneticamente modificada em condições de laboratório. A partir de bioensaios com incorporação de Cry1Ac purificada em dieta artificial na concentração de $100 \mu \mathrm{g}$ Cry1 Ac/mL de dieta, verificaram-se baixa atividade de Cry1Ac para $S$. cosmioides e $S$. eridania, com mortalidade e inibição de desenvolvimento < 13 e 55\%, respectivamente. Para S. frugiperda, a atividade de Cry1Ac foi intermediária com $\approx 50$ e $80 \%$ de mortalidade e inibição de desenvolvimento, respectivamente. Nos bioensaios com discos de folha, a soja MON $87701 \times$ MON 89788 apresentou baixa eficácia para S. cosmioides e S. eridania (mortalidade < 7\%). Já para $S$. frugiperda a mortalidade em soja MON $87701 \times$ MON 89788 variou de 32 a 47\%. A soja MON $87701 \times$ MON 89788 não afetou os parâmetros biológicos de $S$. cosmoides e $S$. eridania. Contudo, para $S$. frugiperda houve prolongamento da fase larval ( $\approx 5$ dias), menor viabilidade larval e de insetos que completaram o ciclo biológico, aumento no intervalo entre gerações $(\approx 8$ dias) e redução de $\approx 41 \%$ na taxa intrínseca de crescimento populacional. Conclui-se que a soja MON $87701 \times$ MON 89788 é um evento de baixa dose para MRI e não é eficiente para o controle de $S$. cosmioides, $S$. eridania e $S$. frugiperda. Outras táticas de controle devem ser utilizadas com a soja MON $87701 \times$ MON 89788 para o controle de espécies de Spodoptera.

Palavras chave: Soja transgênica; Spodoptera spp.; Manejo Integrado de Pragas; Manejo da Resistência de Insetos

\begin{abstract}
In Brazil, Spodotera cosmioides (Walker), Spodoptera eridania Stoll and Spodoptera frugiperda (J. E. Smith) are considered secondary pests in soybean, Glycine max (L.) Merrill, but have great potential for causing crop damage. These species are not target pests of soybean MON $87701 \times$ MON 89788 that expresses the Cry1Ac protein from Bacillus thuringiensis var. kurstaki Berliner, however they will be exposed to Cry1Ac. Therefore, to understand the value of soybean MON $87701 \times$ MON 89788 for the Integrated Pest Management (IPM) and Insect Resistance Management (IRM), we characterized the activity of MON $87701 \times$ MON 89788 soybean to $S$. cosmioides, S. eridania and S. frugiperda by evaluating the toxicity of Cry1Ac and the biological parameters of these species on this genetically modified soybean under laboratory conditions. In bioassays with incorporation of purified Cry1Ac in artificial diet at a concentration of $100 \mu \mathrm{g}$ Cry $1 \mathrm{Ac} / \mathrm{mL}$ of diet, the activity of this protein was low for S.cosmioides and S. eridania, with mortality and growth inhibition rates $<13$ and 55\%, respectively. For S. frugiperda, the activity of Cry1Ac was intermediate with $\approx 50$ and $80 \%$ mortality and growth inhibition, respectively. In leaf disc bioassays, MON
\end{abstract}


$87701 \times$ MON 89788 soybean showed low efficacy to S. cosmioides and S. eridania (mortality $<7 \%$ ). The mortality of $S$. frugiperda in MON $87701 \times$ MON 89788 soybean ranged from 32 to $47 \%$. MON $87701 \times$ MON 89788 soybean did not affect the biological parameters of $S$. cosmoides and S. eridania. However, MON $87701 \times$ MON 89788 soybean prolonged the larval stage of $S$. frugiperda ( $\approx 5$ days), reduced larval viability and insects that completed the life cycle, increased the generation time (8 days) and decreased the intrinsic rate of increase $(\approx 41 \%)$. Therefore, the soybean MON $87701 \times$ MON 89788 is a low dose event for IRM and it is not effective against $S$. cosmioides, S. eridania and $S$. frugiperda. Other control tactics need to be used with MON $87701 \times$ MON 89788 soybean to control Spodoptera species.

Keywords: Transgenic soybean; Spodoptera spp.; Integrated Pest Management; Insect Resistance Management

\subsection{Introdução}

No Brasil, pragas secundárias do gênero Spodoptera têm ocasionado problemas fitossanitários à cultura da soja, Glycine max (L.) Merrill (Fabaceae: Phaseoleae),, causando desfolha e danos a vagens e exigindo a adoção de medidas de controle para evitar prejuízos à produção. Algumas espécies de Spodoptera encontradas frequentemente em soja são Spodoptera eridania Stoll, Spodoptera cosmioides (Walker) e Spodoptera frugiperda (J. E. Smith). S. eridania tem ocorrido em surtos ocasionando danos à soja em áreas de produção no Cerrado (SANTOS; MENEGUIM; NEVES, 2005). S. cosmioides frequentemente ocasiona danos em soja nos estados da região Centro-Sul (HOFFMANN-CAMPO, 2000). Entretanto, S. frugiperda apresenta menor importância em soja, mas com relatos de desfolha e danos em áreas de produção de soja no Brasil Central (GOMEZ, 2009).

$\mathrm{Na}$ cultura da soja o controle de espécies de Spodoptera tem sido realizado via aplicação de inseticidas sintéticos, muitas vezes de forma indireta quando da realização do controle da lagarta-da-soja, lagarta-falsa-medideira ou percevejos. No entanto, as espécies de Spodoptera com frequencia têm escapado aos efeitos dos inseticidas, devido a sua tolerância natural ou estar em ínstar avançado e/ou protegidas no interior do dossel da planta no momento da aplicação. Nesse cenário, a liberação para cultivo comercial da soja MON 87701 $\times$ MON 89788 que expressa genes que codificam a expressão da proteína Cry1Ac de Bacillus thuringiensis Berliner (Bt) (CTNBio, 2010) pode ser uma alternativa para o manejo de espécies de Spodoptera em soja.

De um modo geral, espécies de Spodoptera são naturalmente tolerantes a Cry1Ac (LUTTRELL; WAN; KNIGHTEN, 1999). No contexto do Manejo Integrado de Pragas $(\mathrm{MIP})$, mesmo que a soja MON $87701 \times$ MON 89788 não ocasione efetivo controle de 
espécies de Spodoptera, essas poderiam ter seu desenvolvimento afetado, o que pode aumentar a suscetibilidade aos inseticidas direcionados, por exemplo, ao controle de percevejos, bem como o período de exposição a inimigos naturais. Por outro lado, no contexto de Manejo da Resistência de Insetos (MRI), a tolerância a Cry1Ac aumenta a complexidade do manejo efetivo da resistência, pois as espécies de Spodoptera podem estar sujeitas a pressão de seleção e, consequentemente evoluir para resistência.

Em adição, a ocorrência dessas espécies em milho ( $S$. frugiperda) e algodão $B t(S$. frugiperda, S. eridania e S. cosmioides), em um cenário de sobreposição e/ou sucessão de cultivos de milho, algodão e soja permite a contínua exposição a diferentes proteínas inseticidas de $B t$, aumentando o risco de resistência cruzada, pois várias proteínas expressas em plantas $B t$ comercialmente cultivadas no Brasil possuem mesmo sítio de ação no intestino médio dos insetos-praga-alvo (FERRÉ; VAN RIE, 2002). A capacidade de espécies de Spodoptera evoluírem para resistência a proteínas de $B t$ foi reportada para linhagens de laboratório de Spodoptera exigua (Hübner) e Spodoptera littoralis (Boisduval) a Cry1C (MOAR et al., 1995; MULLER-COHN et al., 1996) e a campo para S. frugiperda a Cry1F (STORER et al., 2010). Essas constatações reforçam a necessidade de estudos para direcionar estratégias de MRI e prover informações ao MIP de espécies de Spodoptera em soja.

Nesse contexto, para entender o valor da soja MON $87701 \times$ MON 89788 para o MRI e MIP foram realizados estudos para caracterizar a atividade da soja MON $87701 \times$ MON 89788 que expressa Cry1Ac para espécies de Spodoptera mediante a avaliação da toxicidade de Cry1Ac para S. frugiperda, S. cosmioides e S. eridania e de parâmetros biológicos dessas espécies alimentadas com soja MON 87701 × MON 89788.

\subsection{Material e métodos}

\subsubsection{Suscetibilidade de espécies de Spodoptera a Cry1Ac}

Para avaliar a suscetibilidade a Cry1Ac, utilizou-se uma única população de $S$. cosmioides coletada em mamona em Pelotas-RS, em 2009, S. frugiperda coletada em milho em Rondonópolis-MS, em 2009 e S. eridania coletada em soja em Ibiporã e Jataizinho-PR, em 2011. Para realização dos bioensaios, a proteína Cry1 Ac purificada na concentração de 1,4 $\mathrm{mg}$ de Cry1Ac ativo/mL e pureza de $80 \%$, foi fornecida pela empresa Monsanto do Brasil Ltda e armazenada em ultra-frezer (temperatura - $80 \pm 5^{\circ} \mathrm{C}$ ). Após descongelamento, a proteína Cry1Ac foi diluída em solução tampão constituída de $50 \mathrm{mM}$ Ácido 3- 
(Ciclohexilamino)-1-Propanosulfônico (CAPS) à pH=10,25, $1 \mathrm{mM}$ Benzomidine-HCl, $1 \mathrm{mM}$ Ácido Etileno Diamino Tetra Acético (EDTA) e 2,5 mM de Ditiotreitol (DTT). Para os bioensaios, a proteína inseticida e a solução tampão foram adicionadas em dieta artificial (Adaptada Greene; Leppla; Dickerson, 1976) (Capítulo 3, Tabela 3.1), quando a temperatura da dieta atingiu $45-50^{\circ} \mathrm{C}$. A incorporação da proteína Cry1Ac em dieta artificial foi realizada por um agitador de tubos do tipo Vortex por no mínimo 2 minutos. Em seguida, a dieta contendo a proteína incorporada foi mantida em banho-maria a $\approx 55^{\circ} \mathrm{C}$ para posterior distribuição nas bandejas de bioensaio (BIO-BA-128, CD International Inc., Pitman, NJ), contendo 128 células ( $1 \mathrm{~mL}$ de dieta/célula) com auxílio de uma pipeta de repetição e ponteira. Para cada espécie foram testadas concentrações no intervalo de 1 a $100 \mu \mathrm{g}$ de Cry $1 \mathrm{Ac} / \mathrm{mL}$ de dieta e como testemunha, somente a solução tampão foi adicionada à dieta. Após a geleificação e esfriamento da dieta, com auxílio de um pincel fino foi inoculada uma lagarta neonata (0 - 24 h de idade) de S. cosmioides, S. eridania ou S. frugiperda em cada célula. As bandejas foram vedadas com lâminas plásticas auto-adesivas (BIO-CV-16, CD International Inc.) que permite as trocas gasosas com o ambiente externo e acondicionadas em câmara climatizada (temperatura $27 \pm 1^{\circ} \mathrm{C}$, umidade relativa $60 \pm 10 \%$ e fotoperíodo $14: 10 \mathrm{~h}$ luz:escuro). O delineamento experimental foi inteiramente casualizado, com 5 a 8 repetições por concentração (16 lagartas/repetição). A atividade biológica da proteína Cry1Ac foi avaliada após 7 dias considerando-se como critérios de resposta a mortalidade (lagartas que não ultrapassaram o $1^{\circ}$ ínstar foram consideradas mortas) e o peso das lagartas sobreviventes. Os dados de mortalidade e peso das lagartas sobreviventes foram submetidos à análise de variância e as médias comparadas pelo teste Tukey $(P \leq 0,05)$ (PROC ANOVA, SAS INSTITUTE, 2000).

\subsubsection{Bioensaios com discos de folha}

Em casa de vegetação foi realizada a semeadura da soja MON $87701 \times$ MON 89788 e soja isolinha não- $B t$ dos grupos de maturação 5.5 e 8.3 em vasos plásticos de 12L (4 sementes/vaso) contendo terra e substrato vegetal na proporção 1:1. Quando as plantas atingiram os estádios fenológicos V3-V4, V5-V6 e R1-R2 foram retiradas folhas completamente expandidas do terço superior e, em laboratório, com auxílio de um vasador metálico, discos de folha de 2,4 cm de diâmetro foram obtidos e acondicionados sobre uma mistura não geleificada de Ágar-água a 2,5\% (1 mL/célula) em placas de acrílico (Costar $\left.{ }^{\circledR}\right)$ com 12 células. Os discos de folha de soja foram separados da camada Ágar-água por um 
disco de papel filtro. Posteriormente, em cada disco de folha de soja foi inoculada uma lagarta neonata (0 - 24 h de idade) de $S$. cosmioides, S. eridania ou $S$. frugiperda com auxílio de um pincel fino. As placas foram vedadas com filme plástico (Magipack ${ }^{\circledR}$ ) e, em seguida pela tampa da placa, sendo acondicionadas em câmara climatizada (temperatura de $27 \pm 1{ }^{\circ} \mathrm{C}$, umidade relativa $60 \pm 10 \%$ e fotoperíodo $14: 10$ h luz:escuro). O delineamento experimental foi inteiramente casualizado com 8 repetições/tratamento, sendo cada repetição constituída de 12 lagartas neonatas, totalizando 96 neonatas testadas/espécie e estádio fenológico. Aos 5 dias após a infestação dos discos de folha se contabilizou a mortalidade, o peso e o enfezamento das lagartas sobreviventes. A mortalidade e o enfezamento em soja MON $87701 \times$ MON 89788 foram corrigidos a partir da respectiva isolinha não-Bt (ABBOTT, 1925). Posteriormente, a porcentagem de mortalidade e redução de peso $(x)$ foram transformados em $\sqrt{x+0,5}$, submetidos à análise de variância e as médias comparadas pelo teste de $t(P \leq$ 0,05) (PROC TTEST, SAS INSTITUTE, 2000). Por apresentarem homogeneidade de variâncias os dados de enfezamento não foram transformados, sendo submetidos ao mesmo procedimento estatístico descrito anteriormente.

\subsubsection{Parâmetros biológicos de espécies de Spodoptera em soja MON $87701 \times$ MON 89788}

Em casa de vegetação realizou-se a semeadura da soja MON $87701 \times$ MON 89788 e soja isolinha não- $B t$ do grupo de maturação 8.3 em vasos plásticos de $12 \mathrm{~L}$ (4 sementes/vaso) contendo terra e substrato vegetal na proporção 1:1. O estudo foi iniciado quando as plantas atingiram o estádio fenológico R1. A partir desse momento, folhas completamente expandidas dos terços mediano e superior das plantas foram retiradas e acondicionadas em tubos de vidro $(8,5 \mathrm{~cm}$ de comprimento $\times 2,5 \mathrm{~cm}$ de diâmetro) previamente esterilizados e tamponados com algodão hidrófobo, para os quais, com o auxílio de um pincel fino, foi transferida uma única lagarta neonata $(0-24$ h) de $S$. cosmioides, S. eridania ou $S$. frugiperda. As folhas foram trocadas a cada $48 \mathrm{~h}$ durante todo o período larval.

O delineamento experimental foi inteiramente casualizado com 10 repetições, sendo cada repetição constituída de 10 lagartas. Para cada tratamento foram avaliados os seguintes parâmetros biológicos: duração e viabilidade dos estágios de ovo, larva, pupa, ciclo total (ovo-adulto), peso de lagartas aos 14 dias após a inoculação, peso de pupas com 24 h de idade, razão sexual, longevidade, duração dos períodos de pré-oviposição, oviposição e pósoviposição, fecundidade e fertilidade de adultos. A razão sexual foi calculada pela fórmula: rs 
= fêmea/(macho + fêmea). A duração e a viabilidade das fases de ovo, larva, pupa e período ovo-adulto foram determinadas em observações diárias.

A longevidade, fecundidade e fertilidade dos adultos foram avaliadas a partir da formação de 10 casais/espécie/tratamento em gaiolas de PVC $(23 \mathrm{~cm}$ altura $\times 10 \mathrm{~cm}$ de diâmetro), revestidas internamente folha papel jornal (substrato de oviposição) e fechadas na parte superior com tecido "voil". Os adultos foram alimentados com uma solução aquosa de mel a 10\% fornecida em algodão saturado. Diariamente contou-se o número de ovos e registrou-se a mortalidade dos adultos. Para determinação do período embrionário e viabilidade foram obtidos $\approx 100$ ovos da segunda postura de cada casal. Os ovos foram acondicionados em tubos de vidro de fundo chato $(8,5 \times 2,5 \mathrm{~cm})$. No interior dos tubos foi colocado um pedaço de papel filtro $(2 \times 1 \mathrm{~cm})$, o qual foi umedecido diariamente com água destilada, sendo fechados na parte superior com filme plástico. As posturas foram observadas diariamente contando-se o número de lagartas eclodidas.

Os dados de viabilidade $(x)$ de cada fase de desenvolvimento das três espécies de Spodoptera foram transformados em $\sqrt{x+0,5}$. Os demais parâmetros biológicos não foram transformados. Posteriormente, cada parâmentro biológico avaliado foi submetido à análise de variância e as médias do tratamento com soja MON $87701 \times$ MON 89788 e soja isolinha não$B t$ para cada espécie de Spodoptera foram comparadas pelo teste $t(P \leq 0,05)$ (PROC TTEST, SAS INSTITUTE, 2000). O possível desvio na proporção dos sexos foi comparado utilizando o teste de Qui-quadrado $\left(\chi^{2}\right)(P \leq 0,05)$ (PROC FREQ, SAS INSTITUTE, 2000). Adicionalmente foi calculada a tabela de vida de fertilidade estimando-se o intervalo médio entre gerações $(\mathrm{T})$, a taxa líquida de reprodução (Ro), a taxa intrínseca de crescimento $\left(\mathrm{r}_{\mathrm{m}}\right)$ e a razão finita de crescimento $(\lambda)$. Os parâmetros da tabela de vida de fertilidade foram estimados por meio do software "Lifetable.sas" (MAIA; LUIZ; CAMPANHOLA, 2000) e comparados pelo teste $t$ bilateral $(P \leq 0,05)$ (SAS Institute, 2000).

\subsection{Resultados}

\subsubsection{Suscetibilidade de espécies de Spodoptera a Cry1Ac}

A toxicidade da proteína Cry1Ac contra $S$. cosmioides, $S$. eridania e $S$. frugiperda foi relativamente baixa (Tabela 5.1). Nas concentrações de 1,8, 10 e $18 \mu \mathrm{g}$ de Cry1Ac/mL de dieta, não houve diferenças significativas na mortalidade $(<12 \%)$ e inibição de desenvolvimento $(<15 \%)$ entre as três espécies de Spodoptera testadas. Em termos de mortalidade, diferenças na suscetibilidade foram verificadas na concentração de $32 \mu \mathrm{g}$ de 
Cry1 Ac/mL de dieta, na qual houve mortalidade significativamente maior de $S$. frugiperda $(\approx$ $30 \%$ de mortalidade), do que para $S$. cosmioides e $S$. eridania (mortalidade $<10 \%)(F=$ 18,13; g.l. = 2, 21; $P<0,0001)$. Na concentração de $100 \mu$ g de Cry1Ac/mL, a mortalidade $S$. frugiperda $(\approx 50 \%$ de mortalidade) foi signifivativamente superior daquela verificada para $S$. cosmioides e $S$. eridania $(<13 \%$ de mortalidade) $(F=34,57$; g.1. $=2,21 ; P<0,0001)$ (Tabela 5.1). A partir dos dados de mortalidade não foi possível estimar a $\mathrm{CL}_{50}$ para as espécies de Spodoptera, pois devido à baixa suscetibilidade desses insetos a Cry1Ac, a $\mathrm{CL}_{50}$ assumiria valores maiores que a máxima concentração testada $(100 \mu \mathrm{g}$ Cry1 Ac/mL de dieta).

Tabela 5.1 - Mortalidade e inibição de desenvolvimento de neonatas de espécies de Spodoptera expostas à proteína Cry1Ac purificada de B. thuringiensis incorporada em dieta artificial nas concentrações de 32 e $100 \mu \mathrm{g}$ Cry $1 \mathrm{Ac} / \mathrm{mL}$

\begin{tabular}{cccc}
\hline \multirow{2}{*}{ Espécie } & $n^{(2)}$ & \multicolumn{2}{c}{ Critério de resposta } \\
\cline { 3 - 4 } & & Mortalidade (\%) & Inibição de desenvolvimento (\%) \\
\hline Spodoptera cosmioides & 125 & $4,89 \pm 0,10 \mathrm{~b}$ & $32 \mu \mathrm{g}$ Cry1 Ac/mL de dieta \\
Spodoptera eridania & 129 & $7,34 \pm 1,24 \mathrm{~b}$ & $38,63 \pm 10,65 \mathrm{a}$ \\
Spodoptera frugiperda & 126 & $30,49 \pm 7,50 \mathrm{a}$ & $44,56 \pm 11,29 \mathrm{a}$ \\
& & & $100 \mu \mathrm{g}$ Cry1 Ac/mL de dieta \\
& & & \\
Spodoptera cosmioides & 129 & $8,63 \pm 3,20 \mathrm{~b}$ & $54,46 \pm 8,29 \mathrm{~b}$ \\
Spodoptera eridania & 129 & $12,26 \pm 4,85 \mathrm{~b}$ & $30,05 \pm 5,28 \mathrm{c}$ \\
Spodoptera frugiperda & 128 & $50,00 \pm 5,02 \mathrm{a}$ & $80,19 \pm 1,24 \mathrm{a}$
\end{tabular}

${ }^{(1)}$ Valores representam médias \pm EP. Uma análise de variância ANOVA (Tukey a $P \leq 0,05$ ) foi realizada comparando-se a suscetibilidade das espécies de Spodoptera a Cry1 Ac para as duas variáveis avaliadas.

${ }^{(2)}$ Número total de insetos testados.

Para a inibição do desenvolvimento, na concentração de $32 \mu \mathrm{g}$ de Cry1Ac/mL de dieta, $S$. frugiperda foi significativamente mais suscetível a Cry1Ac do que $S$. eridania e $S$. cosmioides $(F=1,12 ;$ g.l. $=2,21 ; P=0,3483)$. De modo semelhante, na concentração de 100 $\mu \mathrm{g}$ de Cry $1 \mathrm{Ac} / \mathrm{mL}$ de dieta, a inibição de desenvolvimento de $S$. frugiperda $(\approx 80 \%)$ foi significativamente superior daquele verificado para $S$. cosmioides $(\approx 54 \%)$ e $S$. eridania $(\approx$ $30 \%)(F=24,06 ;$ g.l. $=2,21 ; P<0,0001)$. No entanto, $S$. cosmioides apresentou maior inibição de desenvolvimento que S. eridania (Tabela 5.1). 


\subsubsection{Bioensaios com discos de folha}

De um modo geral, as lagartas neonatas das três espécies de Spodoptera avaliadas foram pouco suscetíveis à proteína Cry1Ac expressa nas folhas de soja MON $87701 \times$ MON 89788 (Tabela 5.2). Aos 5 dias após a infestação dos discos de folha, a mortalidade de $S$. cosmioides e S. eridania em soja MON $87701 \times$ MON 89788 foi < $10 \%$ e não diferiu significativamente daquela observada em soja isolinha não- $B t$ nos estádios fenológicos avaliados dos grupos de maturação 5.5 e 8.3. Por outro lado, S. frugiperda apresentou maior suscetibilidade a Cry1Ac expressa em soja MON $87701 \times$ MON 89788. A mortalidade de $S$. frugiperda foi significativamente maior em soja MON $87701 \times$ MON 89788, variando de 41 a $47 \%$ e 32 a $35 \%$ nos grupos de maturação 5.5 e 8.3, respectivamente (Tabela 5.2).

Entretanto, mesmo que a mortalidade não tenha sido elevada, as lagartas sobreviventes de $S$. cosmioides e $S$. eridania apresentaram significativa inibição de desenvolvimento devido à ingestão de Cry1Ac expressa em soja MON $87701 \times$ MON 89788 (Tabela 5.3). Aos 5 dias após a infestação, a inibição de desenvolvimento $S$. cosmioides e $S$. eridania variou de 28 a $42 \%$ e 33 a 49\%, respectivamente, nos diferentes estádios fenológicos avaliados dos grupos de maturação 5.5 e 8.3. De modo similar, à resposta de mortalidade, S. frugiperda também demonstrou maior inibição de desenvolvimento em soja MON $87701 \times$ MON 89788. A inibição de desenvolvimento de $S$. frugiperda em soja MON $87701 \times$ MON 89788 variou de 63 a 79\% nos estádios fenológicos avaliados dos grupos de maturação 5.5 e 8.3 (Tabela 5.3).

Em termos de enfezamento (lagartas que não atingiram $3^{\circ}$ ínstar larval), aos 5 dias após a infestação dos discos de folha, a proteína Cry1Ac expressa em folhas de soja MON $87701 \times$ MON 89788 ocasionou enfezamento significativo das três espécies de Spodoptera avaliadas (Tabela 5.4). De modo semelhante à mortalidade e inibição de desenvolvimento, $S$. cosmioides e S. eridania foram menos enfezadas do que S. frugiperda. Para $S$. cosmioides e $S$. eridania o enfezamento variou de 22 a $32 \%$ e 40 a 56\%, respectivamente. Por outro lado, para S. frugiperda houve elevado enfezamento, variando de 80 a 96\% nos estádios fenológicos avaliados dos grupos de maturação 5.5 e 8.3 (Tabela 5.4). 
Tabela 5.2 - Porcentagem de mortalidade de neonatas de espécies de Spodoptera após 5 dias da infestação de discos de folha da soja MON 87701 $\times$ MON 89788 do grupo de maturação 5.5 e 8.3 e soja isolinha não-Bt em laboratório, durante a safra 2010/11 e 2011/12. Piracicaba, São Paulo

\begin{tabular}{|c|c|c|c|c|c|c|}
\hline \multirow{2}{*}{ Tratamento } & \multicolumn{3}{|c|}{ Grupo de maturação 5.5 ${ }^{(1)}$} & \multicolumn{3}{|c|}{ Grupo de maturação $8.3^{(1)}$} \\
\hline & V3-V4 & V5-V6 & R1-R2 & V3-V4 & V5-V6 & R1-R2 \\
\hline & \multicolumn{6}{|c|}{ S. cosmioides } \\
\hline Soja MON $87701 \times$ MON 89788 & $3,86 \pm 1,10^{\mathrm{ns}}$ & $6,89 \pm 3,07^{\mathrm{ns}}$ & $5,49 \pm 4,09^{\mathrm{ns}}$ & $4,00 \pm 2,11^{\mathrm{ns}}$ & $6,89 \pm 3,07^{\mathrm{ns}}$ & $5,43 \pm 2,46^{\mathrm{ns}}$ \\
\hline \multirow[t]{2}{*}{ Soja isolinha não- $B t$} & $2,00 \pm 1,20$ & $1,21 \pm 0,90$ & $5,21 \pm 1,52$ & $1,21 \pm 0,90$ & $1,21 \pm 0,90$ & $4,17 \pm 2,23$ \\
\hline & \multicolumn{6}{|c|}{ S. eridania } \\
\hline Soja MON $87701 \times$ MON 89788 & $4,30 \pm 2,92^{\mathrm{ns}}$ & $4,26 \pm 4,09^{\mathrm{ns}}$ & $4,04 \pm 2,09^{\mathrm{ns}}$ & $4,35 \pm 2,15^{\mathrm{ns}}$ & $4,30 \pm 2,46^{\mathrm{ns}}$ & $6,52 \pm 4,09^{\mathrm{ns}}$ \\
\hline \multirow[t]{2}{*}{ Soja isolinha não- $B t$} & $3,13 \pm 1,52$ & $2,08 \pm 1,36$ & $1,96 \pm 1,15$ & $4,17 \pm 2,85$ & $3,13 \pm 2,19$ & $4,17 \pm 2,23$ \\
\hline & \multicolumn{6}{|c|}{ S. frugiperda } \\
\hline Soja MON $87701 \times$ MON 89788 & $41,49 \pm 5,09$ & $47,48 \pm 5,55$ & $41,30 \pm 4,38$ & $35,23 \pm 7,62$ & $34,41 \pm 4,15$ & $32,95 \pm 3,84$ \\
\hline Soja isolinha não- $B t$ & $2,08 \pm 1,36$ & $6,25 \pm 2,61$ & $4,17 \pm 2,23$ & $8,33 \pm 2,23$ & $3,13 \pm 2,19$ & $8,33 \pm 2,73$ \\
\hline
\end{tabular}

${ }^{(1)}$ Valores representam médias \pm EP. Uma análise de variância ANOVA (teste $t$ a $P \leq 0,05$ ) foi realizada entre a soja MON $87701 \times$ MON 89788 e soja isolinha não-Bt para cada espécie de Spodoptera, grupo de maturação e estádio fenológico.

ns ...não significativo $(P \leq 0,05)$. Para Spodoptera frugiperda houve diferença estatística significativa entre a soja MON $87701 \times$ MON 89788 e soja isolinha não-Bt em todos os estádios fenológicos avalidos de cada grupo de maturação. 
Tabela 5.3 - Porcentagem de inibição de desenvolvimento de neonatas de espécies de Spodoptera após 5 dias da infestação de discos de folha da soja MON $87701 \times$ MON 89788 do grupo de maturação 5.5 e 8.3 e soja isolinha não-Bt em laboratório, durante a safra 2010/11 e 2011/12. Piracicaba, São Paulo

\begin{tabular}{|c|c|c|c|c|c|c|}
\hline \multirow{2}{*}{ Tratamento } & \multicolumn{3}{|c|}{ Grupo de maturação $5.5^{(1)}$} & \multicolumn{3}{|c|}{ Grupo de maturação $8.3^{(1)}$} \\
\hline & V3-V4 & V5-V6 & R1-R2 & V3-V4 & V5-V6 & R1-R2 \\
\hline & \multicolumn{6}{|c|}{ S. cosmioides } \\
\hline Soja MON $87701 \times$ MON 89788 & $28,90 \pm 4,97$ & $32,61 \pm 7,16$ & $36,64 \pm 6,13$ & $30,87 \pm 6,58$ & $42,64 \pm 4,34$ & $31,90 \pm 5,38$ \\
\hline \multirow[t]{2}{*}{ Soja isolinha não- $B t$} & $0,00 \pm 0,00$ & $0,00 \pm 0,00$ & $0,00 \pm 0,00$ & $0,00 \pm 0,00$ & $0,00 \pm 0,00$ & $0,00 \pm 0,00$ \\
\hline & \multicolumn{6}{|c|}{ S. eridania } \\
\hline Soja MON $87701 \times$ MON 89788 & $33,24 \pm 6,14$ & $36,77 \pm 2,74$ & $40,86 \pm 4,74$ & $49,19 \pm 5,53$ & $33,32 \pm 7,76$ & $35,78 \pm 6,24$ \\
\hline \multirow[t]{2}{*}{ Soja isolinha não- $B t$} & $0,00 \pm 0,00$ & $0,00 \pm 0,00$ & $0,00 \pm 0,00$ & $0,00 \pm 0,00$ & $0,00 \pm 0,00$ & $0,00 \pm 0,00$ \\
\hline & \multicolumn{6}{|c|}{ S. frugiperda } \\
\hline Soja MON $87701 \times$ MON 89788 & $79,79 \pm 1,61$ & $71,65 \pm 2,23$ & $72,69 \pm 2,52$ & $64,04 \pm 3,08$ & $63,18 \pm 4,13$ & $79,84 \pm 6,39$ \\
\hline Soja isolinha não- $B t$ & $0,00 \pm 0,00$ & $0,00 \pm 0,00$ & $0,00 \pm 0,00$ & $0,00 \pm 0,00$ & $0,00 \pm 0,00$ & $0,00 \pm 0,00$ \\
\hline
\end{tabular}

MON 89788 e soja isolinha não-Bt em todos os estádios fenológicos avaliados de cada grupo de maturação. 
Tabela 5.4 - Porcentagem de enfezamento (lagartas que não atingiram o terceiro ínstar) de espécies de Spodoptera após 5 dias da infestação de discos de folha da soja MON $87701 \times$ MON 89788 do grupo de maturação 5.5 e 8.3 e soja isolinha não-Bt em laboratório, durante a safra 2010/11 e 2011/12. Piracicaba, São Paulo

\begin{tabular}{|c|c|c|c|c|c|c|}
\hline Tratamento & \multicolumn{3}{|c|}{ Grupo de maturação $5.5^{(1)}$} & \multicolumn{3}{|c|}{ Grupo de maturação $8.3^{(1)}$} \\
\hline & \multicolumn{6}{|c|}{ S. cosmioides } \\
\hline Soja MON $87701 \times$ MON 89788 & $22,53 \pm 3,13$ & $27,54 \pm 4,44$ & $30,47 \pm 8,64$ & $24,98 \pm 4,56$ & $32,87 \pm 9,63$ & $26,33 \pm 8,69$ \\
\hline Soja isolinha não- $B t$ & $8,06 \pm 2,14$ & $6,27 \pm 3,36$ & $10,42 \pm 3,61$ & $10,76 \pm 2,11$ & $9,09 \pm 3,21$ & $7,29 \pm 1,04$ \\
\hline Soja MON $87701 \times$ MON 89788 & $56,67 \pm 8,81$ & $48,01 \pm 7,14$ & $46,86 \pm 4,74$ & $42,99 \pm 7,04$ & $44,37 \pm 6,22$ & $40,78 \pm 8,24$ \\
\hline \multirow[t]{2}{*}{ Soja isolinha não- $B t$} & $9,37 \pm 3,13$ & $2,08 \pm 2,08$ & $6,83 \pm 2,70$ & $2,04 \pm 1,39$ & $8,33 \pm 4,50$ & $6,13 \pm 3,41$ \\
\hline & \multicolumn{6}{|c|}{ S. frugiperda } \\
\hline
\end{tabular}




\subsubsection{Parâmetros biológicos de espécies de Spodoptera em soja MON $87701 \times$ MON 89788}

Não houve diferença significativa para a fase de ovo de $S$. cosmioides $(t=6,88$; g.l. = $1,14 ; P=0,4330), S$. eridania $(t=5,62 ;$ g.l. $=1,17 ; P=0,2775)$ e $S$. frugiperda $(t=6,08$; g.l. $=1,18 ; P=0,5560)$ em soja MON $87701 \times$ MON 89788, comparativamente a soja isolinha não- $B t$ (Figura 5.2). Para a fase larval não houve diferença significativas para $S$. cosmioides ( $t$ $=3,98 ;$ g.l. $=1,18 ; P=0,0533)$ e $S$. eridania $(t=4,67 ;$ g.l. $=1,18 ; P=0,1360)$ quando alimentadas com folhas de soja MON $87701 \times$ MON 89788. No entanto, houve um aumento significativo, $\approx 5$ dias na fase larval de $S$. frugiperda $(t=3,00 ;$ g.l. $=1,18 ; P=0,0012) \mathrm{em}$ consequência da alimentação em soja MON $87701 \times$ MON 89788 (Figura 5.2). A duração da fase de pupa de $S$. cosmioides $(t=6,42 ;$ g.1. $=1,18 ; P<0,1157)$, $S$. eridania $(t=7,31 ;$ g.1. $=1$, $18 ; P=0,8795)$ e $S$. frugiperda $(t=7,28 ;$ g.l. $=1,18 ; P=0,9629)$ não foi afetada pela soja MON $87701 \times$ MON 89788 (Figura 5.2). De modo semelhante, ciclo total (ovo-adulto) de $S$. cosmioides $(t=7,17 ;$ g.l. $=1,18 ; P=0,8582)$ e $S$. eridania $(t=4,80 ;$ g.l. $=1,18 ; P=0,1806)$ também não foi afetado pela soja MON $87701 \times$ MON 89788. Em contraste, a maior duração da fase larval de S. frugiperda em soja MON $87701 \times$ MON 89788 impactou significativamente o ciclo total $(t=2,92 ;$ g.l. $=1,18 ; P=0,0298)$, aumentando em $\approx 15 \%(\approx$ 5,5 dias) o tempo necessário para $S$. frugiperda completar o ciclo biológico em soja MON $87701 \times$ MON 89788, comparativamente a soja isolinha não-Bt (Figura 5.2).

A viabilidade de ovos de $S$. cosmioides $(t=5,30 ;$ g.l. $=1,18 ; P=0,6787), S$. eridania $(t=6,87$; g.l. $=1,17 ; P=0,8657)$ e $S$. frugiperda $(t=5,57$; g.l. $=1,18 ; P<0,6988)$ não foi afetada pela soja MON $87701 \times$ MON 89788 (Figura 5.2). De modo semelhante, a viabilidade larval de $S$. cosmioides $(t=6,60 ;$ g.l. $=1,18 ; P=0,8590)$ e $S$. eridania $(t=3,82 ;$ g.l. $=1,18$; $P=0,1034)$ foi similar entre a soja MON $87701 \times$ MON 89788 e soja isolinha não-Bt. Por outro lado, a viabilidade larval de $S$. frugiperda $(t=2,12$; g.l. $=1,18 ; P<0,0001)$ foi significativamente menor em soja MON $87701 \times$ MON 89788 (37\%), comparativamente a soja isolinha não-Bt (82\%). Não houve diferenças significativas na viabilidade pupal de $S$. cosmioides $(t=5,96 ;$ g.l. $=1,18 ; P=0,7521)$, S. eridania $(t=4,02 ;$ g.1. $=1,18 ; P=0,2861) \mathrm{e}$ S. frugiperda $(t=4,98 ;$ g.l. $=1,18 ; P=0,4855)$ em soja MON $87701 \times$ MON 89788. A viabilidade do ciclo total de $S$. cosmioides $(t=7,12$; g.l. $=1,18 ; P=0,9025)$ e $S$. eridania $(t=$ 5,47; g.l. $=1,18 ; P=0,5836)$ também não foi significativamente afetado pela soja MON $87701 \times$ MON 89788. Ao contrário, para S. frugiperda $(t=1,77 ;$ g.l. $=1,18 ; P<0,0001)$ a baixa viabilidade larval em soja MON $87701 \times$ MON 89788 afetou significativamente a viabilidade do ciclo total, com menos de $27 \%$ das lagartas atingindo a fase adulta (Figura 5.2). 

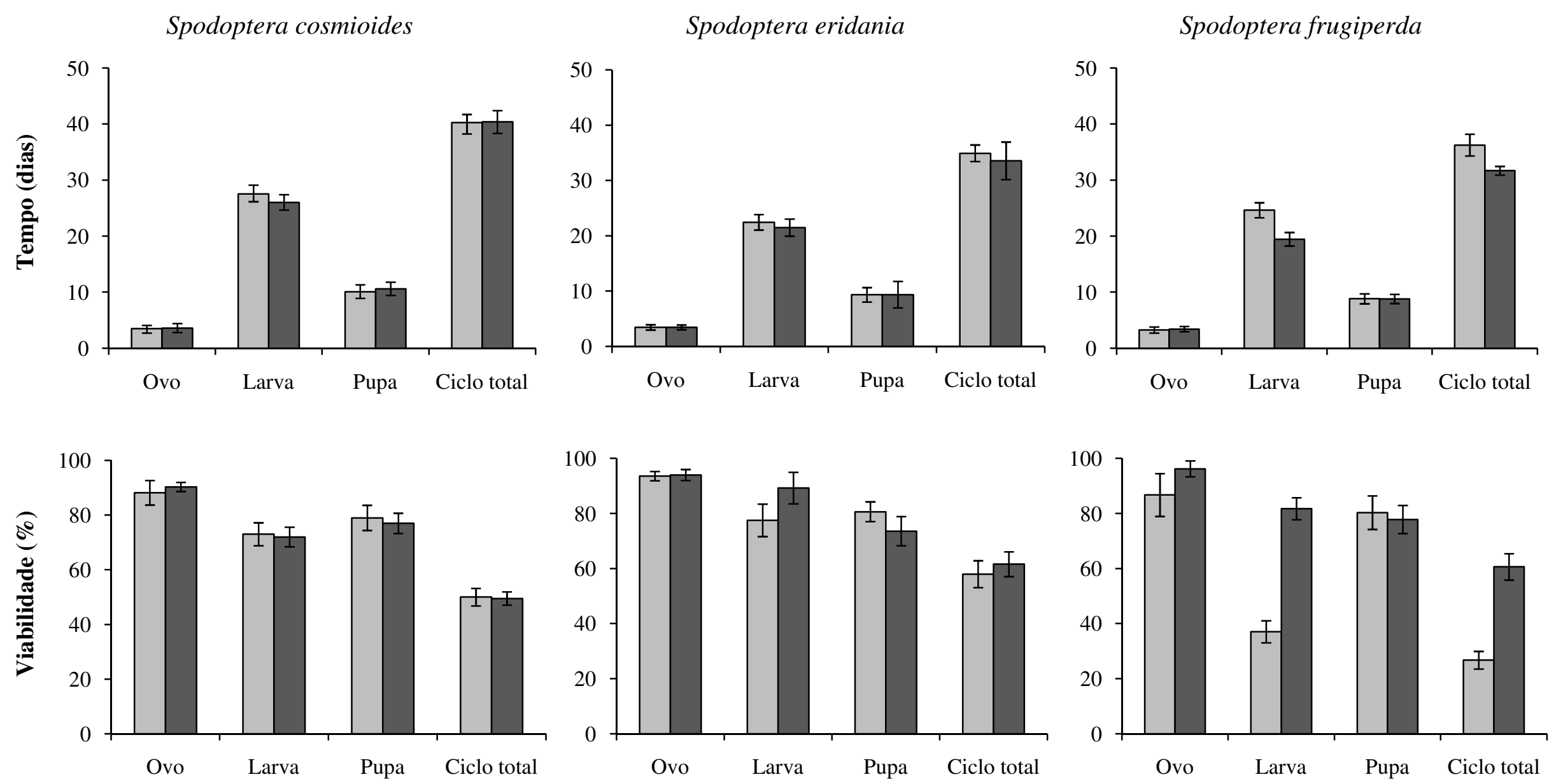

Fases de desenvolvimento

$\square$ Soja MON $87701 \times$ MON $89788 \quad \square$ Soja isolinha não-Bt

Figura 5.2 - Duração e viabilidade ( \pm EP) das fases de ovo, larva, pupa e ciclo total (ovo-adulto) de espécies Spodoptera alimentadas com folhas de soja MON $87701 \times$ MON 89788 e soja isolinha não-Bt do grupo de maturação 8.3. Piracicaba, São Paulo 
A biomassa larval de $S$. cosmioides, $S$. eridania e $S$. frugiperda aos 14 dias após a inoculação (DAI) foi significativamente menor para as lagartas alimentadas com soja MON $87701 \times$ MON 89788, comparativamente àquelas alimentadas com soja isolinha não-Bt. Entretanto, as diferenças no ganho de peso das lagartas não se refletiram na biomassa de pupas de S. cosmioides e S. eridania. Por outro lado, as pupas de S. frugiperda em soja MON $87701 \times$ MON 89788 foram mais leves daquelas obtidas de lagartas alimentadas com soja isolinha não-Bt. A razão sexual das espécies de Spodoptera não foi afetada devido à alimentação das lagartas em soja MON 87701 × MON 89788 (Tabela 5.5).

Tabela 5.5 - Biomassa larval aos 14 dias após a inoculação (DAI), biomassa de pupas e razão sexual de espécies de Spodoptera alimentadas com folhas de soja MON $87701 \times$ MON 89788 e soja isolinha não-Bt do grupo de maturação 8.3. Piracicaba, São Paulo

\begin{tabular}{|c|c|c|c|}
\hline Parâmetro biológico ${ }^{(1)}$ & $\begin{array}{c}\text { Soja } \\
\text { MON } 87701 \times \text { MON } 89788\end{array}$ & $\begin{array}{c}\text { Soja } \\
\text { isolinha não- } B t\end{array}$ & Valor $P$ \\
\hline & \multicolumn{3}{|c|}{ S. cosmioides } \\
\hline Biomassa larval 14 DAI & $305,04 \pm 18,73$ & $378,53 \pm 13,06$ & 0,0060 \\
\hline Biomassa de pupas (mg) & $290,27 \pm 10,76$ & $284,52 \pm 8,54$ & 0,2539 \\
\hline \multirow{2}{*}{ Razão sexual $(+/ q+\widehat{)})$} & $0,48^{\mathrm{ns}}$ & $0,49^{\text {ns }}$ & - \\
\hline & \multicolumn{3}{|c|}{ S. eridania } \\
\hline Biomassa larval 14 DAI & $178,72 \pm 8,83$ & $228,62 \pm 13,18$ & 0,0056 \\
\hline Biomassa de pupas (mg) & $218,89 \pm 9,46$ & $204,52 \pm 2,80$ & 0,1626 \\
\hline \multirow[t]{2}{*}{ Razão sexual $\left(q / q+\bigcirc^{\lambda}\right)$} & $0,51^{\mathrm{ns}}$ & $0,54^{\mathrm{ns}}$ & - \\
\hline & \multicolumn{3}{|c|}{ S. frugiperda } \\
\hline Biomassa larval 14 DAI & $87,05 \pm 6,20$ & $232,89 \pm 7,37$ & $<0,0001$ \\
\hline Biomassa de pupas (mg) & $114,19 \pm 7,97$ & $170,15 \pm 3,17$ & $<0,0001$ \\
\hline Razão sexual $(q / q+\overbrace{}^{\pi})$ & $0,48^{\mathrm{ns}}$ & $0,47^{\mathrm{ns}}$ & - \\
\hline
\end{tabular}

${ }^{(1)}$ Valores representam médias \pm EP. Para cada espécie de Spodoptera uma análise de variância ANOVA (teste $t$ a $P \leq 0,05)$ foi realizada entre a soja MON $87701 \times$ MON 89788 e soja isolinha não-Bt para cada parâmetro biológico.

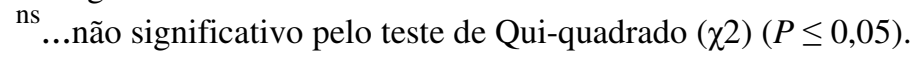

Para as S. cosmioides e S. eridania, o desenvolvimento da fase imatura em soja MON $87701 \times$ MON 89788 não afetou a longevidade de adultos, período de pré-oviposição, oviposição, pós-oviposição e a fecundidade diária e total (Tabela 5.6). Por outro lado, para $S$. frugiperda a soja MON $87701 \times$ MON 89788 afetou a fecundidade diária e total, 
demonstrando que as fêmeas originadas de lagartas alimentadas com soja MON $87701 \times$ MON 89788 reduziram em $\approx 65 \%$ a capacidade de oviposição (fecundidade total), não sendo capazes de manter o mesmo desempenho reprodutivo daz fêmeas originadas em soja isolinha não-Bt.

Tabela 5.6 - Longevidade de adultos, período de pré-oviposição, oviposição, pós-oviposição e fecundidade diária e total de espécies de Spodoptera alimentadas com folhas de soja MON $87701 \times$ MON 89788 e soja isolinha não-Bt do grupo de maturação 8.3. Piracicaba, São Paulo

\begin{tabular}{|c|c|c|c|}
\hline Parâmetro biológico ${ }^{(1)}$ & $\begin{array}{c}\text { Soja } \\
\text { MON } 87701 \times \text { MON } 89788\end{array}$ & $\begin{array}{c}\text { Soja } \\
\text { isolinha não- } B t\end{array}$ & Valor $P$ \\
\hline & \multicolumn{3}{|c|}{ S. cosmioides } \\
\hline Longevidade de adultos (dias) & $12,50 \pm 1,43$ & $12,36 \pm 1,73$ & 0,9446 \\
\hline Pré-oviposição (dias) & $4,50 \pm 0,42$ & $3,00 \pm 0,58$ & 0,0872 \\
\hline Oviposição (dias) & $7,67 \pm 0,98$ & $5,75 \pm 1,44$ & 0,4583 \\
\hline Pós-oviposição (dias) & $3,33 \pm 1,03$ & $4,00 \pm 0,89$ & 0,7297 \\
\hline Fertilidade diária & $296,86 \pm 85,19$ & $234,38 \pm 35,18$ & 0,0937 \\
\hline \multirow[t]{2}{*}{ Fertilidade total } & $1744,47 \pm 373,04$ & $1336,38 \pm 294,33$ & 0,5670 \\
\hline & \multicolumn{3}{|c|}{ S. eridania } \\
\hline Longevidade de adultos (dias) & $15,40 \pm 1,03$ & $14,35 \pm 1,04$ & 0,4779 \\
\hline Pré-oviposição (dias) & $3,20 \pm 0,49$ & $3,10 \pm 0,38$ & 0,8735 \\
\hline Oviposição (dias) & $8,90 \pm 1,04$ & $8,30 \pm 0,97$ & 0,6301 \\
\hline Pós-oviposição (dias) & $5,00 \pm 1,26$ & $4,00 \pm 1,09$ & 0,5560 \\
\hline Fecundidade diária & $167,72 \pm 13,56$ & $186,66 \pm 21,84$ & 0,4700 \\
\hline \multirow[t]{2}{*}{ Fecundidade total } & $1575,20 \pm 210,19$ & $1433,80 \pm 105,95$ & 0,5555 \\
\hline & \multicolumn{3}{|c|}{ S. frugiperda } \\
\hline Longevidade de adultos (dias) & $15,46 \pm 1,82$ & $16,58 \pm 1,21$ & 0,5963 \\
\hline Pré-oviposição (dias) & $4,67 \pm 1,20$ & $3,60 \pm 1,60$ & 0,6030 \\
\hline Oviposição (dias) & $9,67 \pm 1,07$ & $8,11 \pm 1,65$ & 0,4109 \\
\hline Pós-oviposição (dias) & $5,67 \pm 2,88$ & $7,67 \pm 2,55$ & 0,6501 \\
\hline Fertilidade diária & $31,59 \pm 10,83$ & $129,45 \pm 41,30$ & 0,0041 \\
\hline Fertilidade total & $377,70 \pm 133,75$ & $1061,00 \pm 326,93$ & 0,0001 \\
\hline
\end{tabular}

\footnotetext{
(1) Valores representam médias \pm EP. Para cada espécie de Spodoptera uma análise de variância ANOVA (teste $t$ a $P \leq 0,05)$ foi realizada entre a soja MON $87701 \times$ MON 89788 e soja isolinha não-Bt para cada parâmetro biológico.
} 
Devido à soja MON 87701 × MON 89788 não afetar parâmetros biológicos da fase imatura e o desempenho reprodutivo dos adultos de $S$. cosmioides e $S$. eridania, também não houve diferenças significativas $(P \leq 0,05)$ nos parâmetros da tabela de vida de fertilidade dessas duas espécies em soja MON $87701 \times$ MON 89788 e isolinha não-Bt (Tabela 5.7).

Tabela 5.7 - Parâmetros de tabela de vida ( \pm EP) de espécies de Spodoptera em soja MON $87701 \times$ MON 89788 e soja isolinha não-Bt estimados pelo método "jackknife". Piracicaba, São Paulo

\begin{tabular}{|c|c|c|c|}
\hline Parâmetro biológico ${ }^{(1)}$ & $\begin{array}{c}\text { Soja } \\
\text { MON } 87701 \times \text { MON } 89788\end{array}$ & $\begin{array}{c}\text { Soja } \\
\text { isolinha não- } B t\end{array}$ & Valor $P$ \\
\hline & \multicolumn{3}{|c|}{ S. cosmioides } \\
\hline $\mathrm{T}$ & $46,35 \pm 0,35$ & $46,51 \pm 0,33$ & 0,6494 \\
\hline Ro & $358,72 \pm 59,96$ & $320,86 \pm 70,75$ & 0,3355 \\
\hline $\mathrm{r}_{\mathrm{m}}$ & $0,126 \pm 0,004$ & $0,125 \pm 0,003$ & 0,2800 \\
\hline \multirow[t]{2}{*}{$\lambda$} & $1,138 \pm 0,003$ & $1,133 \pm 0,005$ & 0,1833 \\
\hline & \multicolumn{3}{|c|}{ S. eridania } \\
\hline $\mathrm{T}$ & $41,68 \pm 0,30$ & $42,02 \pm 0,41$ & 0,0530 \\
\hline Ro & $475,30 \pm 34,98$ & $457,58 \pm 59,60$ & 0,8035 \\
\hline $\mathrm{r}_{\mathrm{m}}$ & $0,149 \pm 0,002$ & $0,144 \pm 0,004$ & 0,3046 \\
\hline \multirow[t]{2}{*}{$\lambda$} & $1,160 \pm 0,003$ & $1,155 \pm 0,005$ & 0,3044 \\
\hline & \multicolumn{3}{|c|}{ S. frugiperda } \\
\hline $\mathrm{T}$ & $44,54 \pm 1,28$ & $36,33 \pm 3,90$ & 0,0250 \\
\hline Ro & $53,78 \pm 21,27$ & $292,99 \pm 93,81$ & 0,0323 \\
\hline $\mathrm{r}_{\mathrm{m}}$ & $0,091 \pm 0,010$ & $0,154 \pm 0,023$ & 0,0276 \\
\hline$\lambda$ & $1,095 \pm 0,012$ & $1,166 \pm 0,027$ & 0,0324 \\
\hline
\end{tabular}

${ }^{(1)} \mathrm{T}=$ duração de cada geração; Ro = taxa líquida de reprodução; $\mathrm{r}_{\mathrm{m}}=$ razão infinitesimal de aumento e $\lambda=$ razão finita de aumento.

Em contraste, houve diferenças significativas em todos os parâmetros biológicos da tabela de vida de fertilidade de $S$. frugiperda quando da alimentação e desenvolvimento em soja MON $87701 \times$ MON 89788. Para S. frugiperda houve um aumento significativo no intervalo médio entre gerações $(\mathrm{T})$ quando os insetos foram alimentados em soja MON 87701 $\times$ MON 89788. Os valores da taxa líquida de reprodução (Ro) de S. frugiperda indicaram que o fato das lagartas se desenvolverem em soja MON $87701 \times$ MON 89788 reduz em $\approx 81 \%$ a capacidade das fêmeas em aumentar a população. Com base nesses resultados, decorridos 
44,5 dias (T), de desenvolvimento de S. frugiperda em soja MON $87701 \times$ MON 89788 são esperadas $\approx 54$ fêmeas resultantes de cada fêmea em fase de reprodução (Ro), enquanto que, na soja isolinha não- $B t$, após 36,3 dias $(\mathrm{T})$ se espera $\approx 293$ fêmeas (Ro). Além disso, o desenvolvimento de $S$. frugiperda em soja MON $87701 \times$ MON 89788 afetou significativamente os valores de taxa intrínseca de crescimento $\left(\mathrm{r}_{\mathrm{m}}\right)$, indicando redução de $\approx$ $41 \%$ na capacidade de aumento populacional da praga. No que se refere à razão finita de aumento $(\lambda)$ verificou-se que o crescimento populacional diário de $S$. frugiperda foi $\approx 6 \%$ menor em soja MON $87701 \times$ MON 89788, comparativamente a soja isolinha não-Bt (Tabela 5.7).

\subsection{Discussão}

Em geral, S. cosmioides, S. eridania e S. frugiperda foram pouco suscetíveis a Cry1Ac. Entretanto, dentre as três espécies avaliadas, S. frugiperda foi àquela que apresentou maior suscetibilidade a Cry1Ac purificada e expressa em soja MON $87701 \times$ MON 89788, mas o efeito tóxico não foi suficiente para ocasinar elevada mortalidade. A baixa toxicidade da proteína Cry1Ac para S. cosmioides, S. eridania, S. frugiperda foi demonstrado em trabalhos de seleção de cepas de Bt para controle dessas espécies (SANTOS et al., 2009), em incoporação em dieta artificial (LUTTRELL; WAN; KNIGHTEN, 1999) e quando expressa em algodão Bt (Bollgard $^{\circledR}$ ) (ADAMCZYK et al., 2008; SIQUEIRA; MIRANDA, 2009; GREENBERG; LI; LIU, 2010). A baixa toxicidade de Cry1Ac para espécies de Spodoptera, pode estar relacionada com a grande variabilidade genética entre as populações e a tolerância natural desses insetos à diferentes proteínas de $B t$. Isso foi demonstrado para populações nativas de $S$. frugiperda do México, Brasil e Colômbia, as quais apresentam diferenças na suscetibilidade a cepas de $B t$ devido à alta variabilidade genética entre as populações, fato que resulta em grupos que não apresentam receptores para determinadas proteínas de $B t$ e, portanto, são insensíveis às proteínas inseticidas (MONNERAT et al., 2006). Adicionalmente, uma quantidade insuficiente e/ou fraca ligação da proteína inseticida nos sítios de ligação do intestino médio também pode afetar a suscetibilidade a Cry1Ac, isso foi demonstrado para $S$. frugiperda a Cry1Ab (ARANDA et al., 1996) e S. exigua a Cry1C (de MAAGD et al., 2000), também pode estar relacionada com a inativação da proteína inseticida por proteases (MIRANDA; ZAMUDIO; BRAVO, 2001; RAHMAN et al., 2012).

De um modo geral, a soja MON $87701 \times$ MON 89788 apresentou baixa toxicidade para espécie de Spodoptera em bioensaios com discos de folha e estudo de biologia, não 
exercendo controle efetivo desses insetos. Por outro lado, a presença de Cry1Ac em soja MON $87701 \times$ MON 89788 ocasionou mortalidade intermediária de S. frugiperda e afetou a biomassa larval, prolongando a fase de desenvolvimento larval, e consequentemente, o tempo necessário para o inseto completar o ciclo biológico. Recentemente foi demonstrado que $S$. frugiperda quando alimentada com algodão Bt (Bollgard $^{\circledR}$ ) que também expressa Cry1Ac apresenta menor biomassa larval, devido à alteração nos índices nutricionais de ingestão, digestão e assimilação do alimento (RAMALHO et al., 2011).

No contexto do MIP, por não controlar as espécies de Spodoptera, em conjunto com a soja MON $87701 \times$ MON 89788 será necessário o emprego de outra tática de controle quando da infestação a campo. No entanto, devido à soja MON $87701 \times$ MON 89788 ocasionar redução de desenvolvimento e enfezamento das espécies de Spodoptera, especialmente nos ínstares iniciais de desenvolvimento, em teoria isso torna os insetos mais expostos e suscetíveis aos fatores bióticos e abióticos de mortalidade e podem facilitar o manejo a campo, pois a redução de biomassa das lagartas é consequência da redução no consumo foliar e, por conseguinte, dos danos ocasionados às plantas. Não obstante, em início de infestação, o uso de inseticidas seletivos em conjunto com o controle biológico natural pode aumentar a mortalidade das lagartas de Spodoptera em soja MON $87701 \times$ MON 89788, uma vez que nenhum efeito negativo da proteína Cry1Ac foi relatado sobre inimigos naturais (BAUR; BOETHEL, 2003; HEAD et al., 2005; ROMEIS; MEISSLE; BIGLER, 2006).

Em termos de MRI, a elevada sobrevivência de espécies de Spodoptera em soja MON $87701 \times$ MON 89788 caracteriza como sendo evento de baixa dose, pois uma grande quantidade de insetos completa o ciclo biológico. Nessa situação, os coeficientes de seleção serão relativamente baixos, fato que minimiza a pressão de seleção para resistência em populações de $S$. cosmioides, S. eridania e S. frugiperda. Entretanto, a maior toxicidade da soja MON $87701 \times$ MON 89788 para S. frugiperda aumentou a duração do ciclo biológico, afetando a capacidade de aumento populacional e o número de gerações da praga quando o inseto se desenvolver sucessivamente em soja MON $87701 \times$ MON 89788. No contexto de MRI, a diferença na duração do ciclo biológico não caracteriza uma situação de assincronia de acasalamento entre os insetos que emergem na área com soja MON $87701 \times$ MON 89788 e aqueles da área de refúgio (soja não- $B t$ ), pois em condições de campo, há sobreposição de gerações e de plantas hospedeiras de $S$. frugiperda. Não obstante, o tamanho da área de refúgio (20\% de soja não-Bt) aprovado pela CTNBio também contribuirá para o fornecimento de S. frugiperda para acasalamento com os insetos sobreviventes da área com soja MON $87701 \times$ MON 89788 e, consequentemente, minimizar o risco de evolução da resistência. 
Futuramente, para o MRI e MIP de espécies de Spodoptera em soja uma alternativa é a piramidação de proteínas de $B t$. Dentre as proteínas de $B t$ expressas em plantas transgênicas com potencial para piramidação estão Cry1A.105, Cry1F, Cry2Ab2 e VIP3A, as quais possuem maior toxicidade para espécies de Spodoptera. No entanto, num cenário de sobreposição de cultivos de soja, algodão e milho o desafio atual é preservar a suscetibilidade desses insetos às proteínas de $B t$, uma vez que, essas espécies estão expostas a pressão de seleção por diferentes proteínas de $B t$ em milho (S. frugiperda) e algodão $B t$ ( $S$. frugiperda, $S$. eridania e $S$. cosmioides). Diante disso, é de extrema importância considerar as particularidades dos diferentes regimes de seleção que as espécies de Spodoptera estão expostas devido ao sistema de produção para o estabelecimento de estratégias de MRI.

\subsection{Conclusões}

- A protéina Cry1Ac expressa em soja MON $87701 \times$ MON 89788 apresenta baixa toxicidade para espécies de Spodoptera.

- A soja MON 87701 × MON 89788 não afeta parâmetros biológicos de $S$. eridania e $S$. cosmioides.

- A soja MON $87701 \times$ MON 89788 causa redução na taxa intrínseca de crescimento populacional de $S$. frugiperda.

- A soja MON $87701 \times$ MON 89788 é de baixa dose para espécies de Spodoptera.

\section{Referências}

ABBOTT, W.S. A method of computing the effectiveness of an insecticide. Journal of Economic Entomology, Lanham, v. 18, n. 1, p. 265-266, 1925.

ADAMCZYK, J.J.; GREENBERG, S.; ARMSTRONG, J.S.; MULLINS, W.J.; BRAXTON, L.B.; LASSITER, R.B.; SIEBERT, M.W. Evaluations of Bollgard ${ }^{(\circledR)}$, Bollgard II ${ }^{(\circledR)}$, and Widestrike $^{(\circledR)}$ technologies against beet and fall armyworm larvae (Lepidoptera: Noctuidae). Florida Entomologist, Gainesville, v. 91, n. 4, p. 531-536, 2008.

ARANDA, E.; SANCHEZ, J.; PEFEROEN, M.; GÜERECA, L.; BRAVO, A. Interactions of Bacillus thuringiensis crystal proteins with the midgut epithelial cells of Spodoptera frugiperda (Lepidoptera: Noctuidae). Journal of Invertebrate Pathology, San Diego, v. 68, n. 3, p. 203-212, 1996. 
BAUR, M.E.; BOETHEL, D.J. Effect of Bt-cotton expressing Cry1A(c) on the survival and fecundity of two hymenopteran parasitoids (Braconidae, Encyrtidae) in the laboratory.

Biological Control, Orlando, v. 26, n. 3, p. 325-332, 2003.

CTNBIO, Comissão Técnica Nacional de Biossegurança. Liberação comercial de soja geneticamente modificada resistente a insetos e tolerante a herbicida, soja MON $87701 \times$ MON 89788. In: Parecer Técnico no ${ }^{\circ} 2542 / 2010$. Disponível em:

<http://www.ctnbio.gov.br/index.php/content/view/15558.html>. Acesso em: 15 dez. 2010.

de MAAGD, R.A.; WEMEN-HENDRICKS, M.; STIEKEMA, W.; BOSCH, D. Bacillus thuringiensis delta-endotoxin Cry1C domain III can function as a specificity determinant for Spodoptera exigua in different, but not all, Cry1-Cry1C hybrids. Applied and

Environmental Microbiology, Washington, v. 66, n. 4, p. 1559-1563, 2000.

FERRÉ, J.; VAN RIE, J. Biochemistry and genetics of insect resistance to Bacillus thuringiensis. Annual Review of Entomology, Palo Alto, v. 47, p. 501-543, 2002.

GREENBERG, S.M.; LI, Y.X.; LIU, T.X. Effect of age of transgenic cotton on mortality of lepidopteran larvae. Southwestern Entomologist, Weslaco, v. 35, n. 3, p. 261-268, 2010.

GOMEZ, S.A. É tempo de preocupação com as pragas da soja. Revista Campo e Negócios HF, Uberlândia, v. 5, n. 43, p. 2, 2009.

HEAD, G.; MOAR, W.; EUBANKS, M.; FREEMAN, B.; RUBERSON, J.; HAGERTY, A.; TURNIPSEED, S. A multiyear, large-scale comparison of arthropod population on commercially managed $B t$ and Non- $B t$ cotton fields. Journal of Economic Entomology, Lanham, v. 34, n. 5, p. 1257-1266, 2005.

HOFFMANN-CAMPO, C.B.; MOSCRADI, F.; CORRÊA-FERREIRA, B.; OLIVEIRA, L.J.; SOSA-GÓMEZ, D.; PANIZZI, A.R.; CORSO, I.C.; GAZZONI, D.L.; OLIVEIRA, E.B. Pragas da soja no Brasil e seu manejo integrado. Londrina: Embrapa Centro Nacional de Pesquisa de Soja, 2000. 70 p. (Embrapa CNPSo, Circular Técnica, 30).

LUTTRELL R.G.; WAN L.; KNIGHTEN K. Variation in susceptibility of Noctuid (Lepidoptera) larvae attacking cotton and soybean to purified endotoxin proteins and commercial formulations of Bacillus thuringiensis. Journal of Economic Entomology, Lanham, v. 92, n. 1, p. 21-32, 1999.

MAIA, H.N.M.; LUIZ, A.J.B.; CAMPANHOLA, C. Statistical inference on associated fertility life table parameters using jackknife technique: computational aspects. Journal of Economic Entomology, Lanham, v. 93, n. 2, p. 511-518, 2000.

MIRANDA, R.; ZAMUDIO F.Z.; BRAVO, A. Processing of Cry1Ab delta-endotoxin from Bacillus thuringiensis by Manduca sexta and Spodoptera frugiperda midgut proteases: role in protoxin activation and toxin inactivation. Insect Biochemistry and Molecular Biology, Oxford, v. 31, n. 12, p. 1155-1163, 2001. 
MOAR, W.J.; PUSZTAI-CAREY, M.; VAN FAASSEN, H.; BOSCH, D.; FRUTOS, R.; RANG, C.; LUO, K.; ADANG, M.J. Development of Bacillus thuringiensis Cry1C resistance by Spodoptera exigua (Hübner) (Lepidoptera: Noctuidae). Applied and Environmental Microbiology, Washington, v. 61, n. 6, p. 2086-2092, 1995.

MONNERAT, R.; MARTINS, E.; QUEIROZ, P.; ORDÚZ, S.; JARAMILLO, G.; BENINTENDE, G.; COZZI, J.M.; REAL, M.D.; MARTINEZ-RAMIREZ, A.; RAUSELL, C.; CERÓN, J.; IBARRA, J.E.; RINCON-CASTRO, M.C.D.; ESPINOZA, A.M.; MEZABASSO, L.; CABRERA, L.; SÁNCHEZ, J.; SOBERON, M.; BRAVO, A. Genetic variability of Spodoptera frugiperda Smith (Lepidoptera: Noctuidae) populations from Latin America is issociated with variations in susceptibility to Bacillus thuringiensis Cry toxins. Applied and Environmental Microbiology, Washington, v. 72, n. 11, p. 7029-7035, 2006.

MULLER-COHN, J.; CHAUFAUX, J.; BUISSON, C.; GILOIS, N.; SANCHIS, V.; LERECLUS, D. Spodoptera littoralis (Lepidoptera: Noctuidae) resistance to Cry1C and cross-resistance to other Bacillus thuringiensis crystal toxins. Journal of Economic Entomology, Lanham, v. 89, n. 4, p. 791-797, 1996.

RAHMAN, K.; ABDULLAH, M.A.F.; AMBATI, S.; TAYLOR, M.D.; ADANG, M.J. Differential protection of Cry1Fa toxin against Spodoptera frugiperda larval gut proteases by cadherin orthologs correlates with increased synergism. Applied and Environmental Microbiology, Washington, v. 78, n. 2, p. 354-362, 2012.

RAMALHO, F.S.; AZEREDO, T.L.; NASCIMENTO, A.R.B.; FERNANDES, F.S.; NASCIMENTO-JÚNIOR, J.L.; MALAQUIAS, J.B.; SILVA, C.A.D.; ZANUNCIO, J.C. Feeding of fall armyworm, Spodoptera frugiperda, on Bt transgenic cotton and its isoline. Entomologia Experimentalis et Applicata, Dordrecht, v. 139, n. 3, p. 207-214, 2011.

ROMEIS, J.; MEISSLE, M.; BIGLER, F. Transgenic crops expressing Bacillus thuringiensis toxins and biological control. Nature Biotechnology, New York, v. 24, n. 1, p. 63-71, 2006.

SANTOS, K.B. dos; MENEGUIM, A.M.; NEVES, P.M.O.J. Biologia de Spodoptera eridania (Cramer) (Lepidoptera: Noctuidae) em diferentes hospedeiros. Neotropical Entomology, Vacaria, v. 34, n. 6, p. 903-910, 2005.

SANTOS, K.B. dos; NEVES, P.; ANA MARIA MENEGUIMB, A.M.; SANTOS, R.B.; SANTOS, W.J.; VILLAS BOAS, G.; DUMAS, V.; MARTINS, E.; PRAÇA, L.B.; QUEIROZ, P.; COLIN BERRY, C.; MONNERAT, R. Selection and characterization of the Bacillus thuringiensis strains toxic to Spodoptera eridania (Cramer), Spodoptera cosmioides (Walker) and Spodoptera frugiperda (Smith) (Lepidoptera: Noctuidae). Biological Control, Orlando, v. 50, n. 2, p. 157-163, 2009.

SAS INSTITUTE INC. 2000. SAS/STAT: Statistical Analysis System: getting started with the SAS learning. Version 9.1. Cary, NC: SAS Institute, 2000.

SIQUEIRA, J.R.; MIRANDA, J.E. Espécies de Spodoptera: pragas não-alvo do algodão Bt. In. CONGRESSO BRASILEIRO DO ALGODÃO,7., 2009, Foz do Iguaçu. Anais...Campina Grande: EMBRAPA ALGODÃO, 2009. p. 423-427. 
STORER N.P.; BABCOCK J.M.; SCHLENZ M.; MEADE T.; THOMPSON G.D.; BING J.W.; HUCKABA R.M. Discovery and characterization of field resistance to $B t$ maize: Spodoptera frugiperda (Lepidoptera: Noctuidae) in Puerto Rico. Journal of Economic Entomology, Lanham, v. 103, n. 4, p. 1031-1038, 2010. 